ArgOn national laboratory

ANL-AFCI-172

Preliminary Safety Evaluation of the Advanced Burner Test Reactor

Nuclear Engineering Division 


\section{About Argonne National Laboratory}

Argonne is a U.S. Department of Energy laboratory managed by The University of Chicago

under contract W-31-109-Eng-38. The Laboratory's main facility is outside Chicago, at

9700 South Cass Avenue, Argonne, Illinois 60439. For information about Argonne,

see www.anl.gov.

\section{Availability of This Report}

This report is available, at no cost, at http://www.osti.gov/bridge. It is also available

on paper to the U.S. Department of Energy and its contractors, for a processing fee, from:

U.S. Department of Energy

Office of Scientific and Technical Information

P.O. Box 62

Oak Ridge, TN 37831-0062

phone (865) 576-8401

fax (865) 576-5728

reports@adonis.osti.gov

\section{Disclaimer}

This report was prepared as an account of work sponsored by an agency of the United States Government. Neither the United States Government nor any agency thereof, nor The University of Chicago, nor any of their employees or officers, makes any warranty, express or implied, or assumes any legal liability or responsibility for the accuracy, completeness, or usefulness of any information, apparatus, product, or process disclosed, or represents that its use would not infringe privately owned rights. Reference herein to any specific commercial product, process, or service by trade name, trademark, manufacturer, or otherwise, does not necessarily constitute or imply its endorsement, recommendation, or favoring by the United States Government or any agency thereof. The views and opinions of document authors expressed herein do not necessarily state or reflect those of the United States Government or any agency thereof, Argonne National Laboratory, or The University of Chicago. 


\section{Preliminary Safety Evaluation} of the Advanced Burner Test Reactor

by

F.E. Dunn, T.H. Fanning, and J.E. Cahalan

Nuclear Engineering Division, Argonne National Laboratory

September 15, 2006 


\section{Table of Contents}

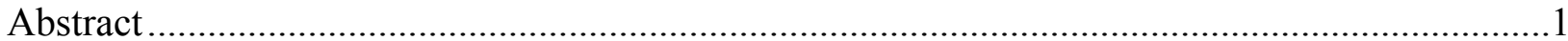

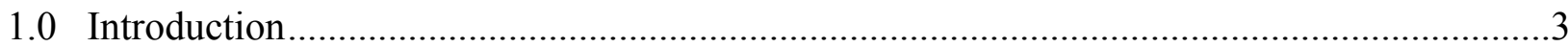

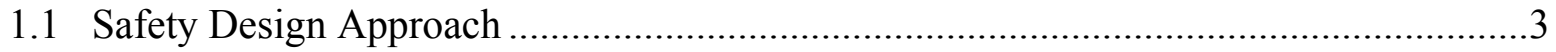

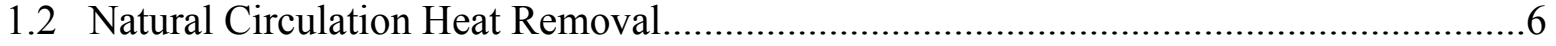

1.3 Inherent Feedback Characteristics ........................................................................ 7

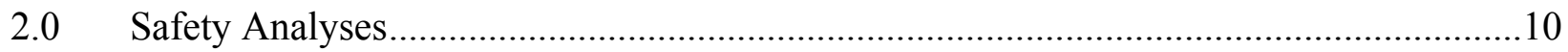

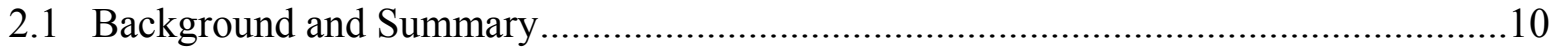

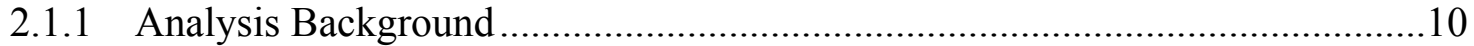

2.1.2 Results Summary .................................................................................. 11

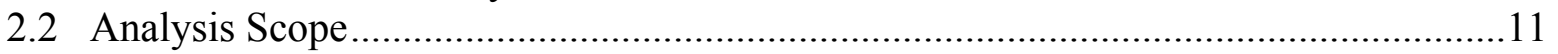

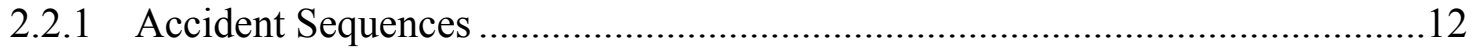

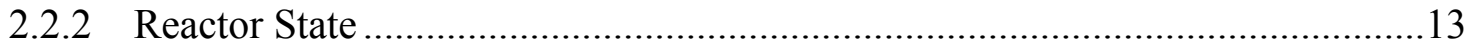

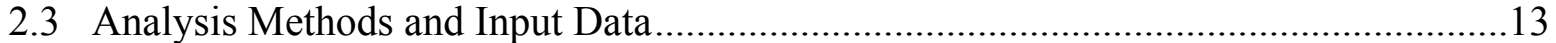

2.3.1 Reactor Thermal Hydraulics ..................................................................... 13

2.3.2 Coolant Systems Thermal Hydraulics ..........................................................20

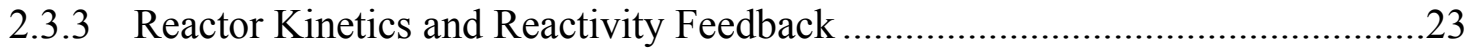

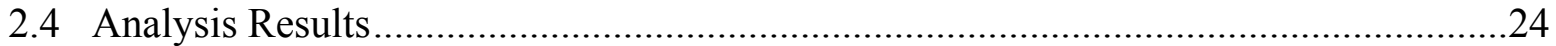

2.4.1 Protected Loss-of-Flow (PLOF) Accident Sequence .....................................24

2.4.2 Unprotected Loss-of-Flow (ULOF) Accident Sequence .................................28

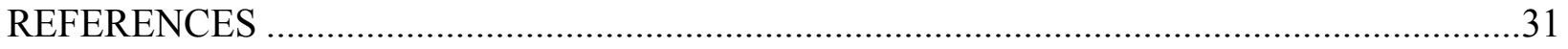

Appendix A Evaluation of Safety Design Criteria for Application to Liquid Metal Cooled

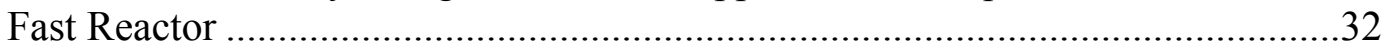

Appendix B SAS4A/SASSYS-1 Capabilities and Enhancements for ABTR Analysis............46 


\section{List of Figures}

$\underline{\text { Page }}$

2.3-1 Single-Pin Channel Model ...................................................................................14

2.3-2 Channel Assignment for Reactor Core Thermal-Hydraulic Model ...........................16

2.3-3 BOEC Initial Subassembly Power (MW) ...........................................................16

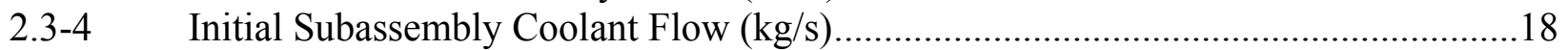

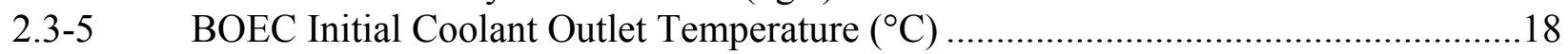

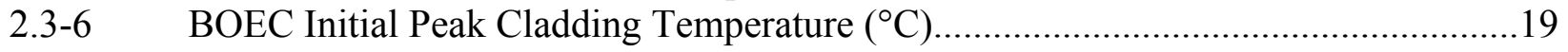

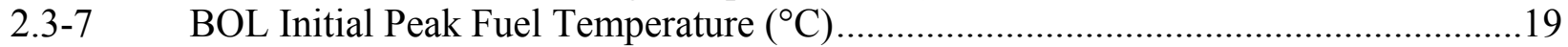

2.3-8 Coolant Systems Thermal Hydraulics Model .................................................21

2.3-9 PLOF Power and Flow History, Early Times ...................................................25

2.3-10 PLOF Power and Flow History, Extended Times .................................................25

2.3-11 PLOF Temperature History, Early Times.....................................................26

2.3-12 PLOF Temperature History, Extended Times ......................................................26

2.3-13 ULOF Transient Total Power and Channel 5 Flow ….........................................29

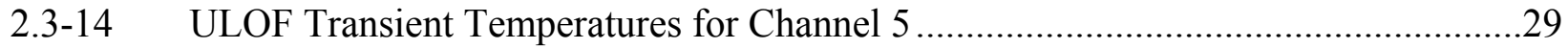

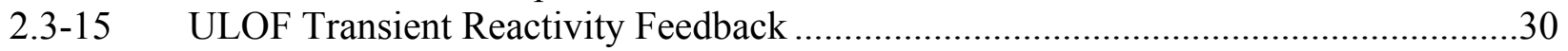

\section{List of Tables}

$\underline{\text { Page }}$

2.3-1 Fuel Assembly, Pin, and Coolant Channel Model Data .........................................17

2.3-2 Compressible Volumes Input Data .....................................................................22

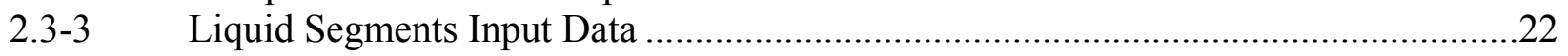

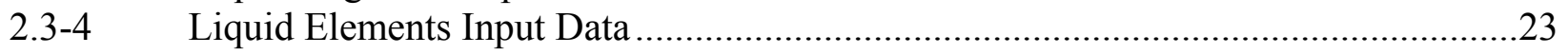




\title{
Preliminary Safety Evaluation of the Advanced Burner Test Reactor
}

\begin{abstract}
Results of a preliminary safety evaluation of the Advanced Burner Test Reactor (ABTR) pre-conceptual design are reported. The ABTR safety design approach is described. Traditional defense-in-depth design features are supplemented with passive safety performance characteristics that include natural circulation emergency decay heat removal and reactor power reduction by inherent reactivity feedbacks in accidents. ABTR safety performance in design-basis and beyonddesign-basis accident sequences is estimated based on analyses. Modeling assumptions and input data for safety analyses are presented. Analysis results for simulation of simultaneous loss of coolant pumping power and normal heat rejection are presented and discussed, both for the case with reactor scram and the case without reactor scram. The analysis results indicate that the ABTR preconceptual design is capable of undergoing bounding design-basis and beyonddesign-basis accidents without fuel cladding failures. The first line of defense for protection of the public against release of radioactivity in accidents remains intact with significant margin. A comparison and evaluation of general safety design criteria for the ABTR conceptual design phase are presented in an appendix. A second appendix presents SASSYS-1 computer code capabilities and modeling enhancements implemented for ABTR analyses.
\end{abstract}




\section{Introduction}

A pre-conceptual design for an Advanced Burner Test Reactor (ABTR) is being developed by the U.S Department of Energy under the Advanced Fuel Cycle Initiative (AFCI) and the Global Nuclear Energy Partnership (GNEP). Within GNEP, it is envisioned that fast spectrum Advanced Burner Reactors (ABRs) will be employed to consume transuranics and produce power. The goals for the ABTR are to prove the concept of effectively burning transuranics for waste management, to support development and qualification of fuels and materials for the ABR standard design, to test safety design features, and to support ABR design certification.

This report provides a preliminary safety evaluation for the pre-conceptual ABTR design [1]. The current ABTR design concept specifies a $250 \mathrm{MWt}$ liquid sodium-cooled fast reactor in a pool-type primary system configuration. The ABTR fuel is a metallic alloy of uranium, zirconium, plutonium, and higher actinides clad with low-swelling stainless steel. The emphasis in this report is to provide an estimate of the performance of the design in bounding design-basis and beyond-design-basis accident sequences. For the design-basis sequence, the analysis focuses on natural circulation decay heat removal capability. For the beyond-design-basis sequence, the analysis examines both inherent reactivity shutdown performance and decay heat removal.

The following sections provide an introductory discussion of the ABTR reactor safety design approach, natural circulation heat removal, and inherent reactivity feedback characteristics.

\subsection{Safety Design Approach}

The safety goals in nuclear power reactor design and operation are to assure the health and safety of the public, to protect the plant operating staff from harm, and to prevent plant damage. Traditionally, these goals have been fulfilled by an approach that 1) minimizes risk by maximizing safety margins, 2) reduces the likelihood of potentially harmful events, and 3) provides additional design features to mitigate the harmful consequences of low probability events. This approach is usually identified as "defense in depth."

The basic principle of "defense in depth" is to provide multiple levels of protection. The protective levels may be physical barriers, like the multiple barriers to release of radioactivity provided by the fuel cladding, the primary coolant system, and the reactor containment building. Alternatively, the multiple layers may be provided by active systems, like the reactor shutdown systems and the reactor cooling systems. In some instances, components of the "defense in depth" strategy may consist of procedures and practices, such as emergency planning. However, in all instances, the "defense in depth" strategy depends on the independence of the protective measures, so that no single event can breech more than one protective level.

The ABTR safety design approach implements the "defense in depth" strategy by adopting the traditional three levels of safety. In addition, the ABTR design features have been selected to provide significant safety margin enhancements by inherent, passive safety responses to upset conditions and equipment failures. 
At the first level, the ABTR is designed to operate with a high level of reliability, so that accident initiators are prevented from occurring. The first level of safety is assured in part by selection of fuel, cladding, coolant, and structural materials that are stable and compatible, and provide large margins between normal operating conditions and limiting failure conditions. Next, the first level of safety is assured by adopting an arrangement of components that allows continuous or periodic monitoring, inspection, and testing for performance changes or degradation. Finally, the ABTR design provides for repair and replacement of components necessary to assure the first level of safety.

For the ABTR pre-conceptual design, the selection of liquid sodium coolant and metallic fuel with a pool-type primary system arrangement for the reference configuration provides a highly reliable reactor system with large operational safety margins. Liquid sodium thermo-physical properties provide superior heat transport and removal characteristics and a large temperature margin to boiling at low operating pressure. Metallic fuel operates at relative low temperature, below the coolant boiling point, due to its high thermal conductivity. The pool-type primary system confines all significantly radioactive materials within a single vessel, and promotes easy removal and replacement of components as well as shutdown heat removal under natural circulation.

At the second level of safety, the ABTR is designed to provide protection in the event of an equipment failure or an operating error. This level of protection is provided by engineered safety systems for reactor shutdown, reactor heat removal, and emergency power. Each of these safetygrade back-up systems functions in the event of failure in the corresponding operating system, and are subjected to continuous monitoring and periodic testing and inspection.

The ABTR design provides a secondary reactor shutdown system that is independently powered and instrumented, and which operates automatically to reduce reactor power rapidly in the event that the primary shutdown system fails. For shutdown cooling, the ABTR design contains a safety-grade emergency heat removal system, independent from the normal heat removal system, which is capable of removing residual decay heat by natural circulation. In addition to the normal off-site power supply, the ABTR is equipped with a second independent off-site power connection. The two off-site power connections are supplemented with a safety-grade on-site emergency power supply.

The third level of safety provides additional protection of the public health and safety in an extremely unlikely event that is not expected to occur in the life of the plant, or which was not foreseen at the time the plant was designed and constructed.

In the ABTR design, level 3 protection for cooling assurance and containment of radioactivity are provided by the reactor guard vessel and the reactor containment building. The reactor guard vessel is designed to hold primary coolant in the extremely unlikely event of a leak in the primary coolant system. The reactor guard vessel assures that the reactor core remains covered with sodium and cooled by the emergency heat removal system, even if the primary reactor vessel fails. In the extremely unlikely event that primary coolant leaks and oxidizes in the reactor building air atmosphere, or if cladding failures release gaseous fission products, the reactor containment building provides a low-leakage barrier to release of radioactivity. 
The three levels of safety together encompass the safety design basis for ABTR. For the purposes of subsequent safety design development, qualification, and documentation, it is customary during the conceptual design phase to identify general design criteria that collectively serve as a safety basis for design assessment. A preliminary cross reference and evaluation of existing general design criteria from 10CFR50 Appendix A, from ANSI/ANS Standard 54.1, and from DOE Order 5480.30 are included in Appendix A of this report.

The normal safety design envelope considers design basis accidents (DBAs) that assume single failures. By definition, accidents within the design basis, usually taken to have a frequency of occurrence of once in a million reactor years or more, must be accommodated by the design and shown to present risks to the public that are within regulatory standards. Beyond the design basis, there exists a class of accidents of such low probability that they are termed "hypothetical." These events involve multiple failures of safety grade systems, and have a frequency less than $10^{-6}$ per reactor year. Because of the potentially severe consequences of accidents in this class, they have received significant regulatory scrutiny in prior sodium-cooled fast reactor licensing reviews for the purpose of characterizing thermal and structural safety margins beyond the design basis.

Three beyond-design-basis accident (BDBA) sequences, each involving failure of both reactor scram systems, have received attention in past licensing safety assessments. In the unprotected loss-of-flow (ULOF) sequence, it is assumed that all primary and secondary coolant pumps cease operation, and the reactor scram systems fail to activate. In the unprotected transient overpower (UTOP) sequence, it is assumed that one or more inserted control rods are withdrawn, and the reactor scram systems fail to operate. In the unprotected loss-of-heat-sink (LOHS) accident, it is assumed that heat removal through the power conversion system is lost, and the reactor scram systems do not activate. Taken collectively, these three accident initiators encompass all the ways that an operating reactor can be perturbed, i.e. by a change in coolant flow, by a change in reactivity, or by a change in coolant inlet temperature.

The proposed ABTR design is capable of accommodating beyond design basis accident initiators without producing high temperatures leading to severe accident conditions such as coolant boiling, cladding failures, or fuel melting. The inherent neutronic, hydraulic, and thermal performance characteristics of the ABTR design provide self-protection in beyond-design-basis sequences to limit accident consequences without activation of engineered systems or operator actions. This characteristic has been termed "passive safety", and has been demonstrated in fullscale tests for the ULOF and ULOHS sequences in Experimental Breeder Reactor-II [2]. Analyses have shown that the passive safety characteristic of the ABTR design is inherent to any design with sodium coolant, metallic fuel, and a pool-type primary system arrangement.

Within the overall safety framework for ABTR, passive safety serves to provide additional margins for public protection in the event of very low probability accidents whose frequency of occurrence is lower than the normal threshold for deterministic assessment. The ABTR passive safety performance characteristic assures that no abnormal radioactivity releases will occur in the event of beyond-design-basis accidents, and that all of the multiple defense-in-depth barriers (fuel cladding, reactor vessel, containment building) for public protection will remain intact, just 
as for design basis accidents. The passive safety performance of ABTR eliminates the potential for severe accident consequences in very low frequency, beyond-design-basis sequences. Consequently, for ABTR, beyond-design-basis accidents need to be considered only in the context of probabilistic risk assessments, and not as the subject of deterministic analysis documented in the safety analysis reports (SARs).

\subsection{Natural Circulation Heat Removal}

The ABTR primary system design is configured to provide natural circulation shutdown heat removal. The capability to remove shutdown decay heat with natural circulation provides a means to maintain reactor component temperatures at acceptable levels even in the event of loss of all off-site and emergency on-site power supplies. This section presents a discussion of the design features that contribute to this capability. A quantitative assessment of ABTR emergency decay heat removal by natural circulation in a protected (i.e. with scram) loss of flow accident sequence is provided in Section 2.4.

Natural circulation flow arises due to the effect of gravity on a continuous fluid with a density difference along the elevation. Heavy fluid sinks to displace lighter fluid. Buoyancy-induced flow can be established when a fluid is heated, decreasing its density, at an axial position below the elevation at which the fluid is cooled, increasing its density. In a one-dimensional model, flow occurs when the buoyancy force is great enough to overcome form, friction, and shear losses. The natural circulation flow rate is regulated by the balance between the buoyancy force and the flow-related pressure losses. When the buoyancy force is provided by a thermally-driven density difference, the fluid flow rate will be determined by the fluid properties, the elevation difference between the heat sink and the heat source, and the temperature difference in the fluid between the heat source and the heat sink.

Liquid sodium and its alloys are excellent fluids for natural circulation heat removal because of their thermo-physical properties. Due primarily to its high thermal conductivity, liquid sodium is capable of very high convective heat transfer rates, even at the modest fluid velocities characteristic of natural circulation. This tends to minimize the temperature differences between the heat source and the fluid, and between the fluid and the heat sink, and to reduce the overall source-to-sink temperature difference required for natural circulation cooling.

The ABTR design is configured to promote natural circulation shutdown heat removal. The key design parameters are 1) provision for a relatively free-flowing fluid natural circulation path, and 2) provision for sufficient elevation difference between the heat source and the heat sink. In the ABTR emergency shutdown heat removal design, each of the direct reactor auxiliary cooling systems (DRACS) consists of two natural circulation loops joined by a heat exchanger. Acting together, these loops remove heat from the reactor to the ultimate heat sink, atmospheric air, by way of a second heat exchanger. The natural circulation path is maintained even in the hypothetical case of a leak in the reactor vessel.

In the primary coolant circuit, natural circulation flow for shutdown heat removal is established along the same flow path used for normal operation. Coolant is heated in the reactor, rises to the hot pool, and flows through the intermediate heat exchangers (IHX) to the cold pool. In 
accidents or emergency shutdown conditions in which no heat is removed from the coolant in the IHXs, heat is removed by multiple DRACS heat exchangers mounted high in the cold pool. Primary coolant chilled in the DRACS heat exchangers falls to near the bottom of the cold pool, where it travels into the primary coolant pump inlet and back to the reactor. This completes the primary coolant natural circulation circuit with heat added in the reactor and removed at the DRACS heat exchangers.

Heat removed from the cold pool at a DRACS heat exchanger is transferred to a second natural circulation loop. In ABTR, the working fluid in this second loop is sodium-potassium alloy (NaK). The NaK loop carries the heat through piping to a second heat exchanger located at a high elevation outside the containment building, where the heat is rejected to environmental air. The relatively low melting point of $\mathrm{NaK}$ minimizes the potential for freezing in the secondary loop.

The ABTR DRACS circuits are designed to operate at reduced flow during power operation, to minimize parasitic heat losses. However, maintaining some flow at all times avoids the high transient DRACS start-up temperatures that would occur upon natural circulation initiation from stagnant conditions.

\subsection{Inherent Feedback Characteristics}

As noted in the prior section, the design of ABTR provides for natural circulation decay heat removal, so that in the event of failures in all active cooling systems, shutdown heat removal is assured. In order to complete the passive safety envelope, it is necessary to provide sufficient negative reactivity to extinguish reactor fission power and bring the reactor to decay heat power level. As long as one of the two active safety-grade reactor scram systems operate, reactor fission power will be rapidly terminated. However, in the extremely unlikely event that both of the reactor scram systems fail, the ABTR inherent reactivity feedback characteristics will act to reduce fission power, and eventually to equilibrate reactor power with the available heat sink.

In the ABTR pre-conceptual design, inherent reactivity feedback characteristics are present due to the reactor physics performance characteristics of the reactor and the thermal, hydraulic, and mechanical design features. The selection of reactor materials and their configuration provides inherent reactivity feedback effects that act to compensate for accidental perturbations to normal reactor operation, such as equipment failures or operator errors leading to reactivity addition, loss of coolant flow, or loss of heat removal. The inherent reactivity feedback characteristics are triggered by changes in fuel, cladding, coolant, or structural temperatures that cause negative reactivity feedback either directly, such as the fuel Doppler resonance reactivity due to an elevation in temperature (power increase), or indirectly, such as radial core thermal expansion associated with heating of the core structural elements (coolant temperature increase) or axial thermal expansion of the fuel pins (fuel and cladding temperature increase). Because the inherent reactivity feedback characteristics do not depend on operator action or activation of an engineered component, such as a valve or pump, the inherent feedbacks contribute to ABTR passive safety performance. 
The very favorable passive safety characteristic of the ABTR design is a direct result of the selection of metallic fuel. To understand the physical basis for this situation, recall that it is necessary to supply positive reactivity to raise the reactor power and temperature to operating conditions, normally by withdrawal of a neutron absorber. Positive reactivity is needed to overcome the negative Doppler reactivity coming from the fuel temperature increase. However, because metallic fuel has a high thermal conductivity, the operating temperature of metallic fuel is relatively low, and consequently a relatively small amount of positive reactivity is needed to bring the ABTR to full power. To reduce the fission power, it is necessary to supply enough negative reactivity to overcome the positive reactivity inserted for power ascension. With metallic fuel, the negative reactivity needed to reduce power is small because the positive reactivity inserted to raise the power is small. In the ABTR design, negative inherent reactivity feedbacks are supplied by a number of thermal and mechanical mechanisms that have been observed and quantified by testing in EBR-II. The ABTR design features have been selected to assure that these mechanisms will act reliably in accident conditions, and will together supply the net negative feedback reactivity needed to limit and reduce reactor fission power.

In ABTR, the mechanisms that supply negative reactivity feedback arise from fuel, coolant, and/or core structural temperature changes. In the unprotected loss-of-flow (ULOF) sequence, reduced coolant flow results in an increase in the coolant outlet temperature, and heating of the cladding and the above-core structure. Thermal expansion of the cladding, combined with the low strength of irradiated metallic fuel, results in elongation of the core fuel, reduction of the fuel density, and negative reactivity feedback. Thermal expansion of the above-core structure, by design, results in radial spreading of the core at the above-core load pad location, and a reduction of effective core density, introducing negative reactivity. These effects counter the positive Doppler reactivity associated with chilling of the fuel during the flow coast-down. In the longer term, as the temperature wave propagates to the hot pool, thermal expansion of the control rod drivelines acts to insert control material and negative reactivity. As long as the core outlet temperature remains below the threshold for coolant boiling or cladding failures, the net negative reactivity will decrease the power to decay heat level, and eventually establish equilibrium between the available heat rejection and the reactor power. This accident sequence, and the reactivity mechanisms described, has been demonstrated from full power and flow in EBR-II [2] without cladding failures or coolant boiling.

In the unprotected loss-of-heat-sink (ULOHS) sequence, the loss of normal heat rejection results in elevation of the core inlet temperature. Heating and thermal expansion of the core support plate spreads the core radially and causes a strongly negative reactivity feedback that quenches the reactor fission power. Other reactivity mechanisms include fuel Doppler, axial expansion and contraction, control rod driveline expansion and contraction, and reactor vessel expansion, but the core support plate expansion dominates. While the decay heat is greater than the available emergency heat sink, the system temperature will continue to rise, albeit slowly because of the large system heat capacity. When the decay heat falls below the heat removal capacity, the entire systems will slowly cool down, and the reactivity balance will establish equilibrium between the available heat sink and the reactor power. This accident sequence, and the associated reactivity mechanisms, has been demonstrated from full power and flow initial conditions in EBR-II [2] without cladding failures or coolant boiling. 
Because of the reduced control requirements (reduced cold-to-hot reactivity swing) for metallic fuel, the initiating reactivity available by control rod withdrawal for the unprotected transient overpower (UTOP) accident sequence is relatively small. Consequently, the inherent reactivity feedbacks are able to limit the power rise during the positive reactivity insertion. Once the insertion is complete, the inherent reactivity feedback mechanisms act to reduce the reactor power until balance is achieved between the heat rejection rate through the balance-of-plant and the reactor power. Because the reactivity initiator for metallic fuel is small, the system temperature rise needed to establish equilibrium is small, and safety margins to cladding failures or coolant boiling are maintained.

The ABTR design relies on design concepts proven in EBR-II testing to supply inherently negative reactivity feedback mechanisms that, when combined with the beneficial thermal and neutronic characteristics of metallic fuel, yield benign temperature rises for all possible beyonddesign-basis accident initiators. Sufficient safety margins are maintained to prevent coolant boiling, cladding failure, or progression into severe accident conditions. Natural circulation heat removal and inherent reactivity feedback characteristics together provide a safety basis for ABTR that surpasses conventional power reactors. This level of safety performance is attainable in a sodium-cooled, metallic fueled, pool-type fast reactor design. 


\subsection{Safety Analyses}

Preliminary analyses have been completed to assess the potential safety performance characteristics of the Advanced Burner Test Reactor (ABTR) pre-conceptual design. The scope of the analyses presented here focuses on the ability of ABTR to provide inherent protection against damaging consequences in low probability accident sequences involving multiple equipment failures.

\subsection{Background and Summary}

This section provides summary descriptions of the accident sequences analyzed and the results obtained. Detailed descriptions are provided in subsequent sections.

\subsubsection{Analysis Background}

One of the primary goals in the ABTR design is to provide not only the customary safety margins in design basis events, but also to deliver superior safety performance in beyond design basis events involving multiple equipment failures or unplanned operator actions. Consequently, the preliminary analyses presented here examines the behavior of ABTR in response to an accident initiator that is normally considered to have a low occurrence frequency, but potentially severe consequences, especially when engineered safety systems are assumed to fail.

The accident initiator examined here is the total loss of normal power to the reactor cooling system while the plant is operating at full rated power. Within the plant, the effect of this initiator is the loss of normal operation of all reactor coolant pumps. According to design, the plant responds with a reactor scram, with activation of emergency power supplies (diesel generators and batteries), and with activation of the normal shutdown heat removal mode. The normal shutdown heat removal path is through the reactor coolant system and the power cycle heat exchanger, with auxiliary power supplied by the emergency power supplies. As a backup, a lowcapacity emergency heat removal system is provided to remove heat directly from the reactor without the need for emergency power.

However, in the accident sequence analyzed here, the loss of power is assumed to be accompanied by a complete failure of the emergency power supply system, resulting in a total loss of power to the reactor and intermediate coolant pumps. It is also assumed that the power generation plant immediately ceases operation, and provides no heat rejection capacity. The sole heat removal path following the loss of forced coolant flow is through the emergency heat removal system by natural circulation. This sequence was analyzed for the case with an immediate reactor scram, and for the case without reactor scram. These cases are identified as the protected loss-of-flow (PLOF) and the unprotected loss-of-flow (ULOF) cases respectively. The PLOF and ULOF accident sequences both assume multiple equipment failures, failures of safety grade protection and cooling systems, and no operator actions. These sequences are an extreme test of the ABTR to provide inherent self-protection against the consequences of the most severe accident initiators. 


\subsubsection{Results Summary}

The detailed analysis results for the PLOF and ULOF accident sequences are presented in Section 2.4 below. Although both sequences simulate accidents that for some reactor designs may cause damage to the fuel and possibly progress into severe accident conditions, in the ABTR these events cause no damage. For both accident sequences, reactor fuel, cladding, and coolant temperatures remain below safety limits.

In the PLOF sequence, the loss of forced coolant flow and normal heat removal is accompanied immediately by a reactor scram, which quickly brings the reactor power to decay heat levels. Early in the sequence, the emergency decay heat removal system does not have sufficient capacity to remove all the heat being produced, so system temperatures rise. However, due to the large heat capacity of the sodium-cooled pool-type concept, the ABTR is able to absorb a significant amount of energy with only a slight temperature increase, and the natural circulation capability of the ABTR promotes heat removal through the available emergency heat sink. After about 5 hours, the reactor decay heat falls to the capacity of the emergency heat removal system, and system temperatures begin to decrease. The analysis predicts that short coolant and cladding temperature spikes occur during the transition to natural circulation, but no significant fuel damage or cladding failures would occur.

In the ULOF accident, the reactor safety system fails to scram the reactor upon loss of forced coolant flow and normal heat removal, so the reactor remains at full power initially. Within the first minute, reactor temperatures increase as the coolant flow rate decreases, and inherent reactivity feedbacks reduce the reactor power. During this time, peak cladding temperatures rise to approximately $600^{\circ} \mathrm{C}$. As coolant flow continues to decline, a second temperature peak occurs, and peak fuel and cladding temperatures reach approximately $660^{\circ} \mathrm{C}$. This increase in temperature provides the necessary driving force to establish natural circulation flow. The development of natural circulation reduces the peak fuel and cladding temperatures back to around $600^{\circ} \mathrm{C}$, after which temperatures remain stable.

The primary significance of the analysis results for the PLOF and ULOF accident sequences is that no significant fuel damage or cladding failures would occur, even when multiple safety systems are assumed to malfunction. Time-at-temperature results from the PLOF and ULOF analyses indicate a maximum fuel/cladding penetration thickness of $0.001 \mathrm{~mm}$, compared to a cladding thickness of $0.52 \mathrm{~mm}$. The neutronic, thermal, and hydraulic performance characteristics of the ABTR design provide a defensive barrier against reactor damage for accident initiators that otherwise progress into severe accident conditions.

\subsection{Analysis Scope}

The analysis results reported here were selected on the basis that they show the safety margins and the inherent ability of a metallic-fueled, sodium-cooled, pool-type reactor system to provide protection against severe, damaging consequences. The accident sequences analyzed here are near the end of the spectrum of the most pessimistic, challenging, and potentially damaging events. The analysis results demonstrate the passive safety performance advantages of ABTR. This performance is possible because of the favorable heat transfer and reactivity feedback 
characteristics of metallic fuel, and the natural circulation shutdown heat removal capability that is possible with low pressure sodium coolant in a pool configuration.

\subsubsection{Accident Sequences}

The basic accident sequence analyzed here is the loss of normal power to the reactor and intermediate coolant pumps, with failure of the emergency power supplies. The result is a loss of forced flow in the primary and intermediate coolant circuits. In addition, it is assumed that heat removal at the power cycle heat exchanger ceases, so that the only heat removal path is through the emergency direct reactor auxiliary cooling system (DRACS).

The natural circulation DRACS consists of heat exchangers located in the cold pool region within the reactor vessel, air dump heat exchangers located outside containment, and the connecting piping. The working fluid in the DRACS is NaK, and fluid flow is by natural circulation. Multiple independent DRACS units are provided for defense in depth. The DRACS is designed to remove $0.5 \%$ of full power $(1250 \mathrm{~kW})$ at normal operating temperatures assuming failure of one DRACS unit. The DRACS system operates continuously, with heat losses limited in normal operation by dampers on the NaK-to-air heat exchangers. In all the accident sequences analyzed here, one DRACS unit is assumed to fail, leaving a nominal system heat rejection capacity of $1250 \mathrm{~kW}$.

The initial condition for the accident sequence is normal operation at full power and flow. With the loss of pumping power, flow in the primary circuit coasts down according to the spinning inertia of the pumps and motors. Following flow coast down, natural circulation flow is established.

With the loss of power, forced flow in the intermediate coolant system is also lost. Further, it is assumed that heat rejection through the power cycle heat exchanger ceases. The intermediate heat transport system (IHTS) is alternately a heat sink or source in the accident sequence, depending on its temperature and the primary system temperature at the intermediate heat exchanger (IHX). During the transient, natural circulation flow in the IHTS may reverse, depending on transient temperature conditions.

Two variations of the loss-of-flow accident sequence have been analyzed. In the first, it is assumed that the reactor safety system acts as designed to insert control rods and reduce reactor power immediately to decay heat. This sequence is called the protected loss-of-flow (PLOF) accident. In the second analysis, it is assumed that the reactor safety system fails to insert the scram control rods, and the loss of forced flow proceeds at full power. This sequence is called the unprotected loss-of-flow (ULOF).

In the PLOF sequence, the absence of normal shutdown heat removal through the reactor coolant system causes a slow system temperature rise following the reactor scram. This temperature increase occurs because the DRACS has insufficient heat removal capacity to overcome both the early decay heat production rate and the stored heat in the primary and intermediate systems. Eventually, the decay heat falls below the DRACS capacity, and the system temperature declines. 
In the ULOF sequence, the system temperature rises significantly with the flow coast down, but the core temperature rise introduces negative reactivity that acts to reduce the reactor fission power. The reactor, with its negative feedback characteristic, seeks equilibrium with the available heat sink by reducing power. This has the effect of reducing the reactor temperature and establishing a quasi-equilibrium condition. However, until the decay heat falls below the available heat rejection capacity, the reactor system will continue to heat slowly, with the long term temperature rise buffered by the thermal heat inertia of the system. When decay heat production falls below the DRACS capacity, the system temperature declines.

\subsubsection{Reactor State}

Safety analyses were performed for the beginning-of-equilibrium-cycle (BOEC) reactor conditions described in Ref. 3. Only the BOEC results are reported here because the EOEC results are similar, even though the reactor radial power distribution changes with irradiation.

For the BOEC safety analysis, it was assumed that sufficient irradiation had taken place to swell the fuel radially into contact with the cladding. Examination of EBR-II irradiated fuel has indicated that fuel-cladding contact will occur early in fuel life (1\% burnup), depending on the initial geometry and local specific power. Fuel-cladding contact has the impact of lowering thermal resistance by eliminating the sodium-filled fuel-cladding gap.

For the PLOF analysis, the decay heat curve was taken as $100 \%$ of the ANSI 5.1 standard [4] for $\mathrm{Pu}-239$. For the ULOF analysis, the decay heat curve was combined with the computed fission power calculated using the reactivity feedback parameters determined by the reactor physics analysis of Ref. 3 for the BOEC core.

\subsection{Analysis Methods and Input Data}

The SASSYS-1 computer code [5] was used to produce all the safety analysis results presented here. New capabilities incorporated for ABTR analyses are described in Appendix B. In the following sections, the reactor and coolant system thermal-hydraulic models are described along with key input data relevant to the determination of ABTR safety performance.

\subsubsection{Reactor Thermal Hydraulics}

The thermal-hydraulic performance of the reactor core is analyzed with a geometric model consisting of a number of single-pin channels. In a multiple-channel, whole-core model, each channel represents a single fuel pin and its associated coolant and structure. The single pin is assumed to characterize the average pin in a fuel subassembly, and subassemblies with similar reactor physics and thermal-hydraulics characteristics are grouped, so a number of channels are selected to represent all the pins in the reactor core.

The geometry assumed in the channel thermal-hydraulic model is shown in Figure 2.3-1. Heat generated in the fuel is assumed to travel through the cylindrically-symmetric pin to the upwardflowing coolant. The structure field is used to represent part of the hexagonal duct and the wire wrap. One-dimensional, radial heat transfer calculations are performed at many axial locations to 


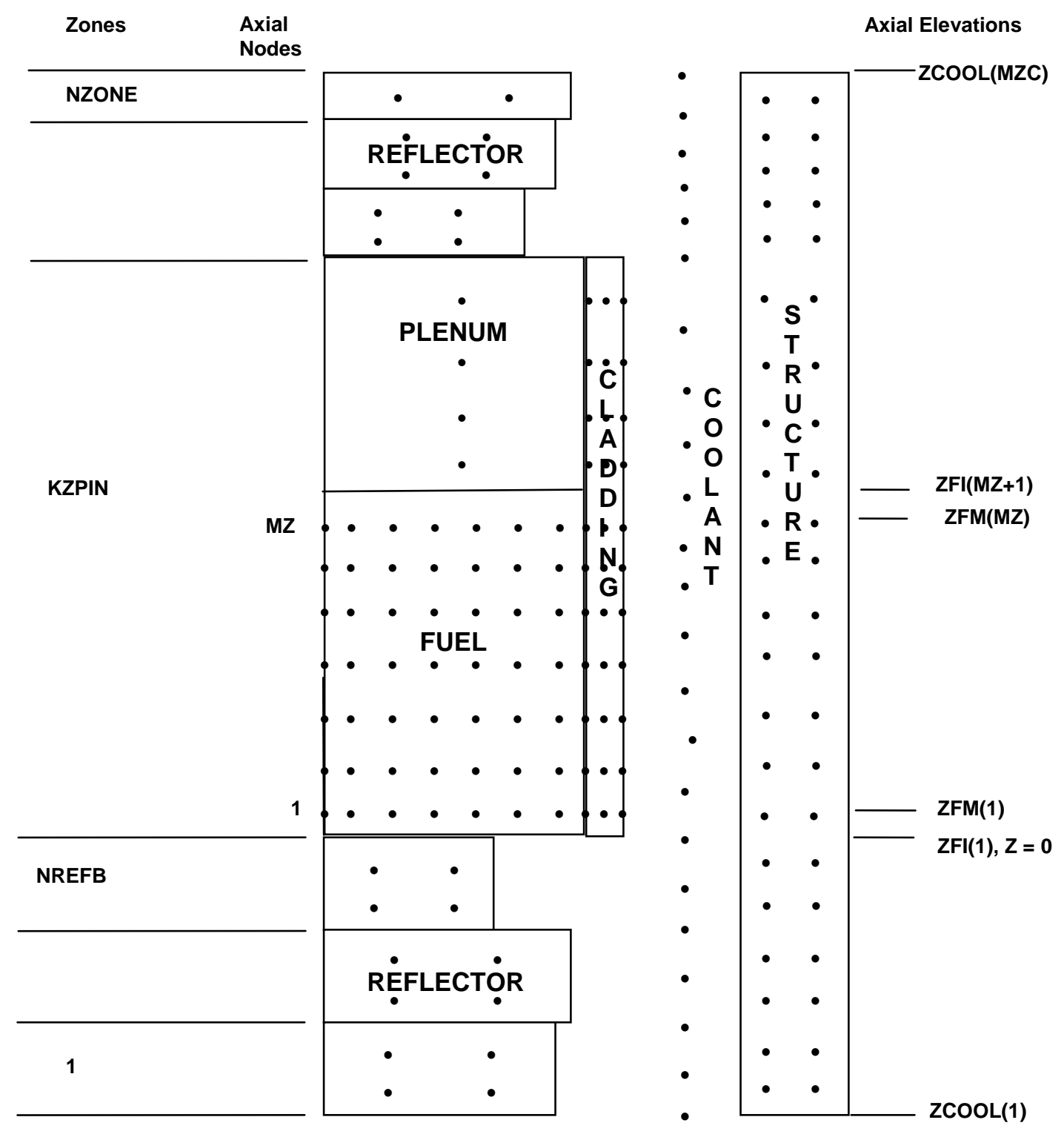

Figure 2.3-1. Single-Pin Channel Model 
model heat transfer from the fuel through the cladding to the coolant, and from the coolant to the structure, the gas plenum, and the reflectors. One-dimensional (axial) coolant mass flow is modeled with a momentum equation solution for the axial pressure profile, and convective heat transfer conditions are assumed at the interfaces between the coolant and the cladding, the reflectors, and the structure. Temperatures are calculated at multiple radial nodes in the fuel, the cladding, the reflectors, and the structure. A single bulk temperature is calculated at each axial location. Axial heat conduction is neglected.

Thermal, transport, and physical properties data for the coolant were taken as the temperaturedependent liquid sodium properties available in SASSYS-1. Cladding properties were taken as the HT9 data presented in Ref. 6. Fuel properties were taken from the SSCOMP correlations in SASSYS-1 Version 3.0; these correlations are based on data generated in the Integral Fast Reactor (IFR) Program.

On the basis of the reactor physics calculations reported in Ref. 3, the multiple-channel model depicted in Figure 2.3-2 was selected for safety analysis calculations. This model approximates the full heterogeneity of the reactor physics model by assigning channels to represent each fuel enrichment zone. Channels 1 and 3 represent the average subassemblies in the inner and outer enrichment zones respectively, while channel 2 represents the average of the mid-core fuel test assemblies. A fourth channel represents all of the non-fuel subassemblies, including the mid-core materials test assemblies. A fifth channel is used to represent the peak-power inner-core subassembly with fresh fuel.

Table 2.3-1 presents geometric input data employed in the multiple-channel whole-core model. In this data, it has been assumed that the irradiated fuel has swollen into contact with the cladding.

Figure 2.3-3 shows the initial subassembly powers for the beginning of equilibrium cycle (BOEC) condition as described in Ref. 3. The subassembly power for the peak assembly assumes fresh fuel in the peak power location. All other subassembly powers represent channel averages from BOEC fuel compositions at various stages of depletion. The initial subassembly flow rates shown in Figure 2.3-4 were determined such that the mixed-mean coolant outlet temperature was $510^{\circ} \mathrm{C}$ for each region (inner core, outer core, fuel test, and reflectors). Flow for the peak subassembly was set so that the outlet temperature would be $510^{\circ} \mathrm{C}$ midway through depletion, with the remaining flow for the inner core allocated to channel 1 . With fresh fuel in the peak subassembly location, the outlet temperature for the peak subassembly is higher than nominal. Initial coolant outlet temperatures at BOEC are shown in Figure 2.3-5.

Based on the above input conditions, SASSYS-1 calculates the initial, steady-state thermalhydraulic conditions in the reactor core prior to the onset of a transient. Peak coolant outlet, peak cladding, and peak fuel temperatures are shown in Figure 2.3-5, 2.3-6, and 2.3-7, respectively. Coolant, cladding, and fuel temperatures that arise during a transient are discussed in the relevant sections below. 

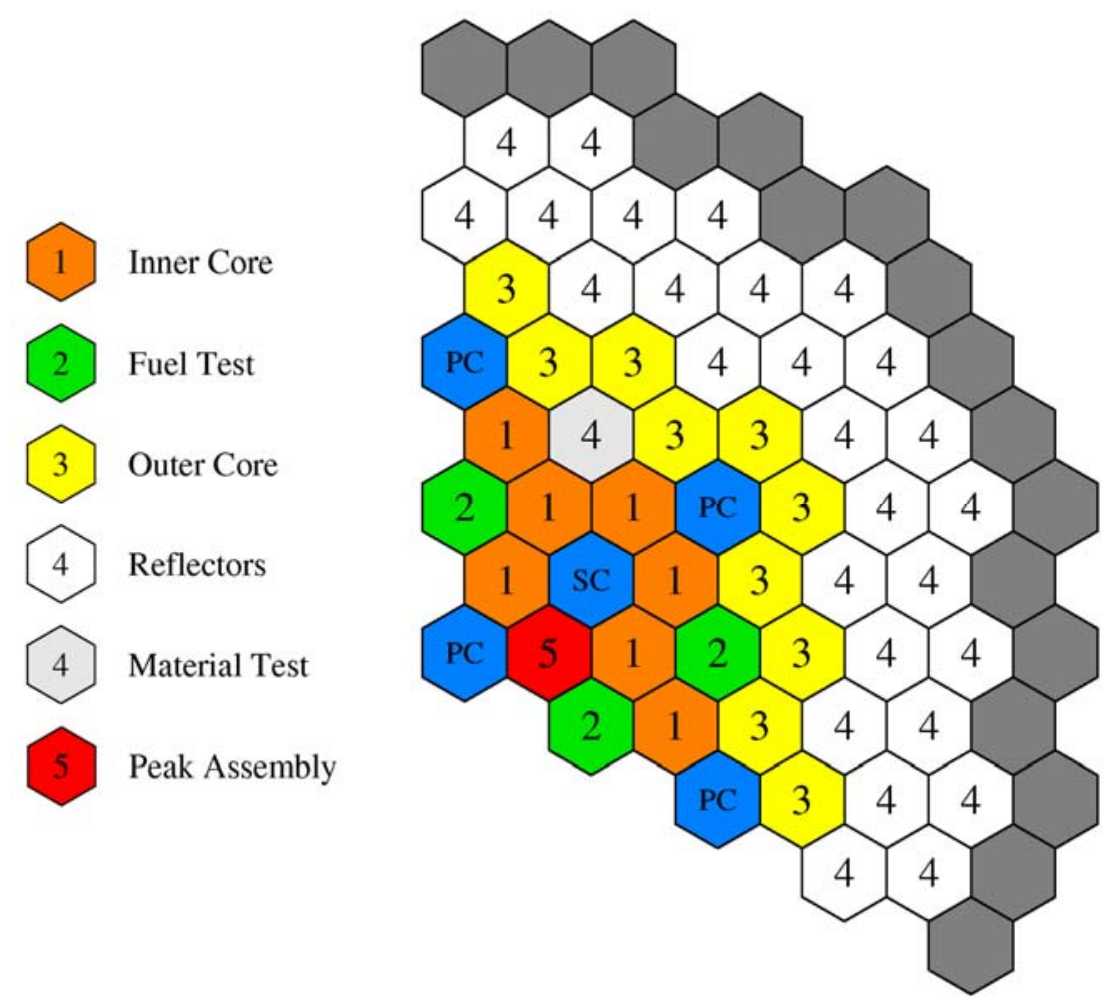

Figure 2.3-2. Channel Assignment for Reactor Core Thermal-Hydraulic Model

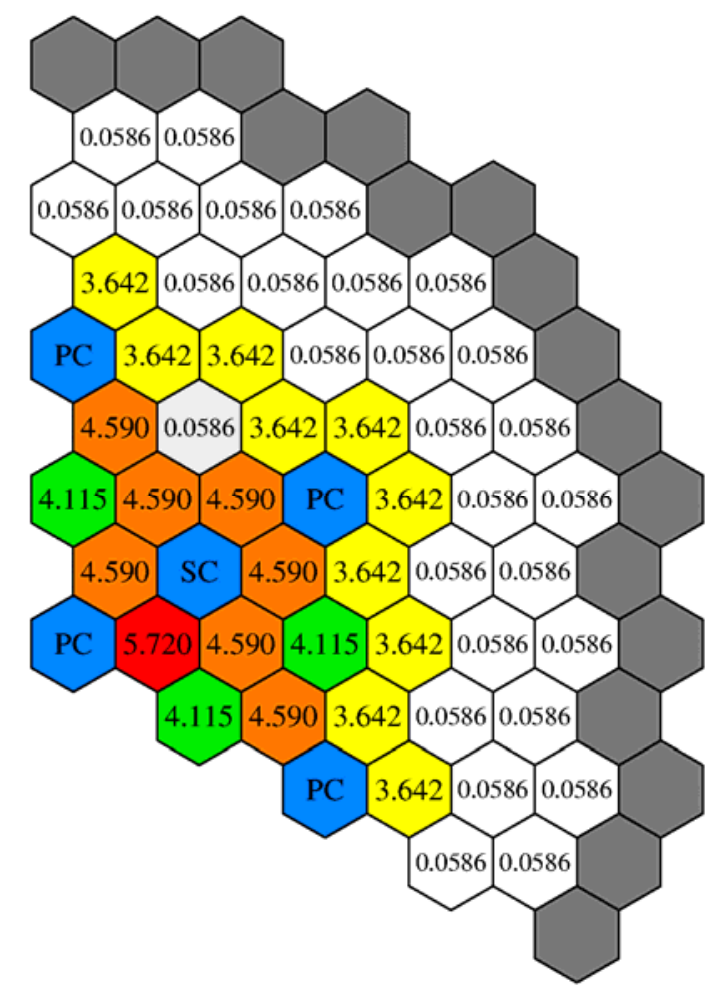

Figure 2.3-3. BOEC Initial Subassembly Power (MW) 
Table 2.3-1. Fuel Assembly, Pin, and Coolant Channel Model Data

\begin{tabular}{ll}
\hline Pins per Assembly & 217 \\
Number of Fuel Assemblies & 60 \\
$\quad$ Channel 1 (Inner Core) & 23 \\
Channel 2 (Fuel Test) & 6 \\
Channel 3 (Outer Core) & 30 \\
$\quad$ Channel 5 (Peak Inner Core) & 1 \\
Fuel Height (mm) & 800 \\
Gas Plenum Height (mm) & 1200 \\
Upper Reflector Height (mm) & 300 \\
Lower Reflector Height (mm) & 600 \\
Axial Node Height (mm) & \\
$\quad$ Core & 40 \\
$\quad$ Gas Plenum & 200 \\
$\quad$ Upper Reflector & 60 \\
$\quad$ Lower Reflector & 120 \\
Hydraulic Diameter (mm) & 2.972 \\
Coolant Flow Area per Pin (mm ${ }^{2}$ ) & 22.69 \\
Outer Fuel Radius (mm) & 3.48 \\
Inner Cladding Radius (mm) & 3.48 \\
Outer Cladding Radius (mm) & 4.00 \\
Structure Thickness ${ }^{\mathrm{a}}$ (mm) & 3.45 \\
Structure Perimeter ${ }^{\text {b }}$ (mm) & 2.46 \\
Reflector Thickness (mm) & 2.00 \\
Reflector Perimeter (mm) & 25.1 \\
\hline a. Structure thickness includes weighted contribution \\
from the inter-assembly gap sodium. \\
b. Structure perimeter includes contribution from wire \\
wrap spacers. \\
$\quad$
\end{tabular}




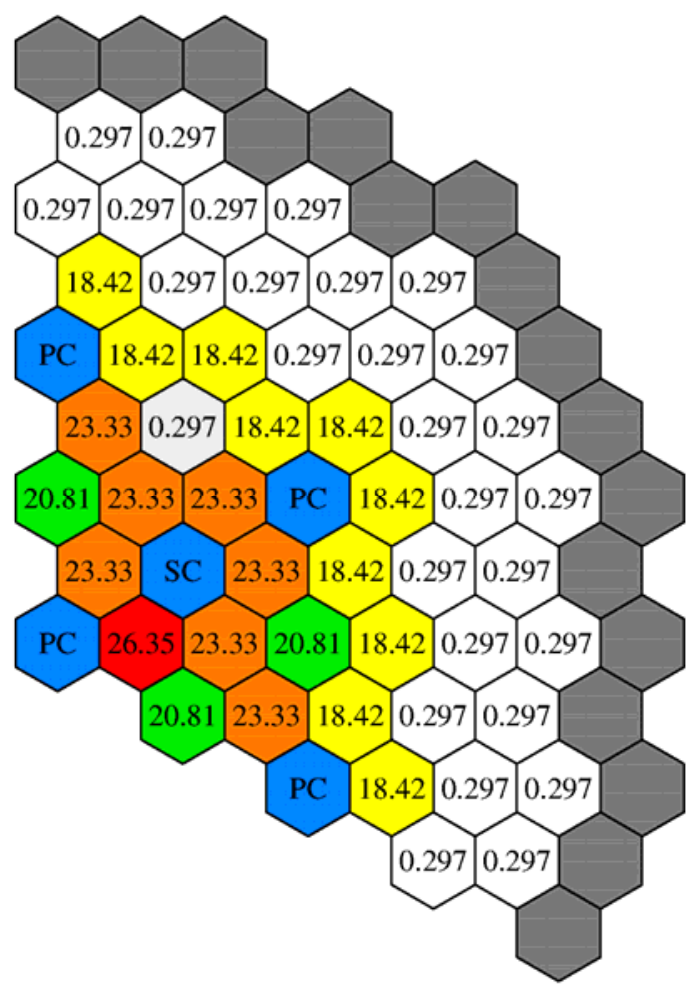

Figure 2.3-4. Initial Subassembly Coolant Flow (kg/s)

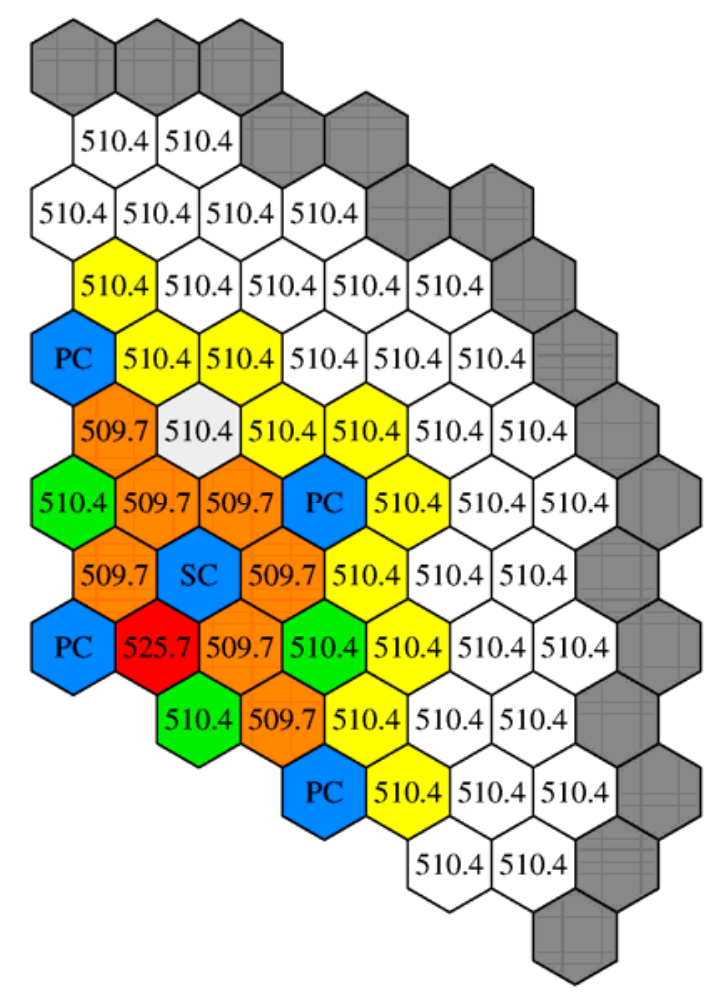

Figure 2.3-5. BOEC Initial Coolant Outlet Temperature $\left({ }^{\circ} \mathrm{C}\right)$ 


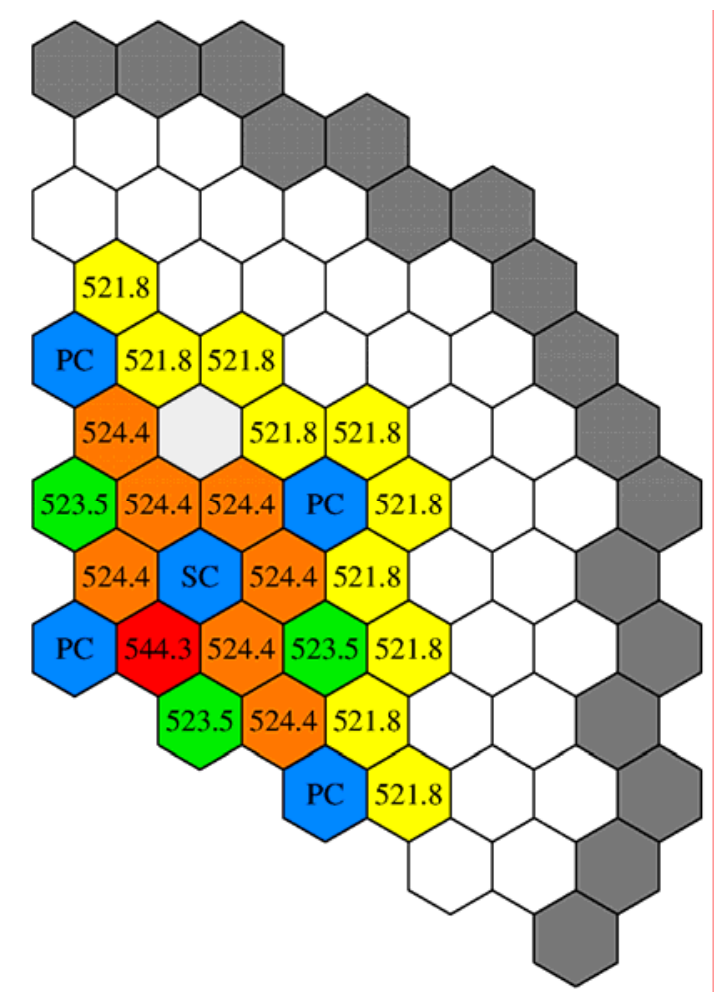

Figure 2.3-6. BOEC Initial Peak Cladding Temperature $\left({ }^{\circ} \mathrm{C}\right)$

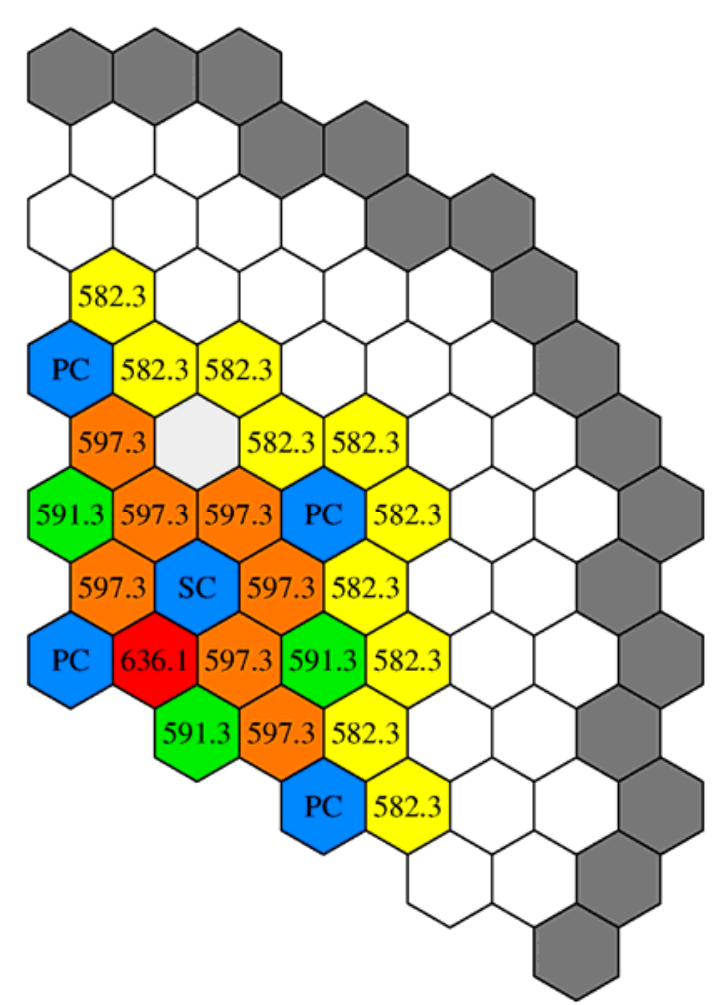

Figure 2.3-7. BOL Initial Peak Fuel Temperature $\left({ }^{\circ} \mathrm{C}\right)$ 


\subsubsection{Coolant Systems Thermal Hydraulics}

The coolant systems thermal hydraulics model represents coolant flow and heat transfer in the primary and intermediate sodium systems, and in the emergency decay heat removal system, with a network of volumes and components connected by flow paths. The coolant systems model is shown in Figure 2.3-8. From the inlet plenum, cold coolant flows through the core and is heated, then exits to the outlet plenum and travels through the shell side of the intermediate heat exchangers (IHXs), where it gives up its heat. Cold primary coolant exits the IHXs and flows to the cold pool. The primary coolant pumps take suction from the cold pool and deliver the coolant back to the inlet plenum. Emergency decay heat removal is provided by the direct reactor auxiliary cooling system (DRACS), a natural circulation system that removes heat by means of a heat exchanger in the upper region of the primary circuit cold leg and rejects heat through an air dump heat exchanger outside the containment. The working fluid in the DRACS system is NaK.

In the primary coolant circuit, volumes 1 and 2 represent the inlet and outlet plenums, and volumes 3 and 4 stand for regions of the primary circuit cold leg. The coolant in volume 4 is essentially stagnant. Volumes 5 and 6 simulate the gas expansion volumes in the intermediate loop and decay heat removal system, respectively. Design parameters assumed for the volumes in the model are shown in Table 2.3-2. All of the volumes in the model are perfectly mixed (i.e. characterized by a single temperature) except for the upper region of the cold pool, which is treated by a stratification model for low flow conditions.

Volumes in the model are connected by one-dimensional flow segments, which are further subdivided into temperature elements for heat transfer calculations. Table 2.3-3 shows the parameters assumed for the liquid segments. Flow segment 1 stands for the core channels, and flow segment 2 represents the shell side of the IHX. The ABTR has two IHXs, but only a single IHX is modeled, and it is assumed in this work that both primary circuits behave identically. Segment 4 represents the four primary coolant pumps and the discharge pipes connected to the inlet plenum. Segment 5 represents the primary coolant flow path through the decay heat removal heat exchanger, and segment 6 connects the upper region of the cold pool with the near stagnant lower region. Segment 7 represents the intermediate heat transfer loop including the loop piping, intermediate heat exchanger, and intermediate coolant pump. Segment 8 represents natural circulation flow in the DRACS loop. In normal operation, heat addition takes place in segment 1 , and heat is rejected in segments 2 and 5 . Segment 2 is thermally connected through the IHX to the intermediate loop, and segment 5 is thermally connected to the DRACS loop through the DRACS heat exchanger.

In the model, liquid flow segments are divided into a number of elements for the purpose of heat transfer and pressure drop calculations. The liquid elements in the coolant systems model are described in Table 2.3-4.

Primary and intermediate circuit flows are driven by both forced circulation at the pumps and by buoyancy due to heat exchange. Transient natural circulation flows adjust to changes in heat generation and transfer. DRACS loop natural circulation flow changes due to temperature changes in the DRACS heat exchanger and the air dump heat exchanger. Heat transfer at the air dump heat exchanger can be enhanced by opening air flow dampers, normally closed. 


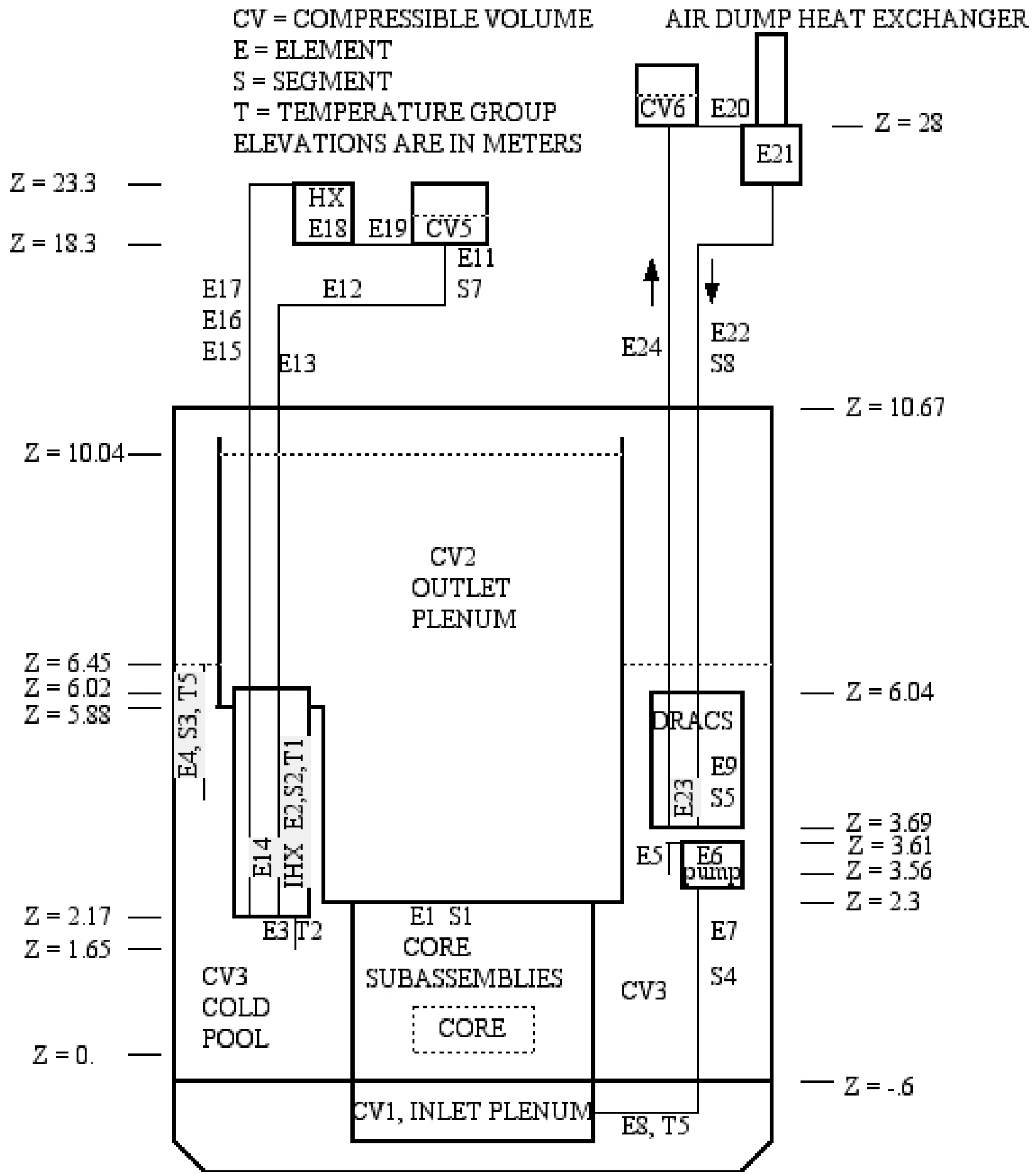

Figure 2.3-8. Coolant Systems Thermal Hydraulics Model 
Table 2.3-2. Compressible Volumes Input Data.

\begin{tabular}{|l|c|c|c|c|c|c|}
\hline $\begin{array}{l}\text { Volume } \\
\text { Number }\end{array}$ & 1 & 2 & 3 & 4 & 5 & 6 \\
\hline $\begin{array}{l}\text { Volume } \\
\text { Description }\end{array}$ & $\begin{array}{c}\text { Inlet } \\
\text { Plenum }\end{array}$ & $\begin{array}{c}\text { Outlet } \\
\text { Plenum }\end{array}$ & $\begin{array}{c}\text { Upper } \\
\text { Cold } \\
\text { Pool } \\
\text { Region }\end{array}$ & $\begin{array}{c}\text { Lower } \\
\text { Cold } \\
\text { Pool } \\
\text { Region }\end{array}$ & $\begin{array}{c}\text { Intermediate } \\
\text { Loop } \\
\text { Junction }\end{array}$ & $\begin{array}{c}\text { DRACS } \\
\text { Loop } \\
\text { Junction }\end{array}$ \\
\hline $\begin{array}{l}\text { Total Volume } \\
\left(\mathrm{m}^{3}\right)\end{array}$ & 3.06 & 92.51 & 152.97 & 28.14 & 6.0 & 4.0 \\
\hline $\begin{array}{l}\text { Initial Gas } \\
\text { Volume }\left(\mathrm{m}^{3}\right)\end{array}$ & - & 6.17 & 60.6 & - & 1.0 & 0.6 \\
\hline $\begin{array}{l}\text { Reference } \\
\text { Liquid } \\
\text { Elevation (m) }\end{array}$ & -0.75 & 3.0 & 7.0 & 0. & 18.3 & 27.0 \\
\hline $\begin{array}{l}\text { Liquid/Gas } \\
\text { Interface Area } \\
\left(\mathrm{m}^{2}\right)\end{array}$ & - & 11.16 & 12.8 & - & 1.0 & 0.8 \\
\hline $\begin{array}{l}\text { Wall Surface } \\
\left.\text { Area (m }{ }^{2}\right)\end{array}$ & 10.5 & 16.5 & 80.0 & 44.0 & 13.0 & 10.0 \\
\hline $\begin{array}{l}\text { Wall Heat } \\
\text { Capacity } \\
(\mathrm{MJ} / \mathrm{K})\end{array}$ & 63.5 & 0.66 & 26.87 & 14.14 & 1.075 & .707 \\
\hline
\end{tabular}

Table 2.3-3. Liquid Segments Input Data.

\begin{tabular}{|c|c|c|c|c|c|}
\hline $\begin{array}{c}\text { Segment } \\
\text { Number }\end{array}$ & Description & $\begin{array}{c}\text { Compressible } \\
\text { Volume } \\
\text { In/Out }\end{array}$ & $\begin{array}{c}\text { Inlet } \\
\text { Elevation } \\
(\mathrm{m})\end{array}$ & $\begin{array}{c}\text { Liquid } \\
\text { Element } \\
\text { In/Out }\end{array}$ & $\begin{array}{c}\text { Initial Flow } \\
(\mathrm{kg} / \mathrm{s})\end{array}$ \\
\hline 1 & $\begin{array}{c}\text { Reactor Sub- } \\
\text { Assemblies }\end{array}$ & $1 / 2$ & -0.60 & $1 / 1$ & 1264.4 \\
\hline 2 & $\begin{array}{c}\text { IHX Shell } \\
\text { Side }\end{array}$ & $2 / 3$ & 6.02 & $2 / 3$ & 632.2 \\
\hline 3 & $\begin{array}{c}\text { Intra-Volume } \\
\text { Heat Transfer }\end{array}$ & $3 / 3$ & 4.0 & $4 / 4$ & 0.0 \\
\hline 4 & $\begin{array}{c}\text { Primary } \\
\text { Pump }\end{array}$ & $3 / 1$ & 3.56 & $5 / 8$ & 316.1 \\
\hline 5 & $\begin{array}{c}\text { DHRX to } \\
\text { Cold Pool }\end{array}$ & $3 / 3$ & 6.035 & $9 / 9$ & 0.0 \\
\hline 6 & $\begin{array}{c}\text { Cold Pool } \\
\text { Transition }\end{array}$ & $3 / 4$ & -.85 & $10 / 10$ & 0.0 \\
\hline 7 & $\begin{array}{c}\text { Intermediate } \\
\text { Loop }\end{array}$ & $5 / 5$ & 18.2 & $11 / 19$ & 634.0 \\
\hline 8 & $\begin{array}{c}\text { DRACS } \\
\text { Loop }\end{array}$ & $6 / 6$ & 28.0 & $20 / 24$ & 0.0 \\
\hline
\end{tabular}


Table 2.3-4. Liquid Elements Input Data.

\begin{tabular}{|c|c|c|c|c|c|}
\hline $\begin{array}{c}\text { Element } \\
\text { Number }\end{array}$ & Description & $\begin{array}{c}\text { Outlet } \\
\text { Elevation } \\
(\mathrm{m})\end{array}$ & $\begin{array}{c}\text { Length } \\
(\mathrm{m})\end{array}$ & $\begin{array}{c}\text { Flow Area } \\
\left(\mathrm{m}^{2}\right)\end{array}$ & $\begin{array}{c}\text { Hydraulic } \\
\text { Diameter } \\
(\mathrm{m})\end{array}$ \\
\hline 1 & Reactor & $*$ & $*$ & $*$ & $*$ \\
\hline 2 & IHX Shell & 2.17 & 3.85 & 0.766 & 0.0186 \\
\hline 3 & IHX Outlet & 1.65 & 0.42 & 0.3 & 0.34 \\
\hline 4 & Cold Pool HT & 6.4 & 2.4 & 0.44 & 0.16 \\
\hline 5 & Pump Inlet & 3.61 & 0.05 & 0.13 & 0.41 \\
\hline 6 & Primary Pump & 3.61 & 0.05 & 0.055 & 0.113 \\
\hline 7 & Pump Outlet & -0.77 & 4.38 & 0.132 & 0.34 \\
\hline 8 & Pump Discharge & -0.77 & 1.26 & 5.36 & 1.0 \\
\hline 9 & DRACS HX & 3.69 & 2.35 & 0.024 & 0.037 \\
\hline 10 & CP Transition & -.87 & 0.02 & 0.092 & 0.34 \\
\hline 11 & IHTS Pipe & 13.0 & 6.4 & 0.092 & 0.34 \\
\hline 12 & IHTS Pipe & 13.0 & 4.3 & 0.092 & 0.34 \\
\hline 13 & IHTS Pipe & 2.17 & 10.8 & 0.092 & 0.34 \\
\hline 14 & IHX Tube & 6.02 & 3.85 & 0.517 & 0.014 \\
\hline 15 & IHTS Pipe & 12.4 & 6.36 & 0.092 & 0.34 \\
\hline 16 & IHTS Pipe & 12.4 & 5.2 & 0.092 & 0.34 \\
\hline 17 & IHTS Pipe & 23.3 & 6.0 & 0.092 & 0.34 \\
\hline 18 & BOP HX & 18.3 & 4.0 & 3.6 & 0.0075 \\
\hline 19 & IHTS Pump & 18.3 & 1.0 & 0.092 & 0.34 \\
\hline 20 & DRACS Pipe & 28.0 & 1.0 & 0.016 & 0.14 \\
\hline 21 & Air Dump HX & 27.0 & 5.7 & 0.17 & 0.05 \\
\hline 22 & DRACS Pipe & 3.7 & 23.3 & 0.016 & 0.14 \\
\hline 23 & Na/NaK HX & 6.04 & 2.35 & 0.010 & 0.037 \\
\hline 24 & DRACS Pipe & 26.9 & 20.9 & 0.016 & 0.14 \\
\hline
\end{tabular}

* See core channel model in Table 2.3-1.

\subsubsection{Reactor Kinetics and Reactivity Feedback}

A point kinetics model is employed to calculate the response of reactor fission power to transient reactivity feedbacks. At any time, the net reactivity is the sum of a number of individual reactivity feedbacks that are determined by the transient thermal, hydraulic, mechanical, and neutronic state of the reactor. The feedback reactivities considered are fuel Doppler, coolant density, fuel and cladding axial expansion, radial core expansion, and control rod driveline thermal expansion. In addition to tracking fission power, a decay heat model is integrated with the point kinetics model to track thermal power in sub-critical conditions.

Fuel Doppler feedback is calculated from the spatially-dependent fuel temperature distribution and the input spatial distribution of the fuel Doppler reactivity coefficient. In each single-pin channel, the axial distribution of the radial pin-average fuel temperature is used to calculate the reactivity feedback. 
Coolant density reactivity feedback is calculated from the spatially dependent coolant density distribution and the input distribution of the coolant density reactivity coefficient calculated from perturbation theory. The reactivity feedback data is entered as a coolant void worth (the negative of the coolant mass worth).

Transient fuel and cladding temperatures are used to predict fuel and cladding axial dimension changes, and in each single-pin channel the reactivity feedbacks associated with fuel and cladding axial expansion are computed from first order perturbation theory.

A simple radial core expansion model accounts for core dilation due to thermal expansion of the above-core load pads and thermal expansion of the core support grid plate. Reactivity feedback is then calculated from the computed core dimension change and an input linear reactivity coefficient based on stand-alone neutronics eigenvalue calculations.

For the control-rod driveline feedback model, it is assumed that the control rod drivelines are washed by the outlet coolant from the core. Thermal expansion of the drivelines due to a rise in core outlet temperature will cause the control rods to be inserted further into the core, providing a negative reactivity component. On the other hand, if the control rod drives are supported on the vessel head, and if the core is supported by the vessel walls, then heating the vessel walls will lower the core, leading to a positive reactivity component. In the present model, both control-rod driveline expansion and vessel wall expansion are treated.

\subsection{Analysis Results}

Analyses of the protected loss-of-flow (PLOF) and unprotected loss-of-flow (ULOF) accident sequences were performed with coupled heat transfer, thermal-hydraulics, and reactor kinetics models available in the SASSYS-1 code. These models have been validated through many applications to EBR-II and FFTF transient tests. Additionally, temperature criteria for assessments of cladding damage thresholds have been established by results from testing of metallic fuel in EBR-II and TREAT. Consequently, there is high confidence that the detailed results from the PLOF and ULOF accident analyses presented here give a true characterization of the physical performance that could be obtained in the ABTR design.

\subsubsection{Protected Loss-of-Flow (PLOF) Accident Sequence}

Results from analysis of the PLOF accident sequence are shown in Figure 2.3-9, -10, -11 and -12. Figures 2.3-9 and -10 show the history of the reactor power, the decay heat power, the DRACS heat removal rate and the coolant flows through the highest temperature subassembly (Channel 5) and an average temperature subassembly (Channel 3). Recall that this transient is initiated by a complete loss of forced coolant flow in the primary and intermediate loops, save the flow coast-downs. Both the primary and intermediate pump systems are designed with sufficient flow inertia to give initial flow halving times of 7 seconds. The primary pumps cease operation at about 450 seconds after the start of the transient, leading to a transition to natural circulation. The transition to natural circulation goes more smoothly in the hotter Channel 5 than in the cooler Channel 3. Almost immediately at initiation, the reactor control system scrams the 


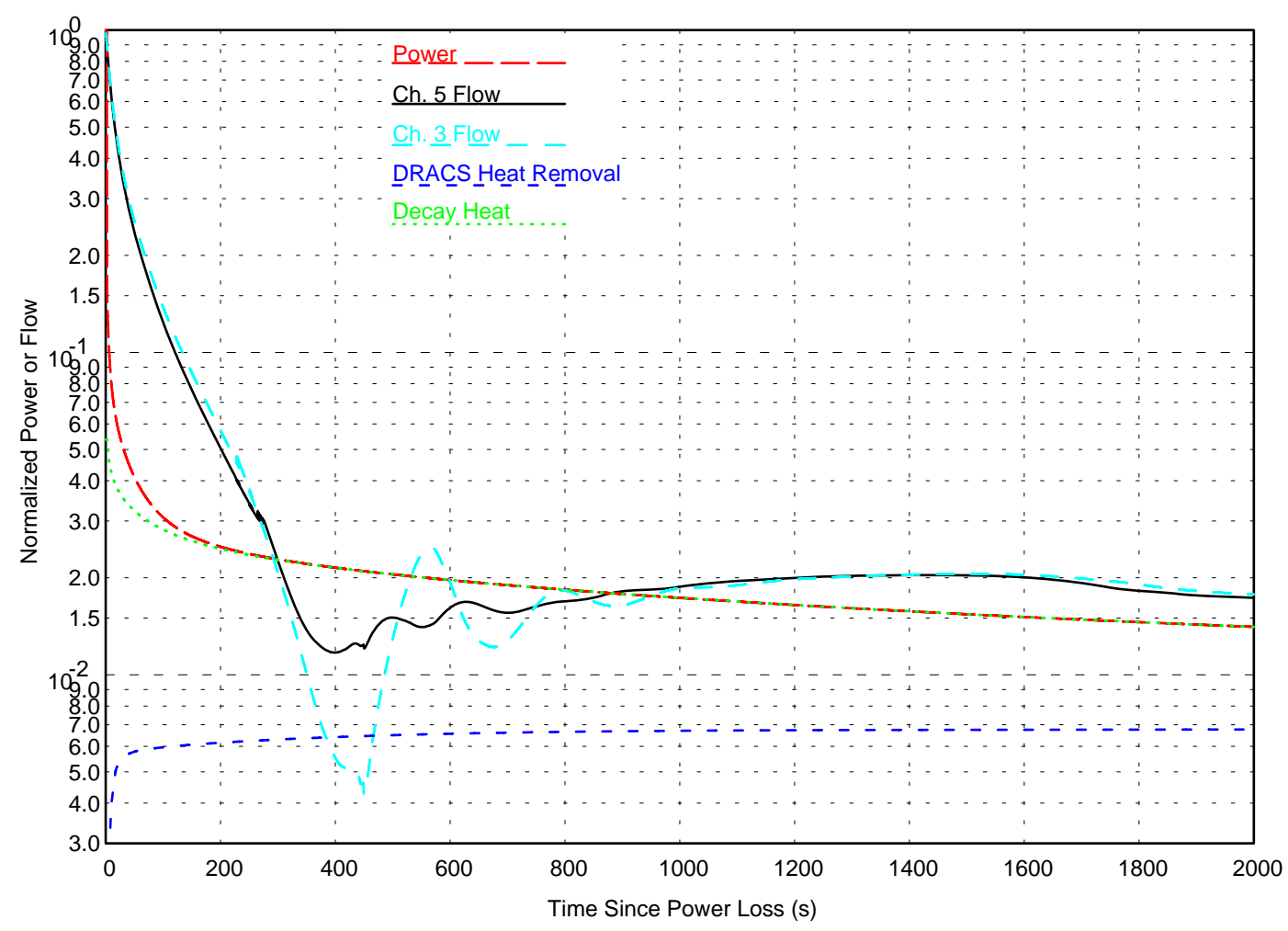

Figure 2.3-9. PLOF Power and Flow History, Early Times

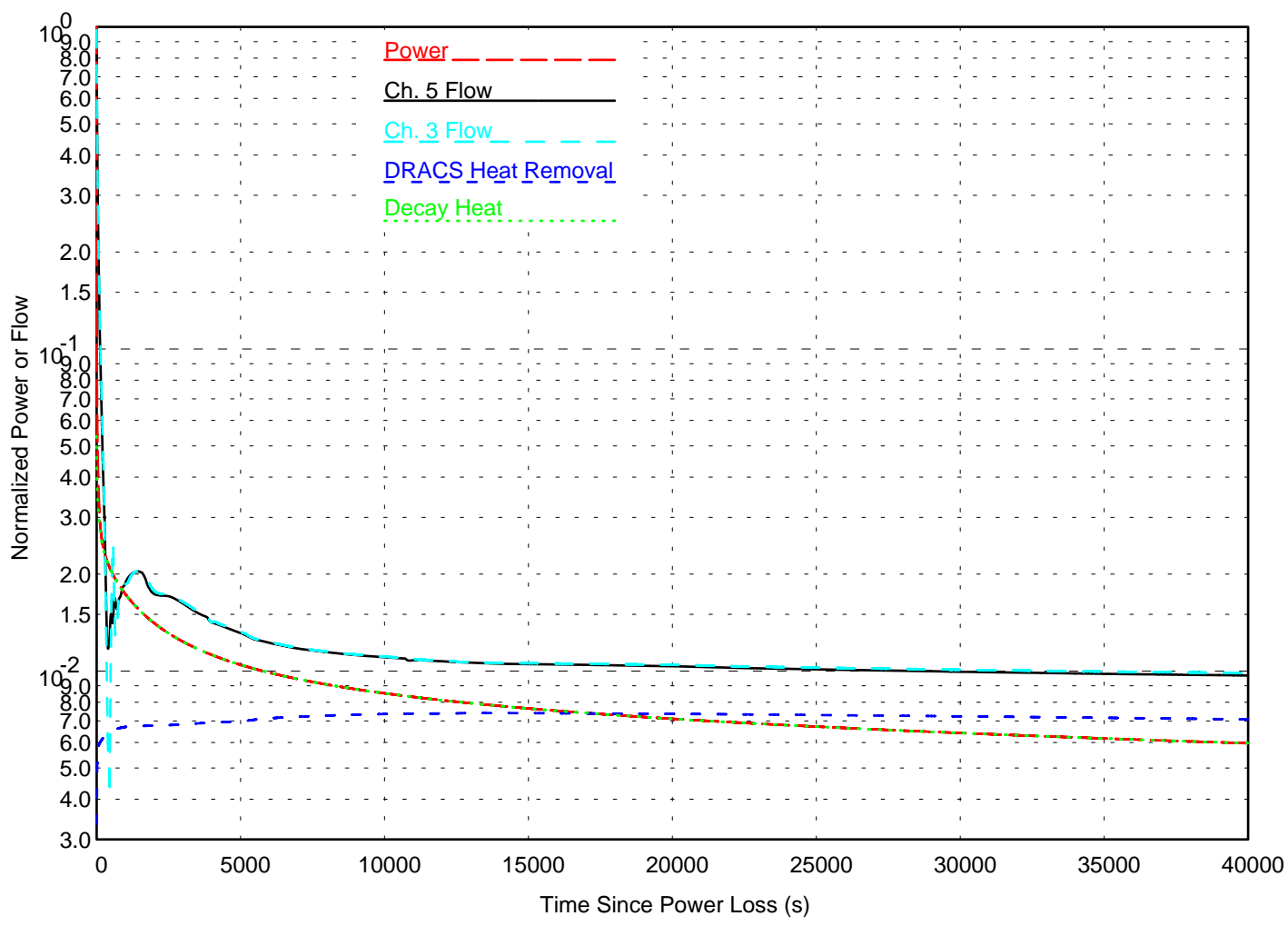

Figure 2.3-10. PLOF Power and Flow History, Extended Times 


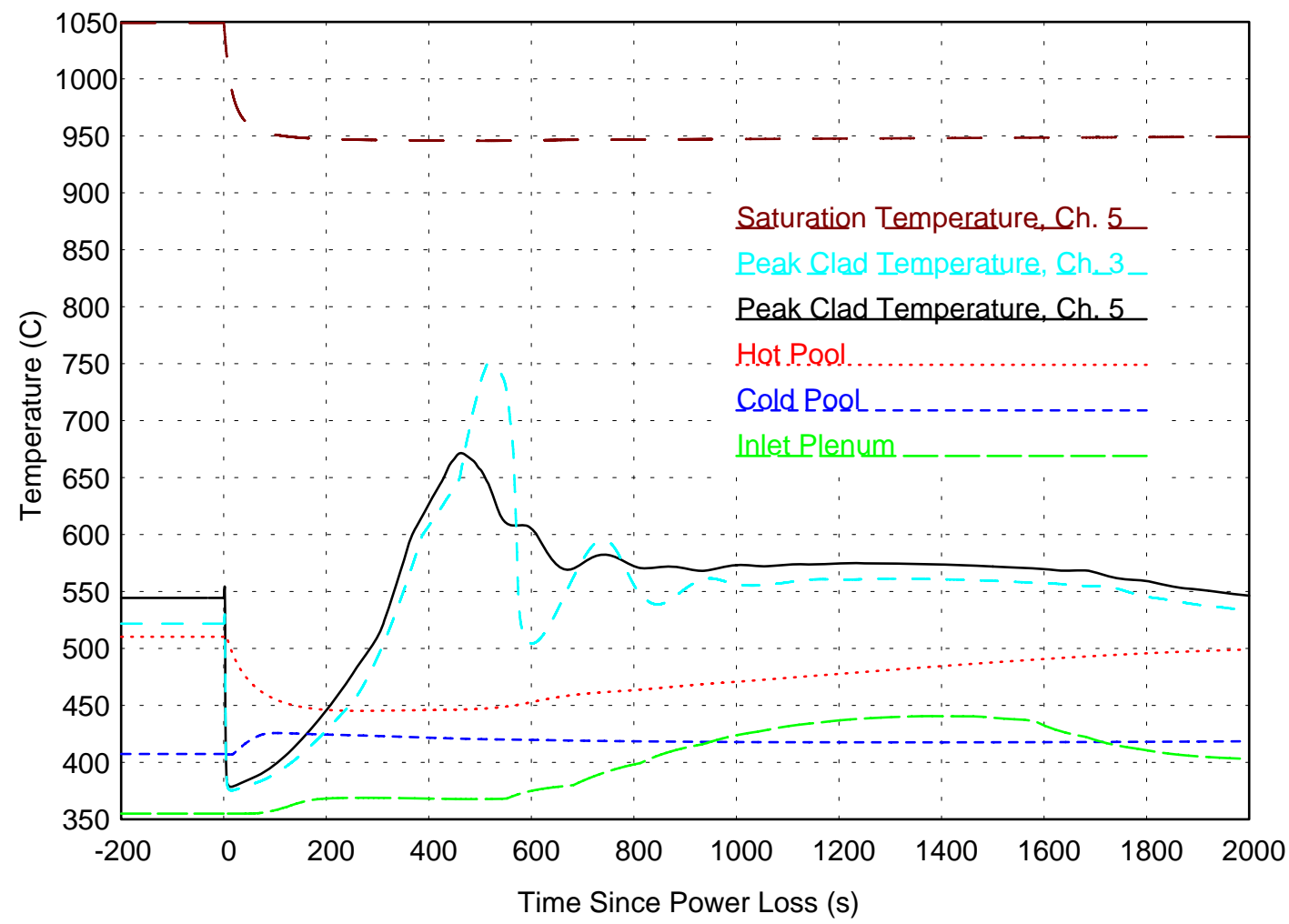

Figure 2.3-11. PLOF Temperature History, Early Times

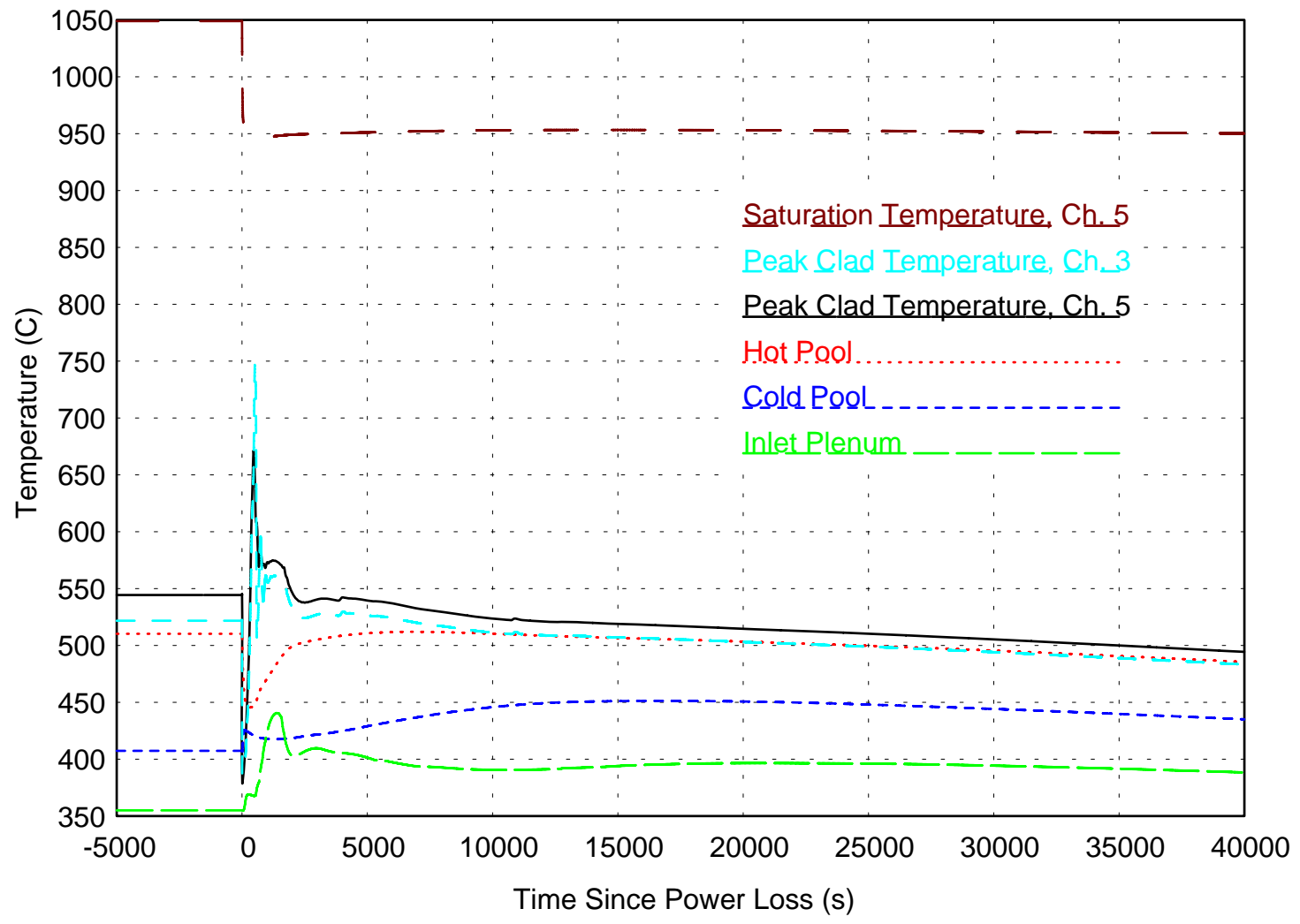

Figure 2.3-12. PLOF Temperature History, Extended Times 
reactor, beginning the power reduction to decay heat shown in Figure 2.3-9, and the dampers on the DRACS air dump heat exchangers open, permitting the DRACS to operate at its full capacity of $0.5 \%$. As the cold pool temperature rises, DRACS heat removal capacity increases, eventually reaching the equivalent of $0.7 \%$ of normal reactor power. Not indicated in this figure is the loss of heat removal to the balance-of-plant, which is assumed to occur after the first 10 seconds. Figure 2.3-10 shows that the reactor decay heat power equals the DRACS heat removal capacity at about 5 hours into the transient.

Figure 2.3-11 shows the early reactor temperature histories during the coolant flow coast down and transition to natural circulation. During this and the following time, the only heat removal is through the DRACS. The rapid reactor power decrease due to the scram initially lowers the coolant and cladding temperatures in the core. Then the drop in core flow as the pumps coast down leads to a rise in core coolant and cladding temperatures. As mentioned above the transition to natural circulation is smoother in Channel 5 than in Channel 3. In channel 3 as the primary pumps stop turning the coolant flow rate temporarily drops to very low values, leading to higher peak coolant and cladding temperatures. This short-term cladding temperature rise may result in some fuel-cladding chemical interaction, but no cladding failure would occur.

A temperature stratification model is used for the cold pool. Early in the transient, heat removal from the IHX stops. After that the hot coolant entering the cold pool from the IHX outlets rises to the upper part of the cold pool, forming a hot layer. The cooler discharge from the DRACS heat exchangers falls to the bottom of the cold pool, forming a cold layer. This thermal stratification enhances the natural circulation performance of the system. The inlets to the DRACS heat exchangers are located in the hot upper part of the cold pool. On the other hand, the pump inlets are in the cooler lower layer, reducing the core inlet temperature.

The magnitude of the temperature stratification effect in the cold pool is indicated by the temperatures plotted in Figures 2.3-11 and -12. For most of the transient the temperature in the upper stratified layer of the cold pool is approximately equal to the hot pool temperature; whereas the temperature in the lower layer is approximately equal to the inlet plenum temperature. This temperature difference is approximately $100^{\circ} \mathrm{C}$. Note that the "Cold Pool" temperature plotted in these figures is the average temperature of the axially stratified distribution.

As the system temperature rises in the early part of the transient, DRACS heat removal capability increases due to an increase in $\mathrm{NaK}$ flow and heat rejection at the air dump heat exchangers. The decay heat production declines throughout the transient, until it becomes equal to the DRACS heat removal at 5 hours. As shown in Figure 2.3-12, the cold pool temperatures reach long-term peak values at about this time, and then uniformly decrease as the whole system cools.

The significance of the PLOF analysis results is emphasized in Figure 2.3-11 which shows the initial peak cladding temperature $\left(522^{\circ} \mathrm{C}\right)$ in channel 3, compared to the short-term transient peak cladding temperature of $750^{\circ} \mathrm{C}$ and the long-term peak cladding temperature just above $500^{\circ} \mathrm{C}$ at around 4 hours. In the PLOF transient, no cladding failures would occur, and the long-term peak temperatures in the accident are lower than the normal operating temperatures. Stated in another way, the long-term temperature safety margins in the accident are greater than the margins at the 
normal operating conditions. This very significant result is obtained as a result of the natural circulation capabilities of the reactor coolant system and the DRACS.

\subsubsection{Unprotected Loss-of-Flow (ULOF) Accident Sequence}

The ULOF transient is initiated by the same set of failures as for the PLOF accident (loss of forced flow and loss of normal heat rejection). However, for the ULOF case, the reactor control system also fails to scram the reactor; so the accident proceeds from full power. All heat rejection is through the DRACS, with a design heat rejection of $0.5 \%$ of full power at nominal conditions. Results from the analysis of the ULOF accident sequence are shown in Figure 2.3-13 through Figure 2.3-15.

Figure 2.3-13 shows the histories for the total reactor power, the decay heat production, and the coolant flow in channel 5 (the peak inner core assembly). The power-to-flow imbalance during the first 800 seconds results in significant transient reactor heating. Peak fuel, peak clad, and coolant outlet temperatures for channel 5 are shown in Figure 2.3-14. Coolant and cladding temperatures increase to approximately $600^{\circ} \mathrm{C}$ within the first 30 seconds. This heating causes the reactivity feedbacks shown in Figure 2.3-15. Axial and radial expansions are the main contributors to the initial negative reactivity feedback, which causes power and fuel temperatures to decline. Reduced fuel temperatures provide a positive Doppler feedback, although the magnitude is modest due to the high thermal conductivity and relatively low operating temperatures of metallic fuel. Shortly after the onset of the transient, higher-temperature coolant begins washing over and heating the control-rod drivelines. As the drivelines expand, an additional negative reactivity component is introduced, as shown in Figure 2.3-15.

The flow coast-down provided by the inertia of the primary pumps ends at approximately 450 seconds. At this point, natural circulation has not yet been fully established, and fuel, cladding, and local coolant temperatures begin to rise to form a second temperature peak at approximately 480 seconds. The increased temperatures provide the necessary driving force to establish natural circulation flow and the coolant flow rate in channel 5 (the peak inner core assembly) begins to increase. While the second temperature peak also causes considerable thermal expansion and negative reactivity feedback, fission power has already been significantly reduced, and residual heating is dominated by decay heat. Therefore, the dramatic changes in reactivity feedback (particularly radial expansion) have negligible impact on subsequent transient development.

As natural circulation is being established, the peak in the coolant temperature moves up through the core and to the subassembly outlet. While the delay in observing the temperature peak at the outlet is partly due to the low flow conditions, a bigger contributor to the delay is the large thermal inertia of the structural materials above the core, which must all be heated before the temperature peak reaches the outlet. Nevertheless, the development of natural circulation reduces peak fuel and cladding temperatures back to around $600^{\circ} \mathrm{C}$. Beyond 800 seconds, the normalized power-to-flow falls below unity, and the temperature difference from inlet to outlet falls below that of normal operating conditions. In the long term, once the decay heat falls below the heat rejection capability of the DRACS, overall system temperatures will begin to decline. 


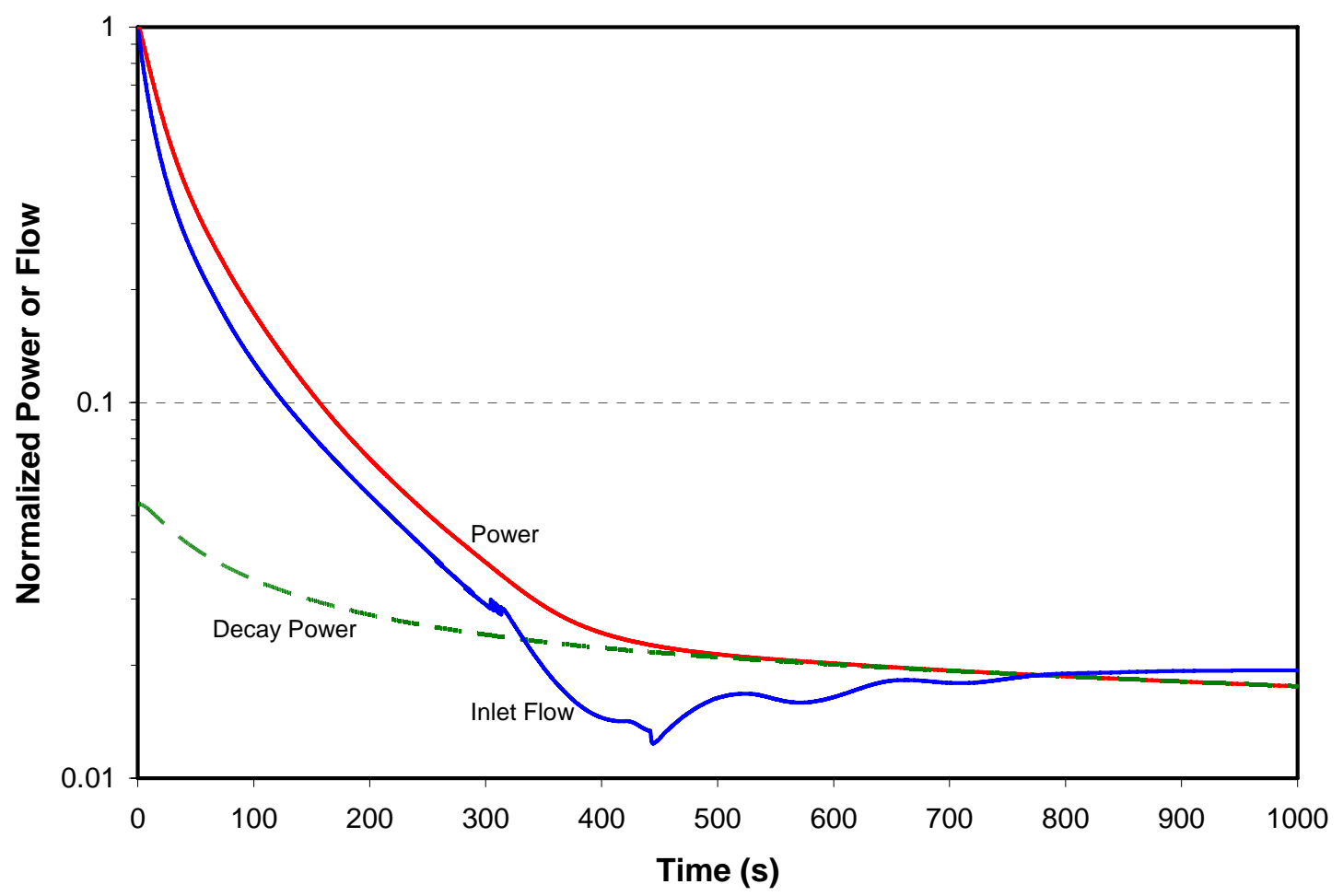

Figure 2.3-13. ULOF Transient Total Power and Channel 5 Flow

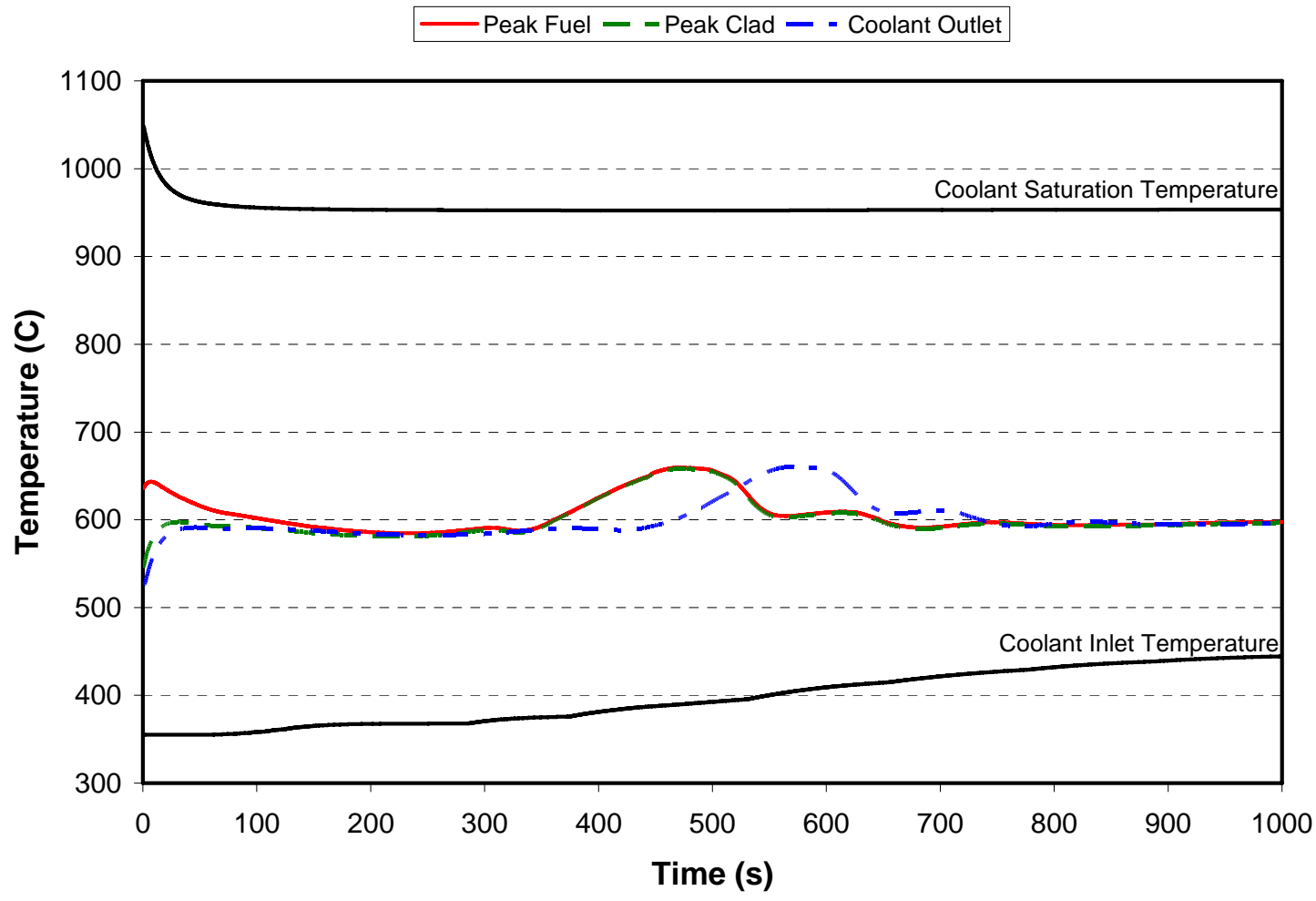

Figure 2.3-14. ULOF Transient Temperatures for Channel 5 


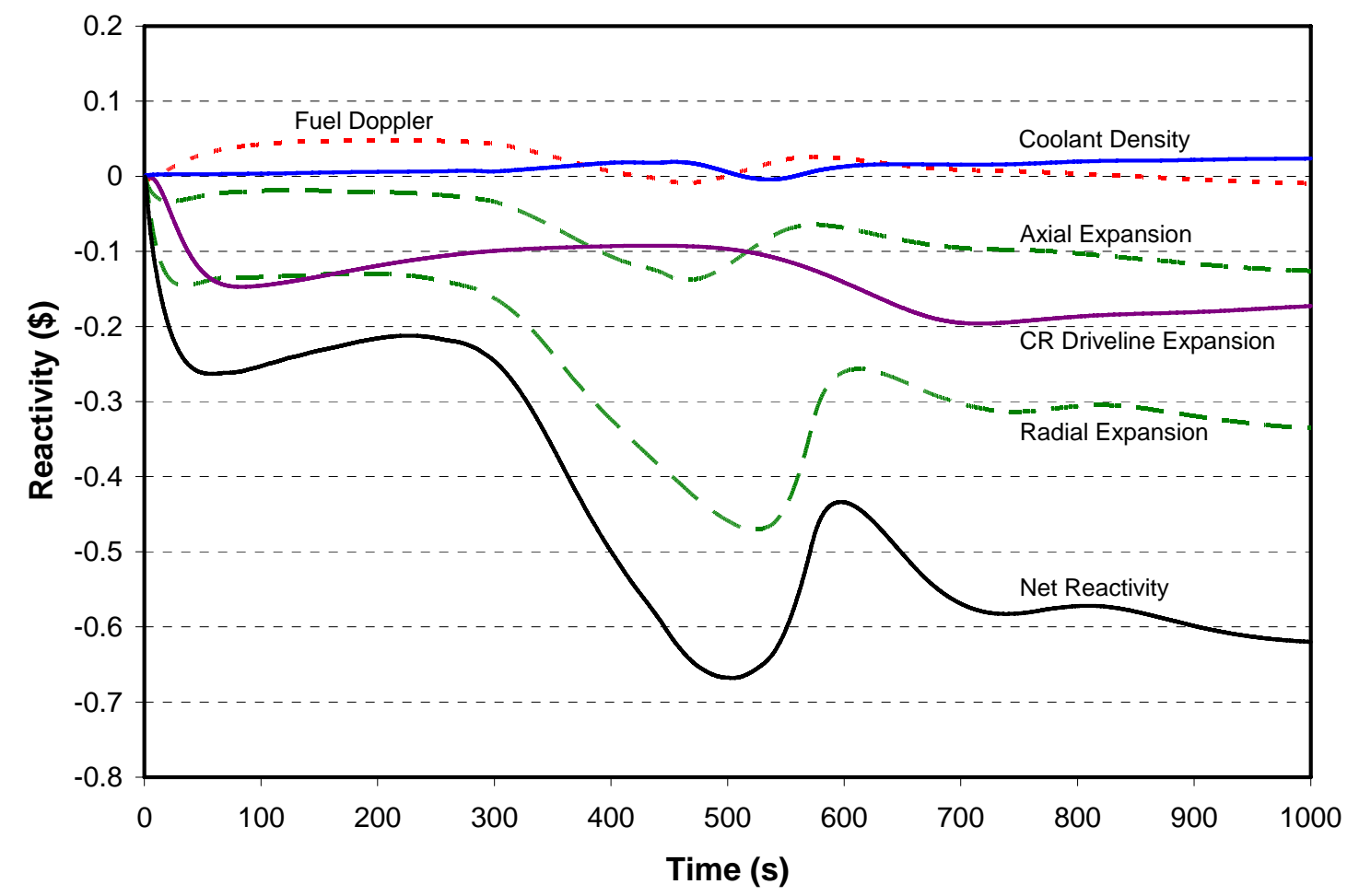

Figure 2.3-15. ULOF Transient Reactivity Feedback

The significance of the ULOF accident analysis results is captured in Figure 2.3-14. As shown for channel 5, the peak fuel, cladding, and coolant temperatures remain well below the coolant saturation (boiling) temperature, with a minimum margin to coolant boiling of nearly $300^{\circ} \mathrm{C}$. The analysis suggests that the core would survive an unprotected loss-of-flow accident without pin failures or significant fuel damage. This very favorable result comes about because of 1) the high thermal conductivity and relatively low operating temperature of metallic fuel, 2) the capability of a sodium-cooled reactor in a pool-type primary system to remove decay heat in natural circulation, and 3) the beneficial negative reactivity feedback coefficients and reactor physics performance of metallic fuel. 


\section{REFERENCES}

1. Advanced Burner Test Reactor Preconceptual Design Report, ANL-ABR-1 (ANL-AFCI173), Argonne National Laboratory, September, 2006.

2. The Experimental Breeder Reactor-II Inherent Safety Demonstration, Nucl. Eng. Des., (Special Issue), Vol. 101, No. 1, 1987.

3. K. Kim, W. S. Yang, E. A. Hoffman, and R. N. Hill, Core Design Studies for Advanced Burner Test Reactor, ANL-AFCI-169, Argonne National Laboratory, June 30, 2006.

4. American National Standard Decay Heat Power in Light Water Reactors, ANSI/ANS5.1-2005, American Nuclear Society, 2005.

5. J. E. Cahalan, A. M. Tentner, and E. E. Morris, Advanced LMR Safety Analysis Capabilities in the SASSYS-1 and SAS4A Computer Codes, Proceedings of the International Topical Meeting on Advanced Reactors Safety, Vol. 2, pp. 1038-1045, Pittsburgh, Pennsylvania USA, April 17-21, 1994.

6. Leibowitz and R. A. Blomquist, Thermal Conductivity and Thermal Expansion of Stainless Steels D9 and HT9, International Journal of Thermophysics, Vol. 9, No. 5, pp. 873-883, September, 1988. 


\title{
APPENDIX A \\ Evaluation of Safety Design Criteria for Application to \\ Liquid Metal Cooled Fast Reactor
}

\begin{abstract}
This Appendix provides a survey of safety design criteria applicable to liquid metal cooled fast reactors (LMRs). Criteria selected for consideration include 1) generalized design criteria specified by Title 10, Part 50, Appendix A of the Code of Federal Regulations for application to light water nuclear power reactors, 2) American National Standard general safety design criteria for a liquid metal reactor nuclear power plant, and 3) U.S. Department of Energy nuclear reactor safety design criteria. Considerations of design criteria by U.S. Nuclear Regulatory Commission in licensing and safety evaluation of proposed liquid metal cooled nuclear power reactor designs are reviewed. Applicability of the selected set of design criteria to LMR plant design features and operational characteristics are discussed. Recommendations are made for modifications to existing safety design criteria for relevance to LMR system designs.
\end{abstract}




\section{A.1 Introduction}

The safety philosophy guiding the design, construction, and operation of nuclear facilities in the U.S. is based on the principle of "defense in depth" [A1]. The objectives of "defense in depth' are first to protect the health and safety of the public and plant operating personnel, and second to preserve the facility investment by assuring its operational readiness. In terms of physical elements, "defense in depth" is exemplified by multiple, successive barriers to guard against the escape of radioactivity from nuclear facilities. However, in the evolution of U.S. nuclear safety philosophy, the "defense in depth" principle has been extended and applied to all aspects of nuclear facility design, construction, and operation, so that all safety critical functions are achieved by multiple systems/procedures/processes that are diverse and independent.

In the nuclear facility design process, the "defense in depth" principle has fostered the development of guidelines for identifying those engineered systems that are important for safety. Safety class systems are designed to be very reliable. They are constructed using specifications and materials that will assure functionality. In addition, multiple systems of diverse design are provided so that failure of any single safety system will not put people or equipment at risk.

The system configurations and functional requirements for nuclear facilities are routinely documented early in the design process as a set of safety design criteria. Commercial water cooled nuclear power plants licensed by the U.S. Nuclear Regulatory Commission must comply with general design criteria documented in the Code of Federal Regulations [A2]. Suggestions for modifications of these criteria for application to liquid metal cooled reactor designs have been supplied by representatives of the nuclear power industry [A3]. Nuclear research reactors built by the U.S. Department of Energy must comply with safety design criteria documented in a DOE Order [A4].

The purpose of this report is to provide a resolution of documented nuclear reactor safety design criteria, with the aim of identifying changes necessary for application to a liquid metal-cooled fast reactor (LMR) design. Existing general design criteria developed by the USNRC for light water reactors [A2], by industry for liquid metal reactors [A3], and by USDOE for research reactors [A4] are examined for relevance. Recommendations are made for modifications to the existing safety design criteria for application to sodium-cooled LMR system designs. 


\section{A.2 Safety Design Criteria Comparison}

In the methodological framework built on the defense-in-depth foundation, the role of safety design criteria is to set requirements for design performance. During the formative stages of design development, safety design criteria specify the configuration and functional performance characteristics the design must have for it to receive construction and operation approvals from the regulatory agency. Once the design is developed, safety analyses are performed and documented to quantify the margins between the safety requirements and expected performance. After the design is constructed, safety tests are performed to verify design safety performance. Therefore, it is necessary to establish safety design criteria early in the design process, and the requirements set by the safety design criteria largely determine the plant configuration, equipment inventory, and equipment arrangement.

The U.S. Nuclear Regulatory Commission has developed a set of general safety design criteria for commercial light water-cooled nuclear power reactors [A2]. These criteria are documented in Appendix A of Title 10, Part 50 of the Code of Federal Regulations (10CFR50 Appendix A). As documented, these criteria are the base-line requirements for nuclear power reactors in the U.S. However, the 10CFR50 Appendix A requirements are intended for application to light water reactors, and so are only partly applicable to the liquid metal cooled reactor designs.

During the years of the U.S. liquid metal reactor development program, industry representatives developed an American National Standard [A3] for safety design criteria applicable to liquid metal-cooled reactors. This set of criteria followed the organization and intent of 10CFR50 Appendix A, but modified certain criteria details for applicability to the low pressure, chemically reactive liquid metal coolant.

The U.S. Department of Energy has developed a set of safety design criteria [A4] to apply to USDOE reactors that are exempt from USNRC regulation. Such reactors include one-of-a-kind designs built for research, and other special purpose reactors. The USDOE criteria are similar in organization and intent to the 10CFR50 Appendix A criteria, with some variations to address generically the design variations of the USDOE reactors.

Table A1 contains a listing of the design criteria from 10CFR50 Appendix A, and a cross reference to the criteria proposed in Refs. A3 and A4. These three sets of safety design criteria have been reviewed for applicability to the liquid metal-cooled reactor design. The "Comments" column in Table A1 references the list of comment statements that follow the Table and record the results of the review. The review takes into account the technical safety evaluations performed by the USNRC for the PRISM [A5] and SAFR [A6] liquid metal reactor designs. 
Table A1. Safety Design Criteria Cross Comparison.

\begin{tabular}{|c|c|c|c|c|}
\hline Criterion/Requirement & $\begin{array}{l}\text { 10CFR50, } \\
\text { App. A }\end{array}$ & $\begin{array}{l}\text { ANSI/ANS } \\
54.1\end{array}$ & $\begin{array}{c}\text { DOE } \\
5480.30\end{array}$ & Comments \\
\hline \multicolumn{5}{|l|}{ I. Overall Requirements } \\
\hline Single Failure & & & $8 . c .1$ & 1,2 \\
\hline Quality Standards and Records & GDC 1 & 3.1 .1 & 8.c. 2 & 1 \\
\hline $\begin{array}{l}\text { Design Bases for Protection Against } \\
\text { Natural Phenomena }\end{array}$ & GDC 2 & 3.1 .2 & 8.c. 3 & 1 \\
\hline Fire Protection & GDC 3 & 3.1 .3 & 8.c. 4 & 1 \\
\hline $\begin{array}{l}\text { Protection Against Sodium and } \mathrm{NaK} \\
\text { Reactions }\end{array}$ & & 3.1 .4 & & 3 \\
\hline $\begin{array}{l}\text { Environmental and Dynamics Effects } \\
\text { Design Bases }\end{array}$ & GDC 4 & 3.1 .5 & $\begin{array}{l}\text { 8.c. } 5, \\
\text { 8.c. } 10\end{array}$ & 4 \\
\hline $\begin{array}{l}\text { Sharing of Structures, Systems, and } \\
\text { Components }\end{array}$ & GDC 5 & 3.1 .6 & 8.c. 6 & 1 \\
\hline Sodium Heating Systems & & 3.1 .7 & & 3 \\
\hline Siting & & & 8.c.7 & 5 \\
\hline Human Factors Engineering & & & 8.c.9 & 6 \\
\hline Safeguards and Security & & & 8.c.11 & 6 \\
\hline $\begin{array}{l}\text { Reactor Decontamination and } \\
\text { Decommissioning }\end{array}$ & & & 8.c.13 & 6 \\
\hline Support Systems & & & 8.c. 15 & 6 \\
\hline $\begin{array}{l}\text { Non-Safety Class Structures, Systems, } \\
\text { and Components }\end{array}$ & & & 8.c.16 & 6 \\
\hline \multicolumn{5}{|l|}{$\begin{array}{l}\text { II. Protection by Multiple Fission } \\
\text { Product Barriers }\end{array}$} \\
\hline Reactor Design & GDC 10 & 3.2 .1 & 8.d.3.a & 1 \\
\hline Reactor Inherent Protection & GDC 11 & 3.2 .2 & 8.d.3.b & 7 \\
\hline $\begin{array}{l}\text { Suppression of Reactor Power } \\
\text { Oscillations }\end{array}$ & GDC 12 & 3.2 .3 & 8.d.3.c & 1 \\
\hline Instrumentation and Control & GDC 13 & 3.2 .4 & 8.d.5.a & 1 \\
\hline Reactor Coolant Pressure Boundary & GDC 14 & 3.2 .5 & 8.d.1.a & 1 \\
\hline Reactor Coolant System Design & GDC 15 & 3.2 .6 & 8.d.6.a & 8 \\
\hline Containment Design & GDC 16 & 3.2 .7 & $8 . c .8$ & 1 \\
\hline Electric Power Systems & GDC 17 & 3.2 .8 & 8.d.2.a & 1 \\
\hline $\begin{array}{l}\text { Inspection and Testing of Electric } \\
\text { Power Systems }\end{array}$ & GDC 18 & 3.2 .9 & 8.d.2.b & 1 \\
\hline Control Room & GDC 19 & 3.2 .10 & 8.d.5.e & 1 \\
\hline Remote Shutdown & & & 8.d.5.f & 9 \\
\hline $\begin{array}{l}\text { Heating, Ventilation, and Air } \\
\text { Conditioning (HVAC) Systems }\end{array}$ & & & 8.d.7.a,b,c & 10 \\
\hline
\end{tabular}


Table A1. Safety Design Criteria Cross Comparison (cont.)

\begin{tabular}{|l|c|c|c|c|}
\hline \multicolumn{1}{|c|}{ Criterion/Requirement } & $\begin{array}{c}\text { 10CFR50, } \\
\text { App. A }\end{array}$ & $\begin{array}{c}\text { ANSI/ANS } \\
54.1\end{array}$ & $\begin{array}{c}\text { DOE } \\
5480.30\end{array}$ & Comments \\
\hline $\begin{array}{l}\text { III. Protection and Reactivity Control } \\
\text { Systems }\end{array}$ & & & & \\
\hline Protection System Functions & GDC 20 & 3.3 .1 & 8. d.4.a & 1 \\
\hline Protection System Reliability and Testing & GDC 21 & 3.3 .2 & 8. d.4.a & 1 \\
\hline Protection System Independence & GDC 22 & 3.3 .3 & 8. d.4.b & 1 \\
\hline Protection System Failure Modes & GDC 23 & 3.3 .4 & 8. d.4.c & 1 \\
\hline $\begin{array}{l}\text { Separation of Protection and Control } \\
\text { Systems }\end{array}$ & GDC 24 & 3.3 .5 & 8.d.4.d & 1 \\
\hline $\begin{array}{l}\text { Protection System Requirements for } \\
\text { Reactivity Control Malfunctions }\end{array}$ & GDC 25 & 3.3 .6 & 8.d.4.e & 1 \\
\hline $\begin{array}{l}\text { Reactivity Control System Redundancy } \\
\text { and Capability }\end{array}$ & GDC 26 & 3.3 .7 & 8.d.5.b & 11 \\
\hline $\begin{array}{l}\text { Combined Reactivity Control Systems } \\
\text { Capability }\end{array}$ & GDC 27 & 3.3 .8 & 8.d.5.c & 11 \\
\hline Reactivity Limits & GDC 28 & 3.3 .9 & 8.d.5.d & 11 \\
\hline $\begin{array}{l}\text { Protection Against Anticipated } \\
\text { Operational Occurrences }\end{array}$ & GDC 29 & 3.3 .10 & 8. d.4.f & 1 \\
\hline
\end{tabular}


Table A1. Safety Design Criteria Cross Comparison (cont.)

\begin{tabular}{|c|c|c|c|c|}
\hline Criterion/Requirement & $\begin{array}{l}\text { 10CFR50, } \\
\text { App. A }\end{array}$ & $\begin{array}{l}\text { ANSI/ANS } \\
54.1\end{array}$ & $\begin{array}{c}\text { DOE } \\
5480.30\end{array}$ & Comments \\
\hline \multicolumn{5}{|l|}{ IV. Fluid Systems } \\
\hline $\begin{array}{l}\text { Assurance of Adequate Reactor Coolant } \\
\text { Inventory }\end{array}$ & & 3.4 .1 & & 12 \\
\hline $\begin{array}{l}\text { Quality of Reactor Coolant Pressure } \\
\text { Boundary }\end{array}$ & GDC 30 & 3.4 .2 & 8.d.1.b & 1 \\
\hline $\begin{array}{l}\text { Fracture Prevention of Reactor Coolant } \\
\text { Pressure Boundary }\end{array}$ & GDC 31 & 3.4 .13 & 8.d.1.c & 4 \\
\hline $\begin{array}{l}\text { Inspection of Reactor Coolant Pressure } \\
\text { Boundary }\end{array}$ & GDC 32 & 3.4 .3 & 8.d.1.d & 1 \\
\hline Reactor Coolant Makeup & GDC 33 & & 8.d.6.c & 13 \\
\hline $\begin{array}{l}\text { Reactor and Intermediate Coolant and } \\
\text { Cover Gas Purity Control }\end{array}$ & & 3.4 .4 & & 14 \\
\hline Intermediate Coolant System & & 3.4 .5 & & 14 \\
\hline $\begin{array}{l}\text { Inspection and Surveillance of } \\
\text { Intermediate Coolant Boundary }\end{array}$ & & 3.4 .6 & & 14 \\
\hline Residual Heat Removal & GDC 34 & 3.4 .7 & 8.d.6.b & 1 \\
\hline Emergency Core Cooling & GDC 35 & & 8.d.6.d & 13 \\
\hline $\begin{array}{l}\text { Inspection of Emergency Core Cooling } \\
\text { System }\end{array}$ & GDC 36 & 3.4 .8 & 8.d.6.d & 15 \\
\hline $\begin{array}{l}\text { Testing of Emergency Core Cooling } \\
\text { System }\end{array}$ & GDC 37 & 3.4 .9 & 8.d.6.d & 15 \\
\hline Containment Heat Removal & GDC 38 & & 8.c. 8 & 16 \\
\hline $\begin{array}{l}\text { Inspection of Containment Heat Removal } \\
\text { System }\end{array}$ & GDC 39 & & 8.c. 8 & 16 \\
\hline $\begin{array}{l}\text { Testing of Containment Heat Removal } \\
\text { System }\end{array}$ & GDC 40 & & 8.c. 8 & 16 \\
\hline Containment Atmosphere Cleanup & GDC 41 & 3.5 .11 & 8.c. 8 & 16 \\
\hline $\begin{array}{l}\text { Inspection of Containment Atmosphere } \\
\text { Cleanup Systems }\end{array}$ & GDC 42 & 3.5 .12 & 8.c. 8 & 16 \\
\hline $\begin{array}{l}\text { Testing of Containment Atmosphere } \\
\text { Cleanup Systems }\end{array}$ & GDC 43 & 3.5 .13 & 8.c. 8 & 16 \\
\hline Cooling Water & GDC 44 & 3.4 .10 & 8.d.6.e & 1 \\
\hline Inspection of Cooling Water System & GDC 45 & 3.4 .11 & 8.d.6.e & 1 \\
\hline Testing of Cooling Water System & GDC 46 & 3.4 .12 & 8.d.6.e & 1 \\
\hline
\end{tabular}


Table A1. Safety Design Criteria Cross Comparison (cont.)

\begin{tabular}{|c|c|c|c|c|}
\hline Criterion/Requirement & $\begin{array}{l}\text { 10CFR50, } \\
\text { App. A }\end{array}$ & $\begin{array}{l}\text { ANSI/ANS } \\
54.1\end{array}$ & $\begin{array}{c}\mathrm{DOE} \\
5480.30\end{array}$ & Comments \\
\hline \multicolumn{5}{|l|}{ V. Reactor Containment } \\
\hline Containment Design Basis & GDC 50 & $\begin{array}{l}3.5 .1,3.5 .2, \\
\quad 3.5 .3 \\
\end{array}$ & 8.c. 8 & 17 \\
\hline $\begin{array}{l}\text { Fracture Prevention of Containment } \\
\text { Pressure Boundary }\end{array}$ & GDC 51 & 3.5.4 & 8.c.8 & 1 \\
\hline $\begin{array}{l}\text { Capability for Containment Leakage } \\
\text { Rate Testing }\end{array}$ & GDC 52 & 3.5 .5 & 8.c. 8 & 1 \\
\hline $\begin{array}{l}\text { Provisions for Containment Testing } \\
\text { and Inspection }\end{array}$ & GDC 53 & 3.5 .6 & 8.c. 8 & 1 \\
\hline $\begin{array}{l}\text { Piping Systems Penetrating } \\
\text { Containment }\end{array}$ & GDC 54 & 3.5.7 & 8.c. 8 & 1 \\
\hline $\begin{array}{l}\text { Reactor Coolant Pressure Boundary } \\
\text { Penetrating Containment }\end{array}$ & GDC 55 & 3.5 .8 & 8.c. 8 & 1 \\
\hline Primary Containment Isolation & GDC 56 & 3.5 .9 & 8.c. 8 & 1 \\
\hline Closed System Isolation Valves & GDC 57 & 3.5 .10 & 8.c. 8 & 1 \\
\hline \multicolumn{5}{|l|}{ VI. Fuel and Radioactivity Control } \\
\hline $\begin{array}{l}\text { Control of Releases of Radioactive } \\
\text { Materials to the Environment }\end{array}$ & GDC 60 & 3.6 .1 & $\begin{array}{l}\text { 8.c.12.a, } \\
\text { 8.c. } 14\end{array}$ & 1 \\
\hline $\begin{array}{l}\text { Fuel Storage and Handling and } \\
\text { Radioactivity Control }\end{array}$ & GDC 61 & 3.6 .2 & 8.d.8.a & 1 \\
\hline $\begin{array}{l}\text { Prevention of Criticality in Fuel } \\
\text { Storage and Handling }\end{array}$ & GDC 62 & 3.6 .3 & 8.d.8.b & 1 \\
\hline Monitoring Fuel and Waste Storage & GDC 63 & 3.6 .4 & 8.d.8.c & 1 \\
\hline Monitoring Radioactivity Releases & GDC 64 & 3.6 .5 & $\begin{array}{l}\text { 8.c. } 12 . b, \\
\text { 8.c. } 14 \\
\end{array}$ & 1 \\
\hline
\end{tabular}

Comment 1. The relevant criteria from Refs. A2, A3, and A4 are essentially congruent in intent and are applicable to the liquid metal-cooled reactor design.

Comment 2. The single failure criterion for safety class structures, systems, and components is listed as a definition applied to specified criteria in Refs. A2 and A3. The single failure criterion is explicit in Ref. A4.

Comment 3. Explicit requirement for liquid metal coolant that considers the impact of chemical reactivity or thermophysical properties. 
Comment 4. The 10CFR50 criterion addresses phenomena for a high pressure water system. The criteria should be revised to address phenomena relevant to low pressure, chemically reactive liquid metal coolant.

Comment 5. Siting criteria are considered in 10CFR100.

Comment 6. Explicit USDOE requirement beyond the scope of 10CFR50 Appendix A.

Comment 7. In LWR designs, the requirement for a prompt, negative power coefficient is met by the combination of the negative fuel Doppler coefficient and the negative moderator density coefficient. If the LMR coolant void coefficient is positive, the regulator may require additional design features to compensate, as noted in the PRISM [A5] and SAFR [A6] safety evaluation reports.

Comment 8. Systems cited should include the liquid metal heating system.

Comment 9. The USDOE separate requirement for a remote shutdown capability is included in GDC 19.

Comment 10. USDOE criterion for confinement superseded by containment criterion, GDC 16.

Comment 11. 10CFR50 Appendix A criteria contain references to LWR specific reactivity mechanisms (Xe, cold shutdown, ECCS boron injection, rod dropout, cold coolant shock) that are either irrelevant or require re-interpretation for fast spectrum LMR.

Comment 12. Liquid metal reactor criterion for maintaining core submersion in coolant is the equivalent of ECCS requirement for light water reactor (GDC 33, 35).

Comment 13. 10CFR50 Appendix A criterion is not applicable for liquid metal coolant.

Comment 14. Intermediate loop criteria for liquid metal cooled design.

Comment 15. The liquid metal reactor design does not include an ECCS, but inspection and testing requirements are applied to the residual heat removal system.

Comment 16. In the light water reactor design, the containment heat removal system is intended to reduce temperature and pressure following a loss-of-coolant accident. Because such an accident sequence is not a design basis for the liquid metal cooled reactor, this criterion may not be relevant.

Comment 17. In the light water reactor design the containment design is based on loss of coolant accident consequences. For the low pressure liquid metal cooled reactor, in which a pipe break event is much less severe (leak before break), an alternative design basis accident must be specified. 


\section{A.3 Evaluation of Safety Design Criteria}

The cross comparison of safety design criteria in Table A1 shows that the sets of design criteria defined by the USNRC [A2], the ANS [A3], and the USDOE [A4] are generally and specifically convergent with regard to scope and content. The NRC design criteria are intended for application to light water cooled power reactors, and the ANS criteria were proposed for liquid metal (sodium) cooled reactors.

In its safety evaluation reports for the PRISM [A5] and SAFR [A6] designs, the USNRC has provided analyses of the applicability of the criteria in Ref. A2 to specific liquid metal reactor designs, taking Ref. A3 into account. These analyses have been reviewed with a perspective of the general characteristics of a liquid metal (sodium) cooled fast reactor system. From this review, the following general statements can be made with regard to the applicability of the design criteria in Ref. A2 to sodium cooled systems:

1. Many of the 10CFR50 Appendix A general design criteria are directly applicable to the liquid sodium cooled, fast reactor systems, without wording changes or modifications. The intent of the design criterion is clear, and the design implication for application to a liquid sodium cooled system is apparent. Criteria included in this class are GDCs 1, 2, 3, $5,10,12,13,14,16,17,18,19,20,21,22,23,24,25,29,30,32,34,44,45,46,51,52$, $53,56,60,61,62,63,64$.

2. Some of the 10CFR50 Appendix A general design criteria are worded with reference to specific light water reactor design features, performance characteristics, or regulatory requirements. These criteria must be reworded to preserve the original intent for liquid sodium cooling. A listing of the criteria in this class and identification of necessary rewording are given in Table A2. 
Table A2. Wording Changes Needed to10CFR50 Appendix A General Design Criteria for Application to Sodium Cooled Systems

\begin{tabular}{|c|c|}
\hline GDC No. & Wording Change Needed \\
\hline 4 & $\begin{array}{l}\text { This criterion is written in reference to a high pressure, water coolant, } \\
\text { and includes explicit references to loss-of-coolant accidents (LOCAs) } \\
\text { and pipe ruptures. The words should be changed 1) to include dynamic } \\
\text { and environmental phenomena relevant to low pressure sodium, e.g. the } \\
\text { environmental effects of aerosols and oxidation products, 2) to delete } \\
\text { references to dynamic and environmental accident phenomena specific } \\
\text { to water coolant, and 3) to include references to generic design basis } \\
\text { events, i.e. "anticipated operational occurrences." }\end{array}$ \\
\hline 11 & $\begin{array}{l}\text { This criterion requires a prompt inherent nuclear feedback effect to } \\
\text { compensate a rapid reactivity increase in the power operating range. } \\
\text { NRC reviews of the PRISM and SAFR designs highlighted the positive } \\
\text { coolant void reactivity worth as an area of significant concern for a } \\
\text { beyond-design-basis loss-of-flow-without-scram accident sequence. } \\
\text { The criterion should be modified to specifically exclude or include } \\
\text { coolant voiding effects, depending on the safety strategy dealing with } \\
\text { severe accident. }\end{array}$ \\
\hline 15 & $\begin{array}{l}\text { This criterion is written to require that the reactor coolant pressure } \\
\text { boundary be built to withstand design basis conditions. Reference A5 } \\
\text { specifically requires inclusion of the sodium heating system in the } \\
\text { listing of coolant systems subject to this requirement. }\end{array}$ \\
\hline 26 & $\begin{array}{l}\text { This criterion requires two independent reactivity control systems, one } \\
\text { of which shall use control rods. Specific control reactivity } \\
\text { requirements are listed in terms of LWR performance characteristics. } \\
\text { The criterion should be rewritten in terms of equivalent LMR } \\
\text { characteristics. }\end{array}$ \\
\hline 27 & $\begin{array}{l}\text { This criterion specifies combined control reactivity requirements } \\
\text { including liquid poison injection. The criterion should be rewritten to } \\
\text { eliminate the explicit mention of liquid poison addition. }\end{array}$ \\
\hline 28 & $\begin{array}{l}\text { This criterion requires that the reactivity control system be designed to } \\
\text { limit the possible rate of reactivity addition to avoid damage to the } \\
\text { reactor and its associated structures, systems, and components. } \\
\text { Specific control reactivity requirements are listed in terms of LWR } \\
\text { performance characteristics. The criterion should be rewritten in terms } \\
\text { of equivalent LMR characteristics. }\end{array}$ \\
\hline 31 & $\begin{array}{l}\text { This criterion specifies conditions and phenomena to be considered in } \\
\text { the design of the reactor coolant pressure boundary. For liquid sodium } \\
\text { coolant, Ref. A5 specifies addition of coolant chemistry and } \\
\text { mechanical properties degradation to the list of considered phenomena, } \\
\text { in recognition of the chemically active nature of sodium. }\end{array}$ \\
\hline
\end{tabular}


Table A2. Wording Changes Needed to 10CFR50 Appendix A General Design Criteria for Application to Sodium Cooled Systems (cont.)

\begin{tabular}{|c|c|}
\hline GDC No. & Wording Change Needed \\
\hline 33 & $\begin{array}{l}\text { This criterion provides for a coolant supply system to assure reactor } \\
\text { coolant inventory in the event of a small break in the coolant pressure } \\
\text { boundary. As formulated, the criterion is not relevant to low pressure } \\
\text { sodium coolant. Reference A3 specifies a replacement criterion } \\
\text { dealing with assurance of adequate coolant inventory to maintain core } \\
\text { cover and operation of the residual heat removal system in all cases. }\end{array}$ \\
\hline 35 & $\begin{array}{l}\text { This criterion provides for emergency core cooling in the event of a } \\
\text { loss of coolant accident. Such an event is outside the design basis for } \\
\text { the low pressure sodium coolant system. Coolant inventory, core } \\
\text { covering, and residual heat removal are assured by GDC } 33 \text { and } 34 \text {. }\end{array}$ \\
\hline 36 & $\begin{array}{l}\text { This criterion provides for inspection of the emergency core cooling } \\
\text { system. Reference A5 recommends rewriting this criterion to provide } \\
\text { for inspection of the residual heat removal system (GDC 34). }\end{array}$ \\
\hline 37 & $\begin{array}{l}\text { This criterion provides for testing of the emergency core cooling } \\
\text { system. Reference A5 recommends rewriting this criterion to provide } \\
\text { for testing of the residual heat removal system (GDC } 34 \text { ). }\end{array}$ \\
\hline 38 & $\begin{array}{l}\text { This criterion provides for the design of a containment heat removal } \\
\text { system with the capability of rapidly reducing the temperature and } \\
\text { pressure within the containment following a loss-of-coolant accident. } \\
\text { The LOCA sequence is not relevant to the low pressure coolant liquid } \\
\text { metal system. The criterion should be rewritten with wording to } \\
\text { replace the LOCA reference with the appropriate design basis accident } \\
\text { reference. }\end{array}$ \\
\hline 39 & $\begin{array}{l}\text { This criterion provides for inspection of the containment heat removal } \\
\text { system, and includes specific reference to design features relevant to } \\
\text { water cooled systems. The criterion should be rewritten to include } \\
\text { design characteristics relevant to sodium cooled systems. }\end{array}$ \\
\hline 40 & $\begin{array}{l}\text { This criterion provides for testing of the containment heat removal } \\
\text { system, and includes specific reference to design features relevant to } \\
\text { water cooled systems. The criterion should be rewritten to include } \\
\text { design characteristics relevant to sodium cooled systems. }\end{array}$ \\
\hline 41 & $\begin{array}{l}\text { This criterion provides for the design of a system to control fission } \\
\text { gases and combustible gases in containment following a postulated } \\
\text { accident. Reference } \mathrm{A} 3 \text { recommends modification of this criterion to } \\
\text { include sodium aerosols and combustion products, and to identify } \\
\text { sodium leakage and interaction with concrete as events in the accident } \\
\text { sequence. The criterion should be rewritten to include design } \\
\text { characteristics relevant to sodium cooled systems. }\end{array}$ \\
\hline 42 & $\begin{array}{l}\text { This criterion provides for inspection of the containment atmosphere } \\
\text { cleanup system provided by GDC } 41 \text {. The criterion should be rewritten } \\
\text { to include design characteristics relevant to sodium cooled systems. }\end{array}$ \\
\hline
\end{tabular}


Table A2. Wording Changes Needed to 10CFR50 Appendix A General Design Criteria for Application to Sodium Cooled Systems (cont.)

\begin{tabular}{|c|l|}
\hline GDC No. & \multicolumn{1}{c|}{ Wording Change Needed } \\
\hline 43 & $\begin{array}{l}\text { This criterion provides for testing of the containment atmosphere } \\
\text { cleanup system provided by GDC 41. The criterion should be rewritten } \\
\text { to include design characteristics relevant to sodium cooled systems. }\end{array}$ \\
\hline 50 & $\begin{array}{l}\text { This criterion stipulates design basis conditions and phenomena for the } \\
\text { containment, and makes specific mention of loss-of-cooling accidents } \\
\text { and metal-water interactions. The criterion should be rewritten to } \\
\text { include design characteristics relevant to sodium cooled systems. } \\
\text { Reference A5 recommends replacement of the LOCA sequence with } \\
\text { the appropriate postulated accident, and replacement of metal-water } \\
\text { interactions with phenomena relevant to sodium cooling. }\end{array}$ \\
\hline 55 & $\begin{array}{l}\text { This criterion provides for isolation design requirements for lines } \\
\text { connected to the reactor coolant pressure boundary that penetrate the } \\
\text { containment. In liquid metal cooled systems, this criterion also applies } \\
\text { to lines connected to the reactor cover gas space. }\end{array}$ \\
\hline
\end{tabular}

Reference A5 identifies nine additional design criteria relevant to liquid metal (sodium) cooled nuclear plant designs that are not explicitly stated in 10CFR50 Appendix A. Six of these additional nine criteria are also cited in Ref. A3. These nine criteria are as follows:

1. Protection Against Sodium Reactions. (Cited in Ref. A3 as Criterion 3.1.4). This criterion explicitly provides for measures to protect against the consequences of chemical reactions resulting from sodium leaks. It calls for prevention, detection, and consequence mitigation design features, as well as measures to protect personnel and equipment from corrosive and potentially radioactive oxidation products.

2. Sodium Heating Systems. (Cited in Ref. A3 as Criterion 3.1.7). This criterion provides safety and performance requirements for systems intended to maintain sodium as a liquid. Such systems are required to perform assuming a single failure.

3. Heat Transport System Design. (No corresponding Criterion in Ref. A3). This requirement ensures sufficient reactor cooling for normal operation and anticipated operational occurrences by providing two independent coolant flow paths between the reactor and the heat sinks, and stipulates that the integrity of the reactor coolant pressure boundary shall be maintained for postulated accidents. This criterion covers the same requirements as GDCs 34 (Residual Heat Removal), 35 (Emergency Core Cooling), and 44 (Cooling Water) in the original 10CFR50 Appendix A.

4. $\quad$ Assurance of Adequate Reactor Coolant Inventory. (Cited as Criterion 3.4.1 in Ref. A3). This criterion provides for sufficient coolant inventory to assure residual heat removal for normal operation, anticipated operational occurrences, and postulated accidents assuming 
a single failure. The criterion has the same intent as the original GDC 33 (Reactor Coolant Makeup).

5. Design of the Intermediate Coolant System. (Cited as Criteria 3.4.5 and 3.4.6 in Ref. A3). These criteria provide for the design, inspection, testing, and surveillance of the intermediate coolant system, and cover the intent of the original GDCs 44, 45, and 46 (Cooling Water).

6. Reactor and Intermediate Coolant and Cover Gas Purity Control. (Cited as Criterion 3.4.4 in Ref. A3). This criterion requires systems to monitor and maintain the purity of reactor and intermediate coolants and cover gases within specified design limits.

7. Inspection and Testing of Residual Heat Removal Systems. (Cited as Criteria 3.4.8 and 3.4.9 in Ref. A3). This criterion provides for inspection, testing, and surveillance of the residual heat removal system. The intent of these criteria is the same as that of the original GDCs 36 and 37, which provide for inspection and testing of the emergency core cooling system for water cooled reactor designs.

8. Protection Against Fuel Rod Failure Propagation. (No corresponding Criterion in Ref. A3). This criterion was proposed for early liquid metal reactor design for which fuel irradiation experience was limited. As fuel irradiation experience was gained, confidence in fuel performance was assured, and this criterion was explicitly excluded in Ref. A5, which notes that fuel design limits and failure performance are included by GDCs 10, 27, and 35 .

9. Protection Against Coolant Flow Blockage. (No corresponding Criterion in Ref. A3). This criterion requires the fuel assembly design to include specific features to prevent and minimize the likelihood of coolant flow blockages, so that such events can be eliminated from the design basis. This consideration arises due to use of ducted fuel assemblies, for which inlet flow blockages or restrictions could lead to fuel damage or failure. 


\section{REFERENCES FOR APPENDIX A}

A1. U.S. Atomic Energy Commission, The Safety of Nuclear Power Reactors (Light WaterCooled) and Related Facilities, WASH-1250, July, 1973.

A2. U.S. Nuclear Regulatory Commission, Code of Federal Regulations, Title 10, "Energy," Part 50, "Domestic Licensing of Production and Utilization Facilities," Appendix A, "General Design Criteria for Nuclear Power Plants."

A3. American National Standards Institute/American Nuclear Society, General Safety Design Criteria for a Liquid Metal Reactor Nuclear Power Plant, ANSI/ANS-54.1-1989, American Nuclear Society, La Grange Park, Illinois.

A4. U.S. Department of Energy, Nuclear Reactor Safety Design Criteria, Order DOE 5480.30, Chg. 1: 3-14-01.

A5. U.S. Nuclear Regulatory Commission, Preapplication Safety Evaluation Report for the Power Reactor Innovative Small Module (PRISM) Liquid Metal Reactor, Final Report, NUREG-1368.

A6. U.S. Nuclear Regulatory Commission, Preapplication Safety Evaluation Report for the Sodium Advanced Fast Reactor (SAFR) Liquid-Metal Reactor, NUREG-1369, December, 1991. 


\title{
APPENDIX B \\ SAS4A/SASSYS-1 Capabilities and Enhancements for ABTR Analysis
}

\begin{abstract}
This Appendix provides an overview of the computer program and methods employed for ABTR analysis. Two modeling features were enhanced for the ABTR analyses, namely 1) modeling of long-term decay heat from transuranic fuel, and 2) modeling of coolant volume temperature stratification for buoyancydriven natural circulation flow.
\end{abstract}




\section{B.1 SAS4A/SASSYS-1 Computer Code}

The SAS4A/SASSYS-1 computer code [B1] was developed at Argonne National Laboratory for transient analysis of liquid metal cooled reactors (LMRs). Originally designed to address the consequences of loss-of-decay-heat-removal accidents, SASSYS-1 evolved into a tool to analyze passive safety response mechanisms in anticipated transients without scram (ATWS), and as a margin assessment tool for design basis accidents (DBAs). To fulfill this role, SASSYS-1 contains models for fuel element heat transfer and reactor coolant hydraulics. In addition, SASSYS-1 has the capability to provide a detailed thermal/hydraulic simulation of the primary and secondary coolant circuits, as well as the balance-of-plant (BOP) circuits. The liquid metal and BOP circuit models include component models for heat exchangers, pumps, valves, steam generators, turbines, and condensers, and thermal/hydraulic models of pipes and plena. SASSYS-1 also contains a control system model, which provides digital representations of reactor control systems, pump and valve controllers, and their response to input signal changes. SASSYS-1 served as the computational engine in a multi-tasking, workstation-based simulator for the EBR-II power plant.

SASSYS-1 contains detailed, mechanistic models for fuel element heat transfer (twodimensional fuel, cladding, coolant, and structure temperatures), oxide and metallic fuel pin and cladding mechanics (steady-state characterization and transient response), single and two-phase coolant fluid dynamics (coolant boiling, post-failure fission gas transport), primary/secondary/balance-of-plant thermal hydraulics, and plant control systems. Reactivity feedbacks from cladding and fuel expansion, fuel temperature (Doppler), core structure expansion, liquid coolant density changes, coolant boiling, and coolant voiding from fission gas release are summed with a user-specified control rod motion reactivity. SASSYS-1 employs a multiple pin per channel modeling concept, in which a single fuel pin and its associated cladding, coolant, and structure (wire wrap, grid, and/or wrapper can) are taken as representative of a number of fuel elements, and many single-pin models are used to represent the whole core. Multiple single-pin heat transfer models may be cooled by a common coolant channel to represent intra-subassembly heterogeneity effects, and channel-to-channel heat transfer may be specified to simulate subassembly-to-subassembly heat transfer effects. Transient solutions are obtained to track the core, liquid metal coolant loops, and balance-of-plant behavior from the initial, steady state through a transient caused by control system trips or an assumed fault. SASSYS-1 calculates the whole-plant response, with detailed temperature and flow predictions for assessment of compliance with technical specifications in design basis transients.

SASSYS-1 has been used extensively as a design basis analysis tool for the EBR-II and FFTF reactors, and as a conceptual design evaluation code in the U.S.D.O.E. reactor development projects (e.g. LSPB, SAFR, PRISM). The models in SASSYS-1 have been validated with extensive analyses of reactor and plant test data from EBR-II and FFTF.

\section{B.1.1 Reactor Core Thermal-Hydraulic Model}

In SASSYS-1, the thermal/hydraulic performance of the reactor core is represented with a singlepin model in multiple channels. In this multiple channel whole-core model, each channel represents a single fuel pin and the associated coolant and structure. The structure field may be 
used to represent some part of the hex-can and the pin spacers. One-dimensional, radial heat transfer calculations are performed at many axial locations to model heat transfer from the fuel through the cladding to the coolant, and from the coolant to the structure, the gas plenum, and the reflectors. One-dimensional (axial) coolant flow is modeled with a momentum equation solution for the axial pressure profile, and convective heat transfer conditions are assumed at the interfaces between the coolant and the cladding, the reflectors, and the structure. Temperatures are calculated at multiple radial nodes in the fuel, the cladding, the reflectors, and the structure. The coolant has a single temperature at each axial location. Axial heat conduction is neglected. Figure 2.3-1 shows the spatial temperature mesh in the SASSYS-1 single-pin model.

For the whole-core model, each of the SASSYS-1 channels represents a single, average pin in a subassembly, and several subassemblies are grouped together, so that a single channel may represent all the pins in a number of subassemblies. Pins with similar geometrical dimensions, power, flow, enrichment, burn-up, thermo-physical properties, and performance characteristics (reactivity feedback, mechanical, thermal, fluid dynamics) are grouped for modeling by a single channel. In this way, all of the pins in the reactor are modeled with a multiple channel model. Typical modeling detail ranges from a few to a few dozen channels, depending on the reactor design and the transient phenomena being simulated.

\section{B.1.2 Coolant Systems Thermal-Hydraulic Model}

The model in SASSYS-1 for thermal-hydraulic representation of primary and intermediate sodium systems is called PRIMAR-4. This model permits representation of coolant flow and heat transfer effects outside the reactor by simulation with a network of volumes connected with flow paths. The PRIMAR-4 model computes coolant pressures, flow rates, and temperatures in the primary and intermediate heat transport circuits. Components represented by PRIMAR-4 include the inlet and outlet plenums, pipes, pumps, heat exchangers, steam generators, and reactor vessel air cooling systems. A typical PRIMAR-4 model for a pool-type primary system is depicted in Fig. 2.3-8.

In the PRIMAR-4 model, a number of compressible volumes are connected by liquid or gas segments, and each liquid segment may consist of one or more elements. This treatment allows SASSYS-1 to be used for an arbitrary arrangement of components, since compressible volumes and segments can be connected in an arbitrary manner. Given a high degree of modeling flexibility, PRIMAR-4 can be used to represent both loop-type and pool-type reactor designs.

The compressible volumes in PRIMAR-4 may be liquid volumes, gas volumes, or partially liquid volumes with a cover gas. If a compressible volume does not contain a cover gas, then the liquid is treated as compressible. Compressible volumes are characterized by pressure, volume, mass, and temperature, and they may accumulate gas or liquid by compressing the cover gas or liquid. The pressure in the compressible volume drives the flows through the liquid and gas segments. Table B1 lists the types of compressible volumes treated in PRIMAR-4. A discussion of the volume thermal stratification model used in the ABTR analysis is included in Section B.3.

The PRIMAR-4 gas segments are treated as pipes that connect the gas space of two compressible volumes. The flow through a gas segment is assumed to be isothermal. 
The liquid segments in PRIMAR-4 are treated with an incompressible flow model and consist of one or more liquid flow elements. Liquid flow elements are characterized by incompressible single-phase flow, with the possibility of heat transfer through the segment wall. Table B2 lists the types of liquid flow elements that can be used to make up a liquid segment. Element type 1 denotes the collection of all the single-pin channels in the core.

\section{B.1.3 Point Kinetics and Reactivity Feedback Model}

In SASSYS-1, a point kinetics model is employed to calculate the reactor fission power response to the transient reactivity state. At any time, the net reactivity is the sum of a number of individual reactivity feedbacks that are determined by the transient thermal, hydraulic, mechanical, and neutronic state of the reactor. The feedback reactivities normally considered are fuel Doppler, coolant density, fuel and cladding axial expansion, radial core expansion, and control rod driveline thermal expansion.

A decay heat model is integrated with the point kinetics model for the fission power to track shutdown events in sub-critical conditions. A discussion of decay heat model enhancements for ABTR analysis is included in Section B.2.

The fuel Doppler feedback is calculated from the spatially dependent fuel temperature distribution and the input spatial distribution of the fuel Doppler reactivity coefficient. In each single-pin channel, the axial distribution of the radial pin-average fuel temperature is used to calculate the reactivity feedback. SASSYS-1 interpolates between coolant-intact and coolantvoided Doppler coefficients using the current local coolant void fraction to determine the local Doppler coefficient.

The coolant density reactivity feedback is calculated from the spatially dependent coolant density distribution and the input distribution of the coolant density reactivity coefficient calculated from perturbation theory. The reactivity feedback data is entered as a coolant void worth (the negative of the coolant mass worth), and the coolant density feedback reactivity is calculated from the time-dependent axial density distribution in each single-pin channel.

The DEFORM-4 (oxide fuel) and DEFORM-5 (metallic fuel) fuel behavior models are available in SASSYS-1 to predict transient fuel and cladding axial dimension changes, and in each singlepin channel, the reactivity feedback associated with fuel and cladding axial expansion are computed from first order perturbation theory. 
Table B1. PRIMAR-4 Compressible Volume Types.

\begin{tabular}{|c|l|}
\hline Type No. & Description \\
\hline 1 & Inlet plenum \\
\hline 2 & Compressible liquid volume, no cover gas \\
\hline 3 & Compressible outlet plenum, no cover gas \\
\hline 4 & Almost incompressible liquid, no cover gas \\
\hline 5 & Pipe rupture source \\
\hline 6 & Pipe rupture sink, guard vessel \\
\hline 7 & Outlet plenum with cover gas \\
\hline 8 & Pool with cover gas \\
\hline 9 & Pump bowl with cover gas \\
\hline 10 & Expansion tank with cover gas \\
\hline 11 & Compressible gas volume, no liquid \\
\hline
\end{tabular}

Table B2. PRIMAR-4 Flow Element Types.

\begin{tabular}{|c|l|}
\hline Type No. & \multicolumn{1}{|c|}{ Description } \\
\hline 1 & Core subassemblies (Single pin channels) \\
\hline 2 & Bypass channel \\
\hline 3 & Pipe \\
\hline 4 & Check valve \\
\hline 5 & Pump impeller \\
\hline 6 & IHX, shell side \\
\hline 7 & IHX, tube side \\
\hline 8 & Steam generator, coolant side \\
\hline 9 & DRACS heat exchanger, tube side \\
\hline 10 & DRACS heat exchanger, shell side \\
\hline 11 & Valve \\
\hline 12 & Air dump heat exchanger, coolant side. \\
\hline 13 & Annular element \\
\hline
\end{tabular}


The detailed radial core expansion model in SASSYS-1 accounts for core dilation due to thermal expansion of the hexcan load pads, thermal expansion of the core support grid plate, and transient bending of the core subassemblies due to radial temperature gradients and constraints imposed by radial restraint rings at the load pad elevations. Reactivity feedback is then calculated from the computed core dimension change and an input linear reactivity coefficient based on stand-alone neutronics eigenvalue calculations.

For the control rod driveline feedback model, it is assumed that the control rod drivelines are washed by the outlet coolant from the core. Thermal expansion of the drives due to a rise in core outlet temperature will cause the control rods to be inserted further into the core, providing a negative reactivity component. On the other hand, if the control rod drives are supported on the vessel head, and if the core is supported by the vessel walls, then heating the vessel walls will either lower the core or raise the control rod drive supports, leading to a positive reactivity component. Both the control drive expansion and the vessel wall expansion are accounted for in SASSYS-1.

\section{B.2 Decay Heat Model Development for ABTR}

A more detailed decay heat model has been developed for the SASSYS-1 code to support the unique decay heat characteristics that might be present in the advanced, actinide-bearing fuels planned for use in the ABTR. The key features of the new model include extending the number of exponential terms that can be used to represent decay heat from six to 24 , the inclusion of built-in decay heat parameters from the most recent ANS decay heat power standard, the ability to mix multiple user-supplied and/or built-in decay heat curves within a single region, and the inclusion of a pre-defined non-decay-heat region. These features allow greater flexibility than the previous model and can more accurately represent decay heat during long term transients. The updated decay heat model has been incorporated in the forthcoming Version 4.0 of the SAS code.

In the following sections, the implementation of the new model with support for multiple decay heat curves per region is discussed, and an improved method for initializing steady-state decay heat prior to a transient calculation is described. First, however, it is useful to describe the ANS decay heat standard, along with how it is applied to the SAS decay heat model.

\section{B.2.1 The ANS Decay Heat Power Standard}

The American Nuclear Society (ANS) recently published an updated standard [B2] for decay heat power in light water reactors. For over 25 years, an extension to the standard has been planned to address fast reactor fuel cycles. In the absence of any such extension, the standard for light-water reactors is used to define the built-in decay heat curves for the updated SAS decay heat model. In addition, the expressions described below apply to both the standard and userdefined curves, and are the expressions solved by the updated decay heat model.

In the ANS standard, decay heat power is defined for each of four different fissionable isotopes in terms of 23-term exponential functions:

$$
f(t)=\sum_{n=1}^{N=23} \alpha_{n} e^{-\lambda_{n} t} \quad(\mathrm{MeV} / \text { Fission-s })
$$


where $\alpha_{n}$ is the immediate contribution (in $\mathrm{MeV} / \mathrm{s}$ ) of exponential term $n$ to the decay power resulting from one fission event, $\lambda_{n}$ is the decay constant for term $n$, and $t$ is time in seconds after the fission event. The standard currently defines decay heat power for thermal fission in U-235 and $\mathrm{Pu}-239$, fast fission in $\mathrm{U}-238$, and thermal fission in Pu-241. In principle, any number of terms may be used in the exponential expansion. The updated decay heat model supports up to 24 terms for each curve.

The ANS standard defines a method for calculating the decay heat power, after shutdown, which results from a known reactor power history. Although not stated in the standard, the method given makes an implicit assumption that the ratio between total power and fission power is fixed when calculating the number of fissions for a given power level. This is not precisely correct, especially for fresh fuel at the start of irradiation, and will generally underestimate the number of fissions and therefore the resulting decay heat power. An examination of the parameters given for U-235 suggest that it takes over ten hours of steady-state operation to reach $90 \%$ of the equilibrium decay power, and roughly $3 \frac{1}{2}$ months to reach $98 \%$. At a fixed total power, then, the fission power will depend on the current level of the decay heat power. The standard avoids the issue by defining decay heat power on a per-fission basis, leaving it up to the user of the standard to provide an appropriate value for the recoverable energy per fission.

In light of this discrepancy and in consideration of the fact that the SAS code performs decay heat calculations based on fission power (not total power) the methods prescribed in the ANS standard are modified so that they can be adapted for use in the SAS code. Furthermore, the standard describes "adjustments" that can be made to the calculated decay heat power to account for neutron capture in fission products. Because these adjustments are specific to a thermalspectrum reactor, they are not accounted for here. In addition, the standard describes a method for including contributions from U-239 and Np-239 decay heat power. Because a fast reactor generally has a significant quantity of actinides contributing to decay heat power, this adjustment is also not accounted for here. Instead, user-supplied decay heat curves can be combined with the ANS standard curves to accomplish the same task in a manner that is relevant to the problem being solved. Finally, the standard describes methods for determining uncertainty. Because SAS is a deterministic code, uncertainty calculations are not performed.

To calculate decay heat power in terms of fission power rather than total power, the total recoverable energy per fission in a fissionable isotope, $Q_{t}$, is separated into "prompt" fission energy, $Q_{f}$, and the energy from complete decay of fission products, $Q_{d}$ :

$$
Q_{t}=Q_{f}+Q_{d} \quad(\mathrm{MeV} / \text { fission })
$$

The energy from decay of fission products can be calculated by integrating Eq (B-1) over all time:

$$
Q_{d}=\sum_{n=1}^{23} \frac{\alpha_{n}}{\lambda_{n}} \quad(\mathrm{MeV} / \text { fission })
$$


If the total recoverable energy per fission is known (or input by the user) then the prompt energy per fission can be determined as $Q_{f}=Q_{t}-Q_{d}$. A useful term, to be used later, is the ratio of the decay energy to the prompt energy,

$$
\beta=\frac{Q_{d}}{Q_{f}}=\sum_{n=1}^{23} \beta_{n}=\sum_{n=1}^{23} \frac{\alpha_{n}}{\lambda_{n} Q_{f}} .
$$

Therefore, $\beta$ is the total decay heat yield per unit fission heat.

Eq (B-1) gives the decay heat power as a function of time after a single fission event. To calculate decay heat power, the number of fissions and their time dependence needs to be known. The fission rate at time $t^{\prime}$ can be written as

$$
\left.F\left(t^{\prime}\right)=P_{0} \frac{P_{f}\left(t^{\prime}\right)}{Q_{f} K} \quad \text { (Fissions } / \mathrm{s}\right)
$$

where $P_{0}$ is the nominal reactor power (Watts), $P_{f}$ is the relative fission power normalized to the nominal reactor power, and $K=1.602177 \times 10^{-13} \mathrm{~J} / \mathrm{MeV}$. The total number of fission events between time $t^{\prime}$ and $t^{\prime}+d t^{\prime}$ is then

$$
F\left(t^{\prime}\right) d t^{\prime}=P_{0} \frac{P_{f}\left(t^{\prime}\right)}{Q_{f} K} d t^{\prime} \quad \text { (Fissions) }
$$

The relative decay power at time $t>t^{\prime}$ resulting from the fissions represented by Eq. (B-3) can be calculated by combining Eq. (B-3) with Eq. (B-1):

$$
P_{d}(t)=\frac{P_{f}\left(t^{\prime}\right)}{Q_{f}} f\left(t-t^{\prime}\right) d t^{\prime} \quad\left(t>t^{\prime}\right)
$$

where $P_{d}$ is the relative decay power normalized to the nominal reactor power, $P_{0}$. The total decay power at time $t$ from all fissions prior to time $t$ can be determined by integrating the above equation:

$$
P_{d}(t)=\int_{-\infty}^{t} \frac{P_{f}\left(t^{\prime}\right)}{Q_{f}} f\left(t-t^{\prime}\right) d t^{\prime}
$$

Note that Eq (B-4) is similar in form to Equation (3) given in the ANS standard, with the exception that the ratio of total power to total recoverable energy, $P_{t} / Q_{t}$, is used in the ANS standard. The equation in the standard underestimates the fission rate in fresh fuel shortly after startup. While this is likely to be a very small error in most calculations, SAS evaluates decay heat in terms of the fission power and the correct form of Eq (B-4) is more convenient. 


\section{B.2.2 Implementation of the Updated Decay Heat Model}

In previous versions of SAS, a channel is assigned to a single decay heat curve. Since multiple decay heat curves may now be assigned to a single channel, each channel is now assigned to a decay heat region, where a region is defined by the properties of multiple decay heat curves. With this, multiple curves can be assigned (with different weights) to a single region, and a single curve can be used within multiple regions. Previous input decks are still supported. In this case, each region is defined by a single curve, and curves and regions have the same meaning.

\section{B.2.2.1 Contributions from Multiple Isotopes}

In the preceding discussion, a single fissionable isotope is assumed, as seen in Eq. (B-4). The determination of decay heat power contributions from multiple fissionable isotopes is straightforward. If $x_{i}$ represents the fraction of the total fission power from isotope $I$, then the normalized fission power from isotope $I$ is written as

$$
P_{f i}=x_{i} P_{f},
$$

and the decay power from isotope $I$ is

$$
P_{d i}(t)=x_{i} \int_{-\infty}^{t} \frac{P_{f}\left(t^{\prime}\right)}{Q_{f}} f_{i}\left(t-t^{\prime}\right) d t^{\prime} .
$$

Here, $f_{i}(t)$ represents the decay heat parameters for isotope $i$.

In practice the decay heat power from isotope $I$ is calculated using the normalized fission power only, as shown in Eq (B-4), such that

$$
P_{d i}^{\prime}(t)=\int_{-\infty}^{t} \frac{P_{f}\left(t^{\prime}\right)}{Q_{f}} f_{i}\left(t-t^{\prime}\right) d t^{\prime}
$$

The fractional fission powers are only applied when total (or integrated) decay heat power is calculated. Therefore, total decay heat power is defined as

$$
P_{d}(t)=\sum_{i} X_{i} P_{d i}^{\prime}(t)
$$

In the following sections, equations are derived for a single isotope, while the summation given by $\mathrm{Eq}(\mathrm{B}-5)$ is implied when total decay heat power is calculated.

\section{B.2.2.2 Transient Calculations}

At the beginning of a transient calculation, the initial decay heat power and fission power are known as a result of the steady-state initialization (see below). From that point on, fission power 
is determined based on the point (or spatial) kinetics equations. Given the normalized fission power, the normalized decay power can be solved using Eq. (B-4). To simplify notation, only a single term from $\mathrm{Eq}(\mathrm{B}-1)$ is considered, and a term for decay heat (i.e. energy) is introduced, where the decay heat, $H_{n}$, is defined by $P_{d}(t)=\Sigma \lambda_{n} H_{n}(t)$. At time step $k$, the time varies from $t_{k}$ to $t_{k}+\tau$. Term $n$ of Eq. (B-4) (in terms of decay heat) can then be written as

$$
H_{n}\left(t_{k}+\tau\right)=e^{-\lambda_{n} \tau} \int_{-\infty}^{t_{k}} P_{f}\left(t^{\prime}\right) \beta_{n} e^{-\lambda_{n}\left(t_{k}-t^{\prime}\right)} d t^{\prime}+\int_{t_{k}}^{t_{k}+\tau} P_{f}\left(t^{\prime}\right) \beta_{n} e^{-\lambda_{n}\left(t_{k}+\tau-t^{\prime}\right)} d t^{\prime}
$$

Note that the first integral is just the (known) decay heat at the beginning of the time step, $H_{n}\left(t_{k}\right)$. To write the second integral in terms of the time within a time step, let $t=t^{\prime}-t_{k}$. Then the above equation can be written as

$$
H_{n}\left(t_{k}+\tau\right)=H_{n}\left(t_{k}\right) e^{-\lambda_{n} \tau}+\beta_{n} e^{-\lambda_{n} \tau} \int_{0}^{\tau} P_{f}^{k}\left(t_{k}+t\right) e^{\lambda_{n} t} d t
$$

From the point kinetics solution used in SAS, the fission power over time step $k$ is represented by a second-order polynomial:

$$
P_{f}^{k}\left(t_{k}+t\right)=P_{0}+P_{1} t+P_{2} t^{2}
$$

where $P_{0}=P_{f}\left(t_{k}\right)$. Using this expansion, the decay heat at the end of the point-kinetics time step can be solved:

$$
H_{n}\left(t_{k}+\tau\right)=H_{n}\left(t_{k}\right) e^{-\lambda_{n} \tau}+\frac{\beta_{n}}{\lambda_{n}}\left[P_{0} I_{0}(\tau)+\frac{P_{1} I_{1}(\tau)}{\lambda_{n}}+\frac{P_{2} I_{2}(\tau)}{\lambda_{n}^{2}}\right]
$$

where

$$
\begin{aligned}
& I_{0}(\tau)=1-e^{-\lambda_{n} \tau} \\
& I_{1}(\tau)=\lambda_{n} \tau-I_{0}(\tau) \\
& I_{2}(\tau)=\left(\lambda_{n} \tau\right)^{2}-2 I_{1}(\tau)
\end{aligned}
$$

\section{B.2.2.3 Steady-State Initialization}

Prior to commencing with the transient calculations, SAS performs a steady-state initialization that includes the determination of initial decay heat. The code provides the option of entering a reactor power history as a histogram of relative reactor power. Assuming no initial decay heat is present at the beginning of the power history (i.e. fresh fuel with no fission products) the initial fission power will be equal to the power level of the first histogram. However, as decay heat builds, fission power will decrease to maintain constant power. 
Like the decay heat calculations during a transient, the decay heat during the constant-power interval, $k$, can be written as

$$
H_{n}\left(t_{k}+\tau\right)=H_{n}\left(t_{k}\right) e^{-\lambda_{n} \tau}+\beta_{n} e^{-\lambda_{n} \tau} \int_{0}^{\tau} P_{f}^{k}\left(t_{k}+t\right) e^{\lambda_{n} t} d t .
$$

However, only the total power is known in this case, not the fission power. The above equation can be rewritten as

$$
H_{n}\left(t_{k}+\tau\right)=H_{n}\left(t_{k}\right) e^{-\lambda_{n} \tau}+\beta_{n} e^{-\lambda_{n} \tau} \int_{0}^{\tau}\left(P_{t}^{k}-\sum_{n=1}^{N} \lambda_{n} H_{n}\left(t_{k}+t\right)\right) e^{\lambda_{n} t} d t
$$

For a single fissionable isotope, this represents a coupled set of $N \leq 24$ integral equations. (Related equations could be written in differential form). When multiple fissionable isotopes contribute to a single decay heat region in the SAS calculation, a second summation is introduced (i.e. by Eq (B-5)) and the number of coupled equations can increase dramatically.

To decouple the terms in Eq. (B-8), two assumptions are made. First, the fraction of fission power contributed by each fissionable isotope is assumed to be fixed by the values of $x_{i}$. Second, the fission power is assumed to be a constant such that the total power at the end of the constantpower interval matches the value supplied by the user. The first assumption only applies to decay heat regions that use more than one decay heat curve and may not be valid where there is significant depletion or breeding of fissionable isotopes during the course of steady-state initialization.

The second assumption was chosen for a number of reasons. First, by matching power at the end of the initiating power interval, it maintains continuity between the steady-state initialization and the transient calculation. Second, it can be shown (by example) to introduce at most only a few hundredths of a percent error in most cases, and up to a few tenths of a percent error in very unusual situations. Third, it correctly predicts the two bounding cases of fresh fuel (no decay heat) and infinitely-long, steady-state equilibrium.

By assuming a constant (although initially unknown) fission power, the integral in Eq. (B-8) can be solved:

$$
H_{n}\left(t_{k}+\tau\right)=H_{n}\left(t_{k}\right) e^{-\lambda_{n} \tau}+P_{f} \frac{\beta_{n}}{\lambda_{n}}\left(1-e^{-\lambda_{n} \tau}\right) .
$$

Note that this is the same as Eq. (B-6) with $P_{0}=P_{f}$ and $P_{1}$ and $P_{2}$ set to zero. By multiplying by $\lambda_{n}$ and summing the above equation over all decay terms, the decay power at the end of the time step is

$$
P_{d}\left(t_{k}+\tau\right)=\sum_{n} \lambda_{n} H_{n}\left(t_{k}\right) e^{-\lambda_{n} \tau}+P_{f} \sum_{n} \beta_{n}\left(1-e^{-\lambda_{n} \tau}\right) .
$$


As previously stated, the additional sum over isotopes with the appropriate $x_{i}$, as shown in Eq. (B-5), is implied.

Given the user-supplied total power and that $P_{t}=P_{f}+P_{d}$, the fission power can now be solved:

$$
P_{f}=\frac{P_{t}-\sum_{n} \lambda_{n} H_{n}\left(t_{k}\right) e^{-\lambda_{n} \tau}}{1+\sum_{n} \beta_{n}\left(1-e^{-\lambda_{n} \tau}\right)}
$$

Again, the sum over isotopes is implied. If the preexisting decay power at the end of the time step (the second term in the numerator) is greater than the user-supplied total power, then the fission power for that histogram is set to zero by the code. This will be the case, for example, if the user specifies a zero-power shutdown period. Otherwise, the numerator represents the fission power if no new decay power is generated during the time step. The denominator then adjusts that value so that the fission power plus accumulated decay power will be equal to the total power at the end of the time step.

Finally, by substituting Eq. (B-10) into Eq. (B-9), the decay heat can be determined at the end of this step in the histogram. For an infinitely-long power interval, Eq. (B-10) simplifies to

$$
P_{f}=P_{t} \frac{1}{1+\beta}
$$

and the decay heat from Eq. (B-9) is

$$
H_{n}\left(t_{k}+\tau\right)=P_{f} \frac{\beta_{n}}{\lambda_{n}} .
$$

These two expressions match the analytical solution exactly.

\section{B.2.3 Verification of the Updated Decay Heat Model}

The updated decay heat model has undergone extensive verification by comparing computed results with the published ANS decay heat standard [B2] as well as with results calculated by independent means. Results of this comparison are described below and verify that the new decay heat model incorporated into the SASSYS-1 code accurately computes decay heat power.

\section{B.2.3.1 Comparisons with the ANS Decay Heat Power Standard}

The ANS standard includes tables of decay heat power as a function of time after shutdown following a steady-state irradiation of $10^{13}$ seconds. While the comparison with the published standard is straightforward, it is complicated somewhat by the fact that 1) unlike the assumptions in the standard, fission power does not immediately drop to zero after shutdown in a SAS transient calculation due to the presence of delayed neutrons, 2) the adaptive time-step control used by SAS during a transient calculation make difficult the direct comparison with tabulated 
values, and 3) tabulated values in the ANS standard extend from 1 second to $10^{10}$ seconds, which is a range that is difficult to reproduce in a SAS calculation.

Two different approaches were used to resolve these difficulties. In the first, a SAS input deck was constructed that represent a "generic" four-channel problem. Within this input deck, the maximum time step size is limited to 0.1 seconds, and a single delayed-neutron precursor group was assumed with a very large decay constant so that fission power would drop rapidly after shutdown, which is triggered by a $-10 \$$ reactivity insertion at time zero. Each of the four channels is assigned to a separate decay heat region representing one of the four isotopes characterized in the standard, and decay heat is initialized with a $10^{13}$ second steady-state irradiation. With the given the point kinetics input, fission power drops essentially to zero within the first time step after shutdown. However, the initial rapid power change causes SAS to temporarily reduce subsequent time-step sizes so that later edits do not exactly match the times in the published tables, although many of them are within a few tenths of a second. The transient calculation is run to 1000 seconds after shutdown.

The second approach taken eliminates all the difficulties described above, but does so by using a modified version of the SAS code that skips the normal transient calculation. After the normal input processing and steady-state initialization (using the same input deck as in the previous approach), a loop is entered that calls the decay heat calculation routines with zero fission power and a prescribed set of time steps. Therefore, the times and fission power history of the tabulated values in the ANS standard can be followed exactly, and direct comparison can be made out to $10^{10}$ seconds. Comparisons of both approaches with the tabulated ANS standard results indicate that the updated SAS decay heat model accurately reproduces the values of the ANS standard. To illustrate, results for $\mathrm{Pu}-239$ are shown in Table B3. Because decay heat power in the ANS standard is reported in terms of $\mathrm{MeV} /$ fission, a total recoverable energy per fission, $Q_{t}$, of 200 $\mathrm{MeV} /$ fission is assumed for converting the values reported in the standard to units of normalized decay power, which are the units reported by SAS. This value of $Q_{t}$ is consistent with the default used in the updated decay heat model.

Table B3 is divided into two components: "a" and "b". Table B3(a) illustrates the results for $\mathrm{Pu}-239$ from the first approach described above. As seen in this table, the time steps do not match with the tabulated ANS standard values. Nevertheless, separately-computed values based on the ANS standard are presented for comparison with the SAS results. Also, for 10, 100, and 1000 seconds, tabulated results from the standard are presented for comparison. Table B3(b) represents results for $\mathrm{Pu}-239$ from the second approach described above, and provides a direct comparison with the ANS standard out to $10^{10}$ seconds.

In Table B3(a) there is excellent agreement prior to the onset of the SAS transient calculation (i.e. at time zero). Because the point kinetics solution starts the transient with a non-zero fission power, there is a brief, but finite period of time where the fission power is non-zero during the shutdown transient despite the large decay constant for the delayed neutron precursors. This results in a slight over-prediction in the decay power relative to the published ANS standard, which assumes immediate shutdown with zero fission power. Nevertheless, by 1000 seconds, the perturbation has mostly died away, and the differences in the results are consistent with Table B3(b) 
Table B3(a): Comparison of Normalized Pu-239 Decay Heat Power after Shutdown Following an Irradiation of $10^{13}$ Seconds.

\begin{tabular}{cccc}
\hline Time (s) & $\begin{array}{c}\text { ANS } \\
\text { Standard }\end{array}$ & $\begin{array}{c}\text { SAS } \\
\text { Model }\end{array}$ & $\begin{array}{c}\text { Difference } \\
\mathbf{( \% )}\end{array}$ \\
\hline 0.000 & $5.467 \mathrm{E}-02$ & $5.468 \mathrm{E}-02$ & 0.0031 \\
9.763 & $4.138 \mathrm{E}-02$ & $4.139 \mathrm{E}-02$ & 0.0170 \\
10.000 & $4.125 \mathrm{E}-02$ & -- & -- \\
19.763 & $3.748 \mathrm{E}-02$ & $3.748 \mathrm{E}-02$ & 0.0107 \\
39.763 & $3.360 \mathrm{E}-02$ & $3.360 \mathrm{E}-02$ & 0.0073 \\
99.763 & $2.847 \mathrm{E}-02$ & $2.847 \mathrm{E}-02$ & 0.0049 \\
100.000 & $2.845 \mathrm{E}-02$ & -- & -- \\
199.763 & $2.494 \mathrm{E}-02$ & $2.495 \mathrm{E}-02$ & 0.0042 \\
399.763 & $2.182 \mathrm{E}-02$ & $2.182 \mathrm{E}-02$ & 0.0036 \\
999.763 & $1.761 \mathrm{E}-02$ & $1.761 \mathrm{E}-02$ & 0.0036 \\
1000.000 & $1.761 \mathrm{E}-02$ & -- & -- \\
\hline
\end{tabular}

Table B3(b): Extended Comparison of Normalized Pu-239 Decay Heat Power after Shutdown Following an Irradiation of $10^{13}$ Seconds.

\begin{tabular}{cccc}
\hline Time (s) & $\begin{array}{c}\text { ANS } \\
\text { Standard }\end{array}$ & $\begin{array}{c}\text { SAS } \\
\text { Model }\end{array}$ & $\begin{array}{c}\text { Difference } \\
(\%)\end{array}$ \\
\hline Shutdown & $5.467 \mathrm{E}-02$ & $5.468 \mathrm{E}-02$ & 0.0031 \\
$1.0 \mathrm{E}+00$ & $5.137 \mathrm{E}-02$ & $5.138 \mathrm{E}-02$ & 0.0030 \\
$1.5 \mathrm{E}+00$ & $5.015 \mathrm{E}-02$ & $5.016 \mathrm{E}-02$ & 0.0031 \\
$2.0 \mathrm{E}+00$ & $4.911 \mathrm{E}-02$ & $4.911 \mathrm{E}-02$ & 0.0031 \\
$4.0 \mathrm{E}+00$ & $4.606 \mathrm{E}-02$ & $4.606 \mathrm{E}-02$ & 0.0031 \\
$6.0 \mathrm{E}+00$ & $4.401 \mathrm{E}-02$ & $4.401 \mathrm{E}-02$ & 0.0030 \\
$8.0 \mathrm{E}+00$ & $4.247 \mathrm{E}-02$ & $4.247 \mathrm{E}-02$ & 0.0031 \\
$1.0 \mathrm{E}+01$ & $4.125 \mathrm{E}-02$ & $4.125 \mathrm{E}-02$ & 0.0030 \\
$1.5 \mathrm{E}+01$ & $3.901 \mathrm{E}-02$ & $3.901 \mathrm{E}-02$ & 0.0031 \\
$2.0 \mathrm{E}+01$ & $3.741 \mathrm{E}-02$ & $3.742 \mathrm{E}-02$ & 0.0031 \\
$4.0 \mathrm{E}+01$ & $3.356 \mathrm{E}-02$ & $3.357 \mathrm{E}-02$ & 0.0031 \\
$6.0 \mathrm{E}+01$ & $3.129 \mathrm{E}-02$ & $3.129 \mathrm{E}-02$ & 0.0030 \\
$8.0 \mathrm{E}+01$ & $2.968 \mathrm{E}-02$ & $2.968 \mathrm{E}-02$ & 0.0030 \\
$1.0 \mathrm{E}+02$ & $2.845 \mathrm{E}-02$ & $2.845 \mathrm{E}-02$ & 0.0032 \\
$1.5 \mathrm{E}+02$ & $2.634 \mathrm{E}-02$ & $2.634 \mathrm{E}-02$ & 0.0031 \\
$2.0 \mathrm{E}+02$ & $2.494 \mathrm{E}-02$ & $2.494 \mathrm{E}-02$ & 0.0030 \\
$4.0 \mathrm{E}+02$ & $2.182 \mathrm{E}-02$ & $2.182 \mathrm{E}-02$ & 0.0032 \\
$6.0 \mathrm{E}+02$ & $1.999 \mathrm{E}-02$ & $1.999 \mathrm{E}-02$ & 0.0032 \\
$8.0 \mathrm{E}+02$ & $1.866 \mathrm{E}-02$ & $1.866 \mathrm{E}-02$ & 0.0032 \\
$1.0 \mathrm{E}+03$ & $1.761 \mathrm{E}-02$ & $1.761 \mathrm{E}-02$ & 0.0032 \\
$1.5 \mathrm{E}+03$ & $1.567 \mathrm{E}-02$ & $1.567 \mathrm{E}-02$ & 0.0028 \\
$2.0 \mathrm{E}+03$ & $1.432 \mathrm{E}-02$ & $1.432 \mathrm{E}-02$ & 0.0033 \\
$4.0 \mathrm{E}+03$ & $1.141 \mathrm{E}-02$ & $1.141 \mathrm{E}-02$ & 0.0034 \\
$6.0 \mathrm{E}+03$ & $1.004 \mathrm{E}-02$ & $1.004 \mathrm{E}-02$ & 0.0026 \\
$8.0 \mathrm{E}+03$ & $9.225 \mathrm{E}-03$ & $9.225 \mathrm{E}-03$ & 0.0031 \\
$1.0 \mathrm{E}+04$ & $8.663 \mathrm{E}-03$ & $8.664 \mathrm{E}-03$ & 0.0031 \\
$1.5 \mathrm{E}+04$ & $7.769 \mathrm{E}-03$ & $7.769 \mathrm{E}-03$ & 0.0031 \\
$2.0 \mathrm{E}+04$ & $7.215 \mathrm{E}-03$ & $7.215 \mathrm{E}-03$ & 0.0030 \\
$4.0 \mathrm{E}+04$ & $6.053 \mathrm{E}-03$ & $6.053 \mathrm{E}-03$ & 0.0031 \\
$6.0 \mathrm{E}+04$ & $5.435 \mathrm{E}-03$ & $5.435 \mathrm{E}-03$ & 0.0030 \\
$8.0 \mathrm{E}+04$ & $5.030 \mathrm{E}-03$ & $5.031 \mathrm{E}-03$ & 0.0030 \\
\hline & & &
\end{tabular}

\begin{tabular}{cccc}
\hline Time (s) & $\begin{array}{c}\text { ANS } \\
\text { Standard }\end{array}$ & $\begin{array}{c}\text { SAS } \\
\text { Model }\end{array}$ & $\begin{array}{c}\text { Difference } \\
\text { (\%) }\end{array}$ \\
\hline $1.0 \mathrm{E}+05$ & $4.741 \mathrm{E}-03$ & $4.741 \mathrm{E}-03$ & 0.0032 \\
$1.5 \mathrm{E}+05$ & $4.270 \mathrm{E}-03$ & $4.270 \mathrm{E}-03$ & 0.0031 \\
$2.0 \mathrm{E}+05$ & $3.975 \mathrm{E}-03$ & $3.975 \mathrm{E}-03$ & 0.0030 \\
$4.0 \mathrm{E}+05$ & $3.348 \mathrm{E}-03$ & $3.348 \mathrm{E}-03$ & 0.0031 \\
$6.0 \mathrm{E}+05$ & $3.002 \mathrm{E}-03$ & $3.002 \mathrm{E}-03$ & 0.0032 \\
$8.0 \mathrm{E}+05$ & $2.762 \mathrm{E}-03$ & $2.762 \mathrm{E}-03$ & 0.0031 \\
$1.0 \mathrm{E}+06$ & $2.579 \mathrm{E}-03$ & $2.579 \mathrm{E}-03$ & 0.0029 \\
$1.5 \mathrm{E}+06$ & $2.262 \mathrm{E}-03$ & $2.263 \mathrm{E}-03$ & 0.0030 \\
$2.0 \mathrm{E}+06$ & $2.054 \mathrm{E}-03$ & $2.054 \mathrm{E}-03$ & 0.0030 \\
$4.0 \mathrm{E}+06$ & $1.612 \mathrm{E}-03$ & $1.612 \mathrm{E}-03$ & 0.0029 \\
$6.0 \mathrm{E}+06$ & $1.401 \mathrm{E}-03$ & $1.401 \mathrm{E}-03$ & 0.0028 \\
$8.0 \mathrm{E}+06$ & $1.269 \mathrm{E}-03$ & $1.269 \mathrm{E}-03$ & 0.0030 \\
$1.0 \mathrm{E}+07$ & $1.171 \mathrm{E}-03$ & $1.171 \mathrm{E}-03$ & 0.0032 \\
$1.5 \mathrm{E}+07$ & $1.003 \mathrm{E}-03$ & $1.003 \mathrm{E}-03$ & 0.0035 \\
$2.0 \mathrm{E}+07$ & $8.944 \mathrm{E}-04$ & $8.944 \mathrm{E}-04$ & 0.0031 \\
$4.0 \mathrm{E}+07$ & $6.813 \mathrm{E}-04$ & $6.813 \mathrm{E}-04$ & 0.0031 \\
$6.0 \mathrm{E}+07$ & $5.798 \mathrm{E}-04$ & $5.798 \mathrm{E}-04$ & 0.0030 \\
$8.0 \mathrm{E}+07$ & $5.175 \mathrm{E}-04$ & $5.175 \mathrm{E}-04$ & 0.0031 \\
$1.0 \mathrm{E}+08$ & $4.771 \mathrm{E}-04$ & $4.771 \mathrm{E}-04$ & 0.0031 \\
$1.5 \mathrm{E}+08$ & $4.235 \mathrm{E}-04$ & $4.235 \mathrm{E}-04$ & 0.0030 \\
$2.0 \mathrm{E}+08$ & $3.978 \mathrm{E}-04$ & $3.978 \mathrm{E}-04$ & 0.0031 \\
$4.0 \mathrm{E}+08$ & $3.444 \mathrm{E}-04$ & $3.444 \mathrm{E}-04$ & 0.0031 \\
$6.0 \mathrm{E}+08$ & $3.043 \mathrm{E}-04$ & $3.043 \mathrm{E}-04$ & 0.0029 \\
$8.0 \mathrm{E}+08$ & $2.699 \mathrm{E}-04$ & $2.699 \mathrm{E}-04$ & 0.0030 \\
$1.0 \mathrm{E}+09$ & $2.402 \mathrm{E}-04$ & $2.402 \mathrm{E}-04$ & 0.0029 \\
$1.5 \mathrm{E}+09$ & $1.826 \mathrm{E}-04$ & $1.826 \mathrm{E}-04$ & 0.0032 \\
$2.0 \mathrm{E}+09$ & $1.426 \mathrm{E}-04$ & $1.426 \mathrm{E}-04$ & 0.0032 \\
$4.0 \mathrm{E}+09$ & $7.336 \mathrm{E}-05$ & $7.336 \mathrm{E}-05$ & 0.0031 \\
$6.0 \mathrm{E}+09$ & $5.737 \mathrm{E}-05$ & $5.737 \mathrm{E}-05$ & 0.0030 \\
$8.0 \mathrm{E}+09$ & $5.364 \mathrm{E}-05$ & $5.364 \mathrm{E}-05$ & 0.0030 \\
$1.0 \mathrm{E}+10$ & $5.275 \mathrm{E}-05$ & $5.275 \mathrm{E}-05$ & 0.0031 \\
\hline & & & \\
\hline
\end{tabular}


In Table B3(b), the extended decay heat calculation is shown out to $10^{10}$ seconds. At all points in time, there is near perfect agreement, with a maximum difference of a few thousandths of a percent. As will be shown in the next section, the apparent bias in the SAS model results is actually due to an assumption made in the ANS standard.

\section{B.2.3.2 Comparison with Numerical Integration}

In the comparisons with the ANS standard presented above, the SAS model calculates decay heat power results that are slightly higher than the standard. As described earlier, the methods described in the ANS standard make an implicit assumption that the ratio between total power and fission power is fixed, which will generally underestimate the number of fissions and therefore the fission-product decay heat power. Even after an irradiation of $10^{13}$ seconds, decay heat power is not at true equilibrium because some of the terms in the exponential expansions documented in the ANS standard have half-lives greater than $10^{13}$ seconds. For shorter irradiation times, the effects of the assumption will be more important.

To assess the impact of this assumption, a separate algorithm was written to numerically integrate the terms of the U-235 decay heat parameters defined in the standard out to $10^{13}$ seconds using a relatively small time step size of 1000 seconds in the integration. During the integration, total power is held constant by adjusting the fission power to account for timedependent increases in decay heat power. Therefore, the coupled decay heat equations are solved accurately.

Results of the numerical integration are shown in Table B4 along with corresponding results from the ANS standard and the SAS decay heat model. As shown in the table, the ANS standard underpredicts the decay heat power. This indicates that the bias seen in the previous tables is due to the implicit assumption made in the ANS standard and not due to the SAS decay heat model. Finally, the differences between the numerical integration and the SAS decay heat model are insignificant as they are within the precision of the printed output used to generate the results.

Table B4: Comparison of Normalized U-235 Decay Heat Power from Numerical Integration with the ANS Standard and SAS Model Following an Irradiation of $10^{13}$ Seconds.

\begin{tabular}{cccccc}
\hline & Numerical & \multicolumn{2}{c}{ ANS Standard } & \multicolumn{2}{c}{ SAS Model } \\
Time (s) & Integration & Decay Heat & Difference (\%) & Decay Heat & Difference (\%) \\
\hline Shutdown & $6.72447 \mathrm{E}-02$ & $6.72421 \mathrm{E}-02$ & -0.0038 & $6.72447 \mathrm{E}-02$ & 0.0001 \\
1000 & $1.89975 \mathrm{E}-02$ & $1.89968 \mathrm{E}-02$ & -0.0038 & $1.89975 \mathrm{E}-02$ & -0.0001 \\
10000 & $9.56024 \mathrm{E}-03$ & $9.55987 \mathrm{E}-03$ & -0.0038 & $9.56024 \mathrm{E}-03$ & 0.0000 \\
100000 & $4.86452 \mathrm{E}-03$ & $4.86433 \mathrm{E}-03$ & -0.0038 & $4.86452 \mathrm{E}-03$ & 0.0000 \\
1000000 & $2.77338 \mathrm{E}-03$ & $2.77328 \mathrm{E}-03$ & -0.0038 & $2.77338 \mathrm{E}-03$ & -0.0001 \\
\hline
\end{tabular}

\section{B.2.3.3 Other Comparisons}

The above comparisons demonstrate that the updated SAS decay heat model accurately predicts fission product decay heat when compared to the ANS standard and when compared with separate numerical integrations. These comparisons were based on results for individual isotopes 
using the built-in decay heat parameters included in the model. The updated SAS decay heat model also supports user-supplied decay heat curves as well as combining multiple curves within a single decay heat region.

To verify these two capabilities, the parameters for the ANS standard curves were entered in the SAS input deck as user-supplied values and the tests were repeated. The resulting calculations matched exactly with the results using the built-in curves. Next, the user-supplied curves were combined with the built-in standard curves such that each decay heat region still represented a single isotope (and could therefore be compared with the standard), but the contribution for each region was the result of the combination of a user-supplied curve and a built-in curve. Again, the results matched exactly with the results using the built-in curves alone. These tests verify that the processing of user-supplied input data and the combination of multiple decay heat curves within a single decay heat region are properly treated by the updated decay heat model.

\section{B.3 Stratified Volume Model Development for ABTR}

In addition to the uniformly mixed compressible volume model, PRIMAR-4 contains a stratified temperature model for the liquid in a compressible volume. This stratified model can be used for an outlet plenum and/or for a pool. This model borrows from the PLENUM-2A model [B3] of Howard and Lorenz, but the PRIMAR-4 model has been extended beyond the capabilities of the PLENUM-2A model. Borrowed from PLENUM-2A is the concept of a small number of distinct temperature regions in the coolant, separated by horizontal interfaces. Also borrowed are the concepts of distinct stages in the calculation, a plenum height correlation, and a correlation for interface rise due to entrainment of a hot layer into a cooler plume rising from the core outlet. One extension of the PRIMAR-4 model is the provision for handling up transients as well as down transients: PLENUM-2A will only handle transients in which the core outlet temperature is cooler than the plenum temperature, whereas the PRIMAR-4 model will also handle transients in which the core outlet temperature is hotter than the plenum temperature. Another extension is the option in the PRIMAR-4 model to handle a horizontal discharge from an IHX into a cold pool: PLENUM-2A will only handle a vertical discharge from the core into an outlet plenum. The PRIMAR-4 model handles up to three regions and five stages, whereas PLENUM-2A considers only two regions and three stages. Also, the PRIMAR-4 model treats thermal conduction across the interface between regions, and this model includes detailed multi-node wall temperature calculations.

Figure B1 shows the various stages and cases considered in this stratified model. At the start of a transient in which the core outlet temperature is dropping, the plume in the outlet plenum goes to the top of the plenum; and the outlet plenum is fully mixed, giving stage 1. As the core outlet temperature and velocity drop, the plume no longer reaches the top of the plenum. This leads to the start of stage 2 in which the outlet coolant goes to layer 1. In stage 2 the layer boundary is at the elevation of the core outlet. After enough cool liquid has entered layer 1 to fill one quarter of its volume, stage 3 , case 3.1 begins. In this case, the plume coolant still goes to layer 1 , but the interface between layers rises as liquid is added to layer 1. In this case, the plume also entrains hot liquid from the interface into layer 1. If the core outlet temperature at the start of the transient becomes hotter than the outlet plenum temperature, then stage 3, case 3.2 is entered. In this case, the core outlet coolant goes to the top hot layer, entraining cool outlet 


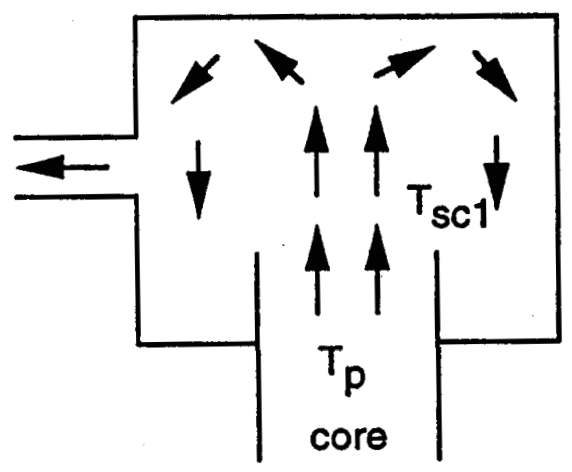

Stage 1 , fully mixed, 1 layer

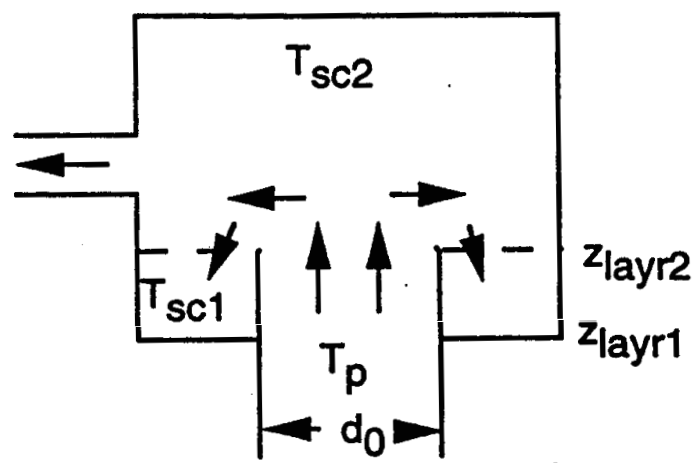

Stage 2, 2 layers, interface at the core outlet, filling the bottom with cool liquid

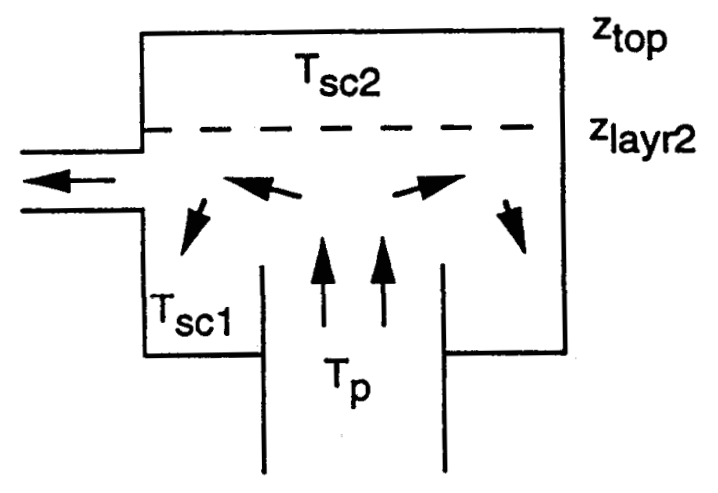

Stage 3, case3.1, 2 layers, interface moving $T_{p}<\left(T_{s c 1}+T_{s c 2}\right) / 2$, entrainment at the interface, plume height $<z_{\text {top }}$

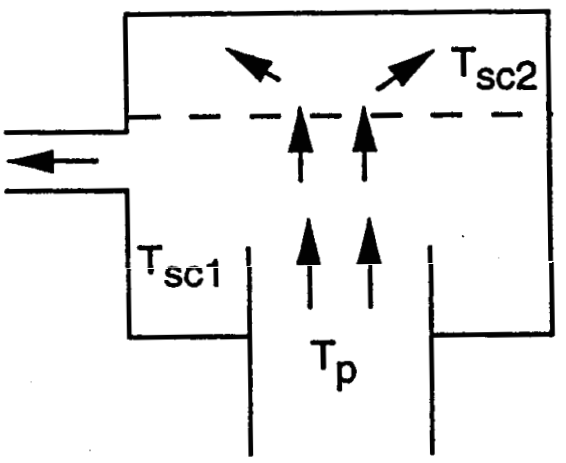

Stage 3, case 3.2, 2 layers, interface moving, $T_{p}>\left(T_{s c 1}+T_{s c 2}\right) / 2$, hot outlet coolant goes to upper layer, entrains from the lower layer as it passes through

$T_{p}=$ plume temperature $=$ core outlet temperature

$T_{s c i}=$ temperature in layer $i$

$z_{\text {top }}=$ elevation at top of plenum

$z_{\text {layri }}=$ interface elevation at bottom of layer $i$

Figure B1. Stratified Volume Stages. 


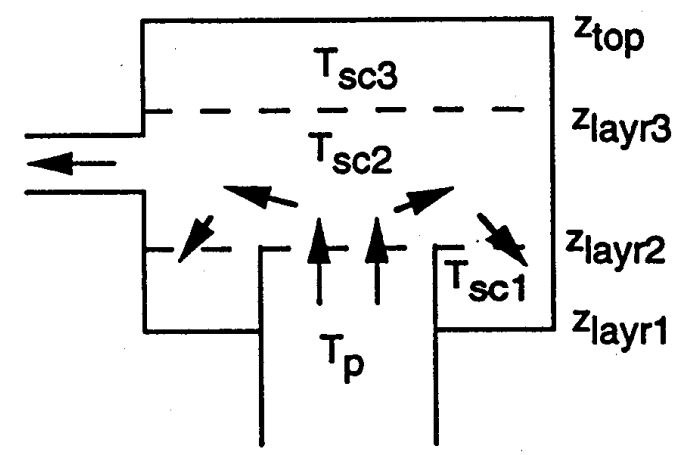

Stage 4, 3 layers, interface at the core outlet, filling the bottom with cool liquid, plume height $<z_{\text {layr } 3}$

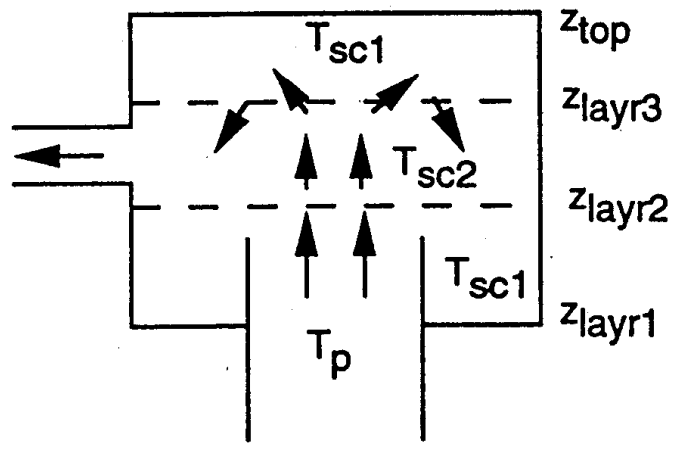

Strage 5, case 5.2, 3 layers, interfaces moving, plume passes through layer 1 to layer 2, entraining from layer 1 as it passes through, also entraining from layer 3 at $z_{\text {layr3 }}$ $T_{s c 2}+T_{s c 3}>2 T_{p}>T_{s c 1}+T_{s c 2}$

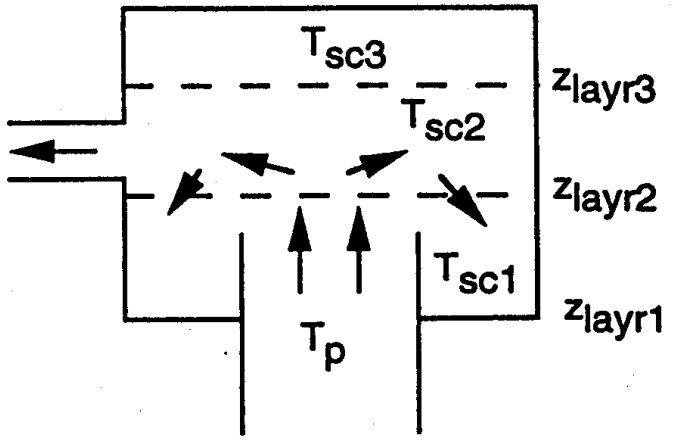

Stage 5, case 5.1, 3 layers, interfaces moving, cool plume liquid goes to layer 1 entrainment from layer 2 at $z_{\text {layr2 }}$ $T_{p}<\left(T_{s c 1}+T_{s c 2}\right) / 2$

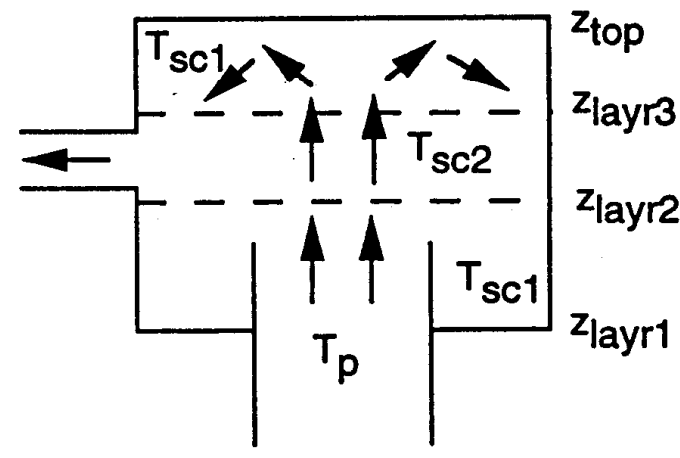

Stage 5, case 5.3, 3 layers, interfaces moving, plume passes through layers 1 and 2 , goes to layer 3 , entraining from layers 1 and 2 as it passes through $T_{p}>\left(T_{s c 2}+T_{s c 3}\right) / 2$

Figure B1. Stratified Volume Stages. (cont.) 
plenum liquid as it passes through. The three layer cases of stages 4 and 5 can occur in the later stages of a transient if the core outlet temperature starts out rising and later falls, or if the core outlet temperature starts out falling and later rises. If the coolant inlet into the volume is horizontal, as in the discharge of an IHX into a cold pool, then only stages 1,3 , and 5 are used.

The jet height or plume height is calculated from an equation given by Yang [B4]:

$$
\mathrm{h}_{\text {jet }}=1.0484 \mathrm{~F}_{\mathrm{r}}^{0.785}
$$

where

$$
\begin{array}{ll}
\mathrm{h}_{\text {jet }} & =\text { height of the jet or the plume } \\
\mathrm{F}_{\mathrm{r}} & =\text { Froude number }=\frac{\mathrm{v}_{\mathrm{o}}^{2} \rho_{\text {plume }}}{\mathrm{g} \mathrm{r}_{\mathrm{o}}^{2}\left(\rho_{\text {plume }}-\rho_{\text {plenum }}\right)} \\
\mathrm{v}_{\mathrm{o}} & =\text { core exit velocity } \\
\rho_{\text {plume }} & =\text { density of the plume } \\
\rho_{\text {plenum }} & =\text { density of the plenum } \\
\mathrm{r}_{\mathrm{o}} & =\text { core effective radius } \\
\mathrm{g} & =\text { acceleration of gravity }
\end{array}
$$

For entrainment at an interface, Howard and Lorenz give:

$$
\mathrm{w}_{\text {ent }}=0.2 \pi \rho_{\text {plume }} \mathrm{v}_{\mathrm{j}} \mathrm{d}_{\mathrm{j}} \mathrm{F}_{\mathrm{r}}^{-1.1}
$$

where

$$
\begin{aligned}
& \mathrm{v}_{\mathrm{j}}=\text { plume average velocity at the interface } \\
& \mathrm{d}_{\mathrm{j}}=\text { plume effective diameter at the interface } \\
& \mathrm{w}_{\mathrm{j}}=\text { entrainment rate }(\mathrm{kg} / \mathrm{s}) .
\end{aligned}
$$

The values of $v_{j}$ and $d_{j}$ depend on elevation and on whether the interface occurs within the zone of flow establishment or in the zone of established flow. The elevation change, $\mathrm{z}_{\mathrm{o}}$, from the core outlet to the top of the flow establishment is:

$$
\mathrm{z}_{\mathrm{o}}=\frac{\mathrm{r}_{\mathrm{o}}}{0.111}
$$


For $\mathrm{z}<\mathrm{z}_{\mathrm{o}}$, or the zone of flow establishment:

$$
\frac{\mathrm{v}_{\mathrm{j}}}{\mathrm{v}_{\mathrm{o}}}=\frac{0.25+0.02095\left(\mathrm{z} / \mathrm{d}_{\mathrm{o}}\right)+0.003969\left(\mathrm{z} / \mathrm{d}_{\mathrm{o}}\right)^{2}}{\left[1 / 2+0.1052\left(\mathrm{z} / \mathrm{d}_{\mathrm{o}}\right)\right]^{2}}
$$

and

$$
\frac{\mathrm{d}_{\mathrm{j}}}{\mathrm{d}_{\mathrm{o}}}=1+0.2104\left(\mathrm{z} / \mathrm{d}_{\mathrm{o}}\right)
$$

For $\mathrm{z}>\mathrm{z}_{\mathrm{o}}$, or the zone of established flow:

$$
\frac{\mathrm{v}_{\mathrm{j}}}{\mathrm{v}_{\mathrm{o}}}=\frac{2.018}{\mathrm{z} / \mathrm{d}_{\mathrm{o}}}
$$

and

$$
\frac{\mathrm{d}_{\mathrm{j}}}{\mathrm{d}_{\mathrm{o}}}=0.8649\left(\mathrm{z} / \mathrm{d}_{\mathrm{o}}\right) \text {. }
$$

For the wall temperatures, multi-node treatments are used. The vertical wall around the outside of the outlet plenum or pool is treated with a number of vertical nodes. Each vertical node contains a number of lateral nodes, with coolant in contact with the first node. There is also an option to have another coolant compressible volume in contact with the last lateral node to account for heat transfer from a hot outlet plenum to a cold pool. The model has an option for a horizontal wall at the top or bottom of the plenum. This wall is handled with a 1-D multimode treatment. Again, the first node is in contact with the plenum liquid, and the last node can be in contact with the coolant in another compressible volume. 


\section{REFERENCES FOR APPENDIX B}

B1. J. E. Cahalan, A. M. Tentner, and E. E. Morris, Advanced LMR Safety Analysis Capabilities in the SASSYS-1 and SAS4A Computer Codes, Proceedings of the International Topical Meeting on Advanced Reactors Safety, Vol. 2, pp. 1038-1045, Pittsburgh, Pennsylvania USA, April 17-21, 1994.

B2. American National Standard Decay Heat Power in Light Water Reactors, ANSI/ANS5.1-2005, American Nuclear Society, 2005.

B3. J. J. Lorenz and P. A. Howard, Entrainment by a Jet at a Density Interface in a Thermally Stratified Vessel, Transactions of the ASME, 101, 538 (1979).

B4. J. W. Yang, Penetration of a Turbulent Jet with Negative Buoyancy into the Upper Plenum of an LMFBR, Nuclear Engineering and Design, 40, 297 (1977). 
Argonne

Nuclear Engineering Division

Argonne National Laboratory

9700 South Cass Avenue, Bldg. 208

Argonne, IL 60439-4842

www.anl.gov

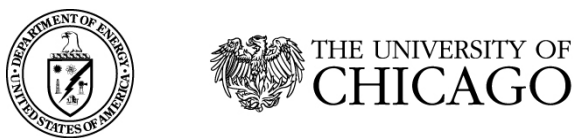

A U.S. Department of Energy laboratory managed by The University of Chicago 